\title{
A review of the brachyuran deep-sea vent community of the western Pacific, with two new species of Austinograea Hessler \& Martin, 1989 (Crustacea, Decapoda, Brachyura, Bythograeidae) from the Lau and North Fiji Back-Arc Basins
}

\author{
Danièle GUINOT \\ Michel SEGONZAC \\ Institut de Systématique, Évolution, Biodiversité (ISYEB), \\ Muséum national d'Histoire naturelle, CNRS, Sorbonne Université, EPHE, \\ case postale 53, 57 rue Cuvier, F-75231 Paris cedex 05 (France) \\ guinot@mnhn.fr (corresponding author) \\ segonzac@mnhn.fr
}

Submitted on 9 August 2017 | Accepted on 12 December 2017 | Published on 13 March 2018

urn:Isid:zoobank.org:pub:4ECDC922-E66F-4C63-A01B-0304C88A9CCB

Guinot D. \& Segonzac M. 2018. - A review of the brachyuran deep-sea vent community of the western Pacific, with two new species of Austinograea Hessler \& Martin, 1989 (Crustacea, Decapoda, Brachyura, Bythograeidae) from the Lau and North Fiji Back-Arc Basins. Zoosystema 40 (5): 75-107. https://doi.org/10.5252/zoosystema2018v40a5. http://zoosystema.com/40/5

\begin{abstract}
Two new species of the genus Austinograea Hessler \& Martin, 1989 (Bythograeidae Williams, 1980), distinct from A. williamsi Hessler \& Martin, 1989 and A. alayseae Guinot, 1990, are here reported from hydrothermal vent fields of the southwestern Pacific: A. hourdezi n. sp. and A. jolliveti n. sp., both in the Lau and North Fiji Back-Arc Basins. Austinograea hourdezi n. sp. is characterised by two depressions appearing as dark spots on the palm of both chelipeds in males and differs from the more northern $A$. williamsi and the Indian A. rodriguezensis Tsuchida \& Hashimoto, 2002, which show only one spot on the male chelae, near the base of the dactylus. Some individuals exhibiting all morphological characters of $A$. hourdezi n. sp. bear only one spot on the chelae, near the base of dactylus; the fact that most are left-handed corresponds to the presence of a regenerated cheliped, with handedness reversal after the accidental loss of the major cheliped: these atypical individuals are here treated as $A$. hourdezi $\mathrm{n}$. sp. The single spot that characterises each chela of A. jolliveti n. sp. is located at the base of the fixed finger in both sexes and shows as a differently pigmented, violaceous "pustule", being similar to that of Bythograea microps Saint Laurent, 1984 from the East Pacific Rise. Moreover, A. jolliveti n. sp. can be distinguished by the shortest G2 found in Austinograea, especially by its reduced flagellum. A. hourdezi n. sp., represented by numerous specimens, was found to cooccur with $A$. alayseae in several vent sites of the Lau and North Fiji Back-Arc Basins, and both are probably distributed across a wide geographical range, whereas $A$. jolliveti $\mathrm{n}$. sp., represented by only a few specimens, was collected from only two vent sites (ABE and Mussel Valley). In the northwestern Pacific, A. williamsi is apparently restricted to the Mariana Trough, where it is the only one member of the family Bythograeidae. The Manus Basin perhaps hosts an additional Austinograea species. In the western Pacific, vent fields are the only hydrothermal systems, except the East Pacific Ridge, that are not linearly distributed; different basins may host different species within the same brachyuran genus (five congeneric species of Austinograea, including A. rodriguezensis from the western Indian Ocean). The morphological distinction between the Austinograea species is supported by molecular analyses, for A. williamsi, A. alayseae, and A. hourdezi n. sp. A key to the five species of Austinograea is provided, in order to be able to potentially identify the crabs photographed in situ in their natural environment.
\end{abstract}

KEY WORDS Gandalfus, hydrothermal site, western Pacific,

Lau Back-Arc Basin, North Fiji Back-Arc Basin, Manus Basin, Mariana Trough, deep-sea fauna, new species. 


\begin{abstract}
RÉSUMÉ
Révision de la communauté hydrothermale brachyourienne du Pacifique occidental, avec deux espèces nouvelles d'Austinograea Hessler \& Martin, 1989 (Crustacea, Decapoda, Brachyura, Bythograeidae) des bassins arrière-arc de Lau et Nord-Fidjien.

Deux nouvelles espèces du genre Austinograea Hessler \& Martin, 1989 (Bythograeidae Williams, 1980), distinctes d'A. williamsi Hessler \& Martin, 1989 et d'A. alayseae Guinot, 1990, sont décrites des sources hydrothermales du Pacifique Sud-Ouest: $A$. hourdezi $n$ n. sp. et $A$. jolliveti n. sp., toutes deux récoltées dans les bassins arrière-arc de Lau et Nord-Fidjien. Austinograea hourdezi n. sp. est caractérisée par deux dépressions apparaissant comme des taches sombres sur la main des deux chélipèdes chez le mâle; elle diffère d'A. williamsi, plus septentrional, et d'A. rodriguezensis Tsuchida \& Hashimoto, 2002, de l'océan Indien, qui, toutes deux, montrent une seule tache sur la main des pinces des mâles, près de la base du dactyle. Certains individus, qui présentent tous les caractères morphologiques d'A. hourdezi n. sp., ne portent qu'une seule tache sur les pinces, à la base du dactyle; ils sont pour la plupart gauchers, ce qui correspond à la présence d'un chélipède régénéré avec réversion de la dextralité, après la perte accidentelle du grand chélipède: ces individus atypiques sont traités ici comme A. hourdezi n. sp. L'unique tache qui caractérise chaque pince d'A. jolliveti $\mathrm{n}$. sp. est située à la base du doigt fixe dans les deux sexes et se présente comme une sorte de pustule différemment pigmentée, violacée, ressemblant à celle de Bythograea microps Saint Laurent, 1984, de la dorsale du Pacifique oriental. De plus, A. jolliveti n. sp. se distingue par le plus court G2 connu chez Austinograea, surtout par son flagellum très réduit. Austinograea hourdezi n. sp., représentée par de nombreux spécimens, cohabite avec $A$. alayseae sur de nombreux sites des bassins arrière-arc de Lau et Nord-Fidjien, et ces deux espèces ont probablement une large répartition géographique; à l'inverse, $A$. jolliveti n. sp., représentée seulement par quelques spécimens, n’a été trouvée que sur deux sites (ABE et Mussel Valley). Dans le Pacifique Nord-Ouest, $A$. williamsi est apparemment distribuée dans la seule zone d'accrétion des Mariannes, où elle est le seul représentant de la famille des Bythograeidae. Il est possible que le bassin de Manus abrite une espèce encore différente d'Austinograea. Dans le Pacifique occidental, les champs de cheminées sont les seuls sites hydrothermaux, excepté sur la dorsale du Pacifique oriental, qui ne sont pas répartis de manière linéaire; des bassins différents peuvent abriter différentes espèces appartenant au même genre de Brachyoures (cinq espèces congénériques d'Austinograea, y compris $A$. rodriguezensis de l'océan Indien occidental). La distinction morphologique des espèces d'Austinograea est confirmée par les analyses moléculaires, pour $A$. williamsi, A. alayseae et $A$. hourdezi n. sp. Une clé d'identification des cinq espèces d'Austinograea est proposée, dans le but de permettre l'identification des crabes photographiés in situ dans leur environnement naturel.
\end{abstract}

\section{MOTS CLES} site hydrothermal, Pacifique occidental, bassin arriêre-arc de Lau, bassin arrière-arc Nord-Fidjien, bassin de Manus, bassin des Mariannes, faune profonde espèces nouvelles.

\section{INTRODUCTION}

Two brachyuran genera, Austinograea Hessler \& Martin, 1989 and Gandalfus McLay, 2007, both characterised by the most highly reduced, degenerate eyes of the family Bythograeidae Williams, 1980, are known from the northwestern and southwestern Pacific Back-Arc Basins (Fig. 1). To date, Austinograea, one of the most widespread of the known bythograeid genera, is represented by two species in the western Pacific:

1) Austinograea williamsi Hessler \& Martin, 1989 (type species by original designation) from vent west of the Mariana Islands (southernmost region of the Mariana Trough, Mariana Back-Arc Basin). Austinograea williamsi was originally collected in abundance on three active vent fields along the crest of the spreading center, at about latitude $18^{\circ} \mathrm{N}$ and longitude $144^{\circ} \mathrm{E}, 3600 \mathrm{~m}$ depth; later found on vent sites of the Mariana Trough at $13^{\circ} 23.7^{\prime} \mathrm{N}, 143^{\circ} 55.2^{\prime} \mathrm{E}$, about $1450 \mathrm{~m}$ depth, and at $18^{\circ} 12.9^{\prime} \mathrm{N}, 144^{\circ} 42.5^{\prime} \mathrm{E}$, about $3600 \mathrm{~m}$ depth (Hessler et al. 1988; Hessler \& Martin 1989; Guinot 1990; Hessler \& Lonsdale 1991; Tsuchida \& Fujikura 2000; Tsuchida \& Hashimoto 2002; Martin \& Haney 2005; Segonzac 2006; McLay 2007; Ng et al. 2008; Zelnio \& Hourdez 2009; Hamasaki et al. 2010: fig. 1; Podowski et al. 2010; Sen et al. 2013, 2014,
2016; Kojima \& Watanabe 2015). Records of A. williamsi from the Lau and North Fiji Back-Arc Basins appear to be quite doubtful and at the very least need to be checked.

And 2) Austinograea alayseae Guinot, 1990, originally collected from the Lau Back-Arc Basin, west the Tonga Islands (behind the Tonga subduction zone), along the Valu Fa Ridge, at about $176^{\circ} 38^{\prime} \mathrm{W}$ and between $22^{\circ} 34^{\prime} \mathrm{S}$ and $22^{\circ} 10^{\prime} \mathrm{S}$, from 3595 to $3660 \mathrm{~m}$ depth; subsequently found distributed over a wide geographical range along the Eastern Lau Spreading Center (Fig. 2), and also reported from the North Fiji Basin (Jollivet et al. 1989, as bythograeid sp.; Hashimoto et al. 1989, as bythograeid sp.; Guinot 1990, 1997 in Desbruyères \& Segonzac 1997; Galkin 1997; Tsuchida \& Hashimoto 2002; Komai \& Segonzac 2004; Martin \& Haney 2005; López-González et al. 2005; Segonzac 2006; Guinot \& Segonzac 2006a, b; Desbruyères et al. 2006b; McLay 2007; Shields \& Segonzac 2007; Ng et al. 2008; Erickson et al. 2009; Corbera \& Segonzac 2010; Podowski et al. 2010; Mateos et al. 2012; Kim et al. 2013, 2014; Sen et al. 2013, 2014, 2016; Yang et al. 2013; Hui et al. 2017). Some of these records, however, deserve to be checked.

Another Austinograea species, A. rodriguezensis Tsuchida \& Hashimoto, 2002, was found in the western Indian Ocean, from four vent sites on the Central Indian Ridge, $22 \mathrm{~km} \mathrm{~N}$ 


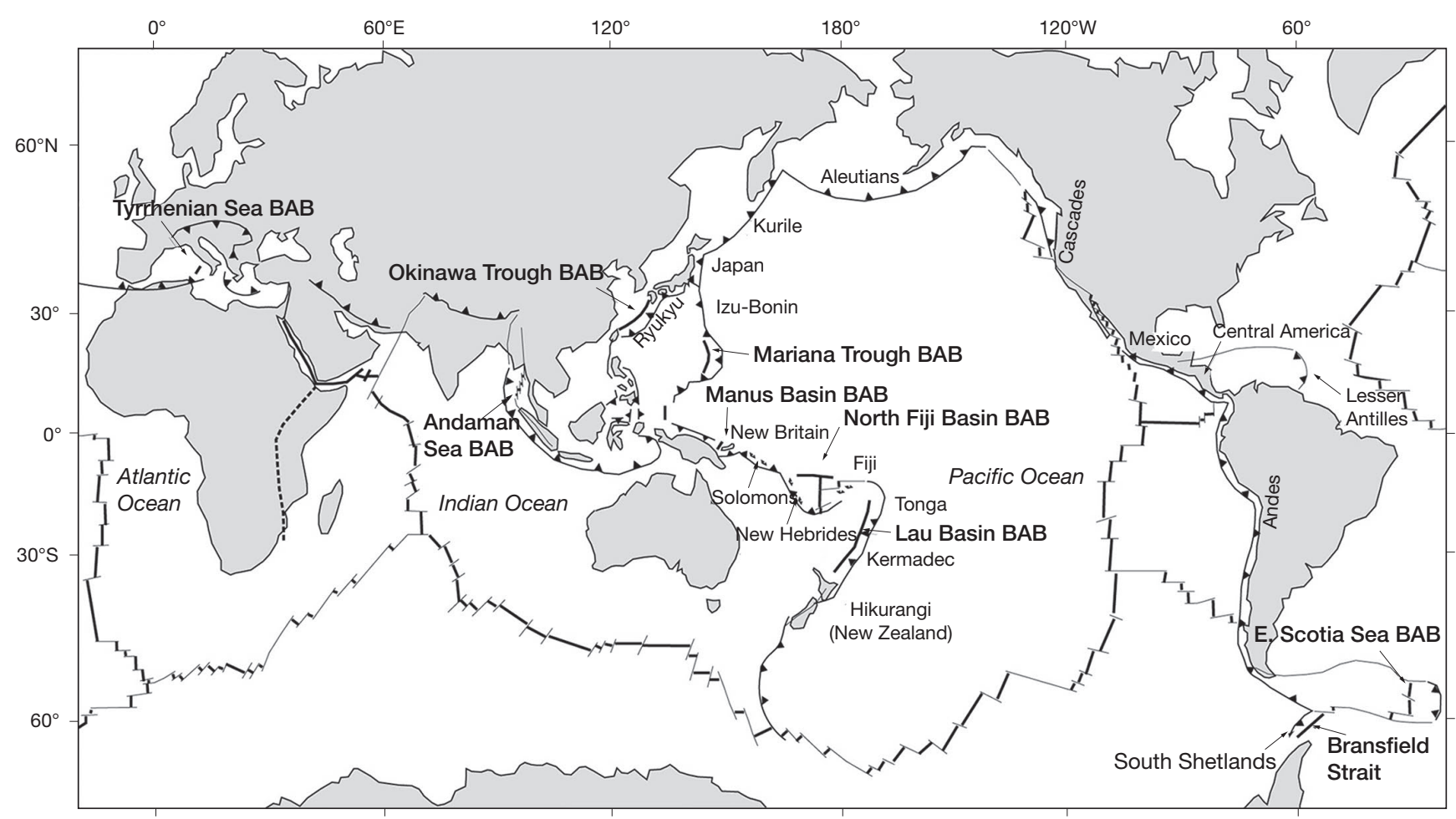

FIG. 1. - Map of active Back-Arc Basins of the world.

of the Rodriguez Triple Junction (Van Dover et al. 2001: fig. 2D, as "Austinograea n. sp."; Van Dover 2002: 761, tables 1-4, as "Austinograea n. sp."; Tsuchida \& Hashimoto 2002; Tsuchida 2006; Ng et al. 2008; Haimin et al. 2010; Kojima \& Watanabe 2015). It is distributed over a relatively wide area of brownish stained lava around the vent fields, being most abundant adjacent to the black smoker chimneys (Nakamura et al. 2012: figs 2A, 4A, B, E, F, table 1), without genetic differences between local populations (Van Dover et al. 2001; Beedessee et al. 2013: figs 4, 5, tables 2, 3; Watanabe \& Beedessee 2015: table 16.1). Its main characteristics are: chelae not markedly dimorphic; sexual dimorphism weak; external surface of male chela with one spot on propodus, described as "small blackened mark located near base of dactylus" (Tsuchida \& Hashimoto 2002: fig. 6); inner surface of chela propodus glabrous, and dense patch of setae only near occluding margins; on cutter, occluding margins straight, with teeth of similar size; G1 only with four small stout spines arranged along dorsal surface.

The genus Gandalfus, sister genus of Austinograea, is mainly distinguished from Austinograea by the epistomial margin being gently sinuous (versus strongly sinuous in Austinograea) and G2 approximately as long as G1 (versus distinctly shorter than G1 in Austinograea) (McLay 2007: 15). Gandalfus contains two species:

- G. puia McLay, 2007 (type species by original designation), from vent fields in the Tonga-Kermadec Arc between $30^{\circ} 12^{\prime} \mathrm{S}-35^{\circ} 44^{\prime} \mathrm{S}$ and $181^{\circ} 33^{\prime} \mathrm{E}-178^{\circ} 29^{\prime} \mathrm{E}$, at depths varing from 270-239 m to 1647 m (McLay 2007; de Ronde \& Stucker 2015: fig. 47.1);
- G. yunohana (Takeda, Hashimoto \& Ohta, 2000), distributed at eastern edge of Philippine Sea Plate, $32^{\circ} 06.19^{\prime} \mathrm{N}, 139^{\circ} 52.04^{\prime} \mathrm{E}$, $1263 \mathrm{~m}$, and from vents on the Suiyo, Kaikata and Nikko Seamounts, all off central Japan, occurring in great abundance at some sites (Hashimoto et al. 1995, as bythograeid sp.; Tsuchida et al. 1998; Takeda et al. 2000; Kojima 2002; Martin \& Haney 2005; Hashimoto 2006; McLay 2007; Miyake et al. 2007; Ng et al. 2008; Hamasaki et al. 2010; Nakajima et al. 2010; Yang et al. 2010; Ma 2011; Mateos et al. 2012; Yorisue et al. 2012; de Ronde \& Stucker 2015: fig. 47.1; see also Kabasawa 1992). On the Izu-Ogasawara Ridge $G$. yunohana has been found at the massive Nikko Seamount, $472 \mathrm{~m}$ (Yang et al. 2010) that is only located $5 \mathrm{~km}$ from the Northeast Nikko Seamounts, an area without any hydrothermalism (except weak shimmering near the top of the seamount) where three brachyuran species collected at depths of 520-680 m do not belong to Bythograeidae (Komai \& Tsuchida 2014).

Most vent crabs in the family Bythograeidae are typically found at great depths. In contrast, the two species of Gandalfus are by far the shallowest bythograeids, from $270-239 \mathrm{~m}$ to $1647 \mathrm{~m}$ (see Tarasov et al. 2005), whereas Austinograea williamsi shows the deepest records, $3600 \mathrm{~m}$ depth, in the western Pacific.

When describing Austinograea alayseae collected by the French BIOLAU 1989 cruise, Guinot (1990: 900) suspected the presence of a second species, probably a new Austinograea in two explored sites of the Lau Back-Arc Basin (Vai Lili and Hine Hina sites, see Fig. 2) and suggested that it should be distinguished as Austinograea sp. aff. williamsi. Since then, a large number of specimens of this unnamed species have been 


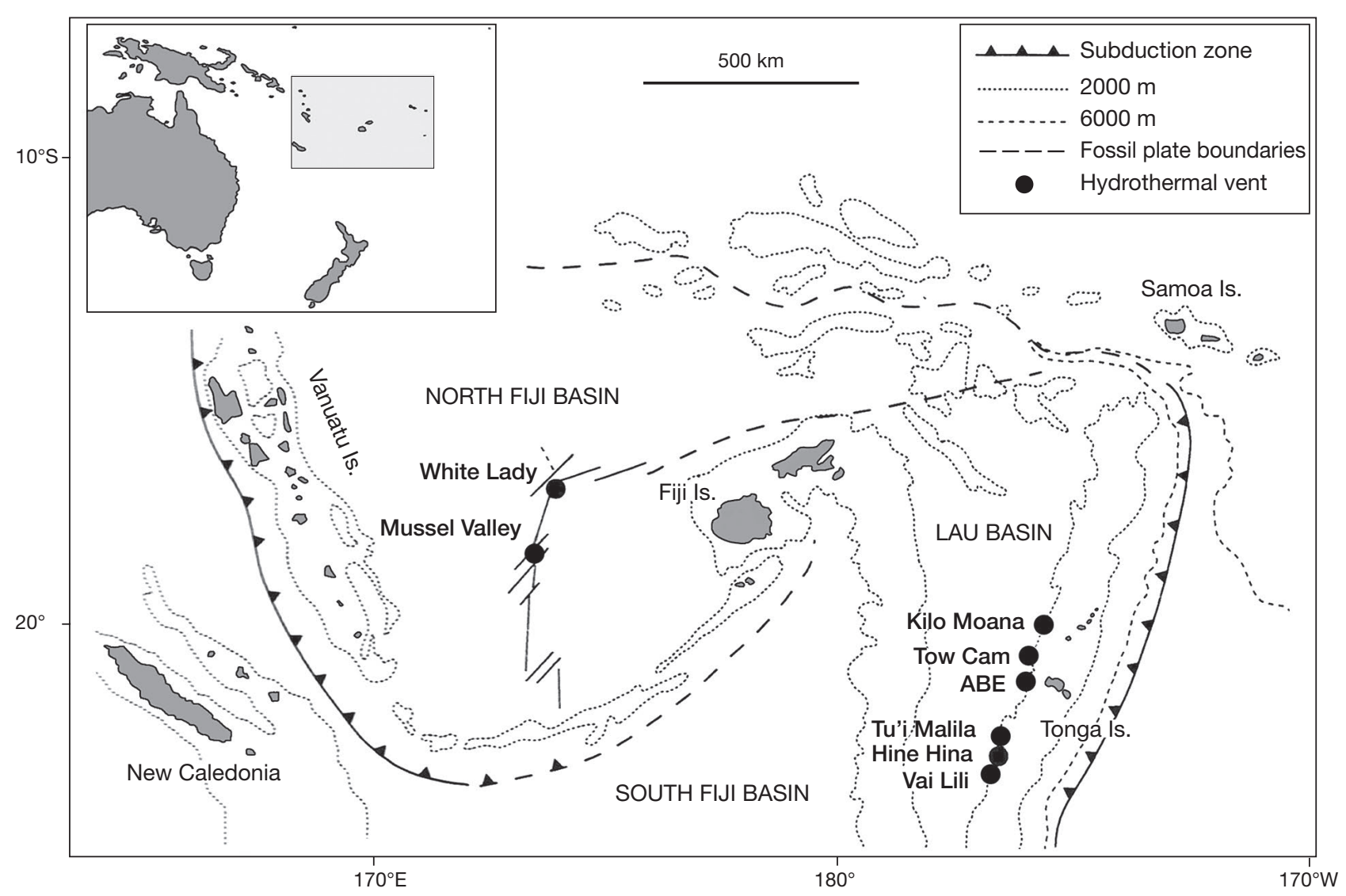

FIG. 2. - Map of the Lau and North Fiji Back-Arc Basins showing the vent field location along the Eastern Lau Spreading Center and Valu Fa Ridge. After Corbera \& Segonzac (2010).

found in the material collected by several cruises in the Lau and North Fiji Basins, notably French-Japanese STARMER II; American cruises (TUIM06MV, TUIM07MV, MGLN07MV, Lau Basin 2009) (Tables 1, 2). This allows us now to describe with confidence this unnamed crab as Austinograea hourdezi n. sp. The presence of a species distinct from $A$. alayseae and $A$. hourdezi n. sp. was supported by molecular sequence data (Mateos et al. 2012). Unfortunately, the existence of this separate, new species Austinograea sp. aff. williamsi close to A. williamsi and $A$. alayseae has been largely overlooked, although clearly mentioned in the Handbook of Deep-Sea Hydrothermal Vent Fauna of Desbruyères et al. (2006b) by Guinot \& Segonzac (2006a, b: 460) and included in a molecular phylogenetic analysis by Mateos et al. (2012: 1, 3, 6, 10, fig. 2, table 1).

The need to bring this issue to a conclusion and give a name to this species is pressing. In fact, various papers on the faunal communities of the western Pacific recently reported either only $A$. alayseae or two bythograeid species, one as $A$. alayseae and a second one, often named $A$. williamsi. We have re-examined the morphological characters of all the individuals sampled from across numerous sites in the southwestern Pacific. We will show that the investigated hydrothermal fields of the Lau and North Fiji Basins host not only two but three Austinograea species. The re-identification of all $A$. alayseae housed in various institutions is required in the event of confusion with the widespread $A$. alayseae and $A$. hourdezi n. sp.
In this study, which examines a representative sample of the hydrothermal brachyuran fauna from the deep-sea vent communities of the western Pacific, some males and females could not be first readily identified as $A$. hourdezi n. sp. Most of these individuals, atypical with regards to the pattern of spot(s) on the chelae but, however, without other equivocal morphological evidence, proved to be left-handed, with a small regenerated cheliped (see below, Individuals with regenerated chelae).

The perplexing results on the genome of southwestern Pacific bythograeids published in several recent papers suggested the presence of at least two species, formally designated as $A$. alayseae and $A$. williamsi (a species that was previously found confined to the northwestern Pacific), and even more, as Austinograea spp. These published accounts deserve to be inspected. One reason for such shortcomings is that obtained data may have been biased by possible incorrect identifications of specimens used for molecular sequences. Such an assumption means that, in these genetic studies, the assignment to A. williamsi of the crabs inhabiting the Lau and North Fiji vent fields was probably erroneous, being likely $A$. hourdezi n. sp. that seems rather common.

Another new species has been found in the Lau Back-Arc Basin (ABE site, MGLN07MV cruise) and North Fiji Back-Arc Basin (Mussel Valley site, STARMER II cruise, see Table 1) and, although represented by only a few specimens, it is established here as Austinograea jolliveti n. sp. 
TABLE 1. - Cruises to the southwestern and northwestern Pacific Ocean where the Austinograea crabs here studied were collected. Abbreviations: LB, Lau Back-Arc Basin; NFB, North Fiji Back-Arc Basin; MA, Mariana Back-Arc Basin; SM, manned submersible.

\begin{tabular}{|c|c|c|c|c|c|c|}
\hline Cruise & Location & Dates & Vessel & SM & Chief Scientist & Organism \\
\hline American cruise DWC & MA & 04.V.1987 & Atlantis II & Alvin & P. Lonsdale & Scripps Institution of Oceanography, USA \\
\hline BIOLAU & LB & 12-27.V.1989 & Nadir & Nautile & A.-M. Alayse & Ifremer, France \\
\hline STARMER II & LB \& NFB & 30.VI-19.VII.1989 & Atalante & Nautile & $\begin{array}{l}\text { D. Desbruyères \& } \\
\text { S. Ohta }\end{array}$ & Ifremer, France \& \\
\hline BIOACCESS 98 & $\mathrm{MB}$ & 13-25.XI.1998 & Natsuchima & Shinkai 2000 & Jun Hashimoto & JAMSTEC, Japan \\
\hline TUIM06MV & LB \& NFB & 15-03.V.2005 & Melville & Jason II & R. C. Vrijenhoek & Mbari, USA \\
\hline TUIM07MV & LB & 08-30.V.2005 & Melville & Jason II & C. R. Fisher & Penn State University, USA \\
\hline MGLN07MV & LB & 05.IX-20.X.2006 & Melville & Jason II & C. R. Fisher & Penn State University, USA \\
\hline Lau Basin 2009 & LB & 16.V-08.VI.2009 & Thomas Thomps & on Jason II & C. R. Fisher & Penn State University, USA \\
\hline
\end{tabular}

TABLE 2. - List and location of the vent sites from where the material here studied was collected.

\begin{tabular}{|c|c|c|c|c|c|}
\hline Cruises, dive & Basin & Vent site & Coordinates & Depth (m) & Date \\
\hline American cruise DWC, dive 1845 & Mariana Basin & Alice Springs & $18^{\circ} 12.60^{\prime} \mathrm{N}, 144^{\circ} 42.42^{\prime} \mathrm{E}$ & 3640 & 06.V.1987 \\
\hline BIOLAU, BL 03 & Lau Basin & Hine Hina & $22^{\circ} 32^{\prime} \mathrm{S}, 176^{\circ} 43^{\prime} \mathrm{W}$ & 1900 & 15.V.1989 \\
\hline BIOLAU, BL 12 & Lau Basin & Vai Lili & $23^{\circ} 13^{\prime} \mathrm{S}, 176^{\circ} 38^{\prime} \mathrm{W}$ & 1750 & 24.V.1989 \\
\hline TUIM06MV, dive 140 & Lau Basin & Kilo Moana & $20^{\circ} 03.23^{\prime} \mathrm{S}, 176^{\circ} 08.01^{\prime} \mathrm{W}$ & 2623 & 17.V.2005 \\
\hline MGLN07MV, dive 230 & & & & & $07 . I X .2006$ \\
\hline Lau Basin 2009, dive 424 & & & & & 07.IX.2009 \\
\hline TUIM06MV, dive 142 & Lau Basin & Tow Cam & $20^{\circ} 19.07^{\prime} \mathrm{S}, 176^{\circ} 08.24^{\prime} \mathrm{W}$ & 2719 & 19.V.2005 \\
\hline $\begin{array}{l}\text { MGLN07MV, dives 231, } 237 \\
\text { Lau Basin 2009, dive } 425\end{array}$ & Lau Basin & $\mathrm{ABE}$ & $20^{\circ} 45.65^{\prime} \mathrm{S}, 176^{\circ} 11.45^{\prime} \mathrm{W}$ & 2130 & $\begin{array}{l}\text { 09.IX.2006, 01.X.2006 } \\
\text { 25.V.2009 }\end{array}$ \\
\hline Lau Basin 2009, dive 427 & & & & & 28.V.2009 \\
\hline TUIM06MV, dive 143 & Lau Basin & Tu'i Malila & $21^{\circ} 59.34^{\prime} \mathrm{S}, 176^{\circ} 34.09^{\prime} \mathrm{W}$ & 1891 & 20.V.2005 \\
\hline MGLN07MV, dive 232 & & & & & 11.IX.2006 \\
\hline Lau Basin 2009, dive 428 & & & & & 30.V.2009 \\
\hline $\begin{array}{l}\text { STARMER II, PL 11, PL 16, PL } 20 \\
\text { TUIM06MV, dives } 151 \& 152\end{array}$ & North Fiji Basin & White Lady & $16^{\circ} 59.50^{\prime} \mathrm{S}, 173^{\circ} 55.47^{\prime} \mathrm{E}$ & 2000 & $\begin{array}{l}\text { 06.VII.1989, 11.VII.1989 } \\
\text { 15.VII.1989 } \\
\text { 30.V.2005, 31.V.2005 }\end{array}$ \\
\hline STARMER II, PL 18 & North Fiji Basin & Mussel Valley & $18^{\circ} 50^{\prime} \mathrm{S}, 173^{\circ} 29^{\prime} \mathrm{E}$ & 2750 & 13.VII.1989 \\
\hline
\end{tabular}

\section{MATERIAL AND METHODS}

Specimens studied here were collected during several deepsea surveys at the hydrothermal vents of the Lau and North Fiji Basins, southwestern Pacific, by a long series of cruises, operating manned submersibles Alvin, Nautile, Shinkai 2000 and the ROV Jason II, deployed on board of RV Atlantis II, Nadir, Atalante, Natsuchima, Melville, and Thomas Thompson (Table 1). Individuals were caught with a suction sampler or by baited traps. A list, with the location of the vent sites from where the material was collected is provided Table 2.

To provide a report as comprehensive as possible, in addition to the material separated by Guinot (1990) as Austinograea sp. aff. williamsi we have included all the specimens of the genus deposited in the MNHN, either preliminarily identified or unsorted. In total, the material from eight cruises (Table 1) has been examined and has allowed discovery of two new species, and a new appreciation of the abundance of specimens of $A$. alayseae.

Measurements provided (in $\mathrm{mm}$ ) are for the carapace length (cl) followed by the maximum carapace width $(\mathrm{cw})$. The abbreviations P1, P2, P3, P4, P5 are used for the first to fifth pairs of pereopods, respectively, P1 being the chelipeds; G1, G2 for the male first and second pleopods or gonopods, respectively; mxp3 for external maxillipeds; PL, dive; ROV, remotely operated vehicle; $R V$, research vessel; SM, submersible.
The material examined is deposited in the Muséum national d'Histoire naturelle (MNHN), Paris. Specimens sent in loan from Pennsylvania State University are housed in USA (Collection C. R. Fisher). Paratypes of A. hourdezi n. sp. will be sent to some institutions.

\section{COMPARATIVE MATERIAL OF AUSTINOGRAEA ALAYSEAE (SEE GUINOT 1990)}

Lau Basin, BIOLAU 2009 cruise, Valu Fa Ridge, Vai Lili site, $22^{\circ} 13^{\prime} \mathrm{S}, 176^{\circ} 38^{\prime} \mathrm{W}, 1900 \mathrm{~m}$ : dive BL09, 21.V.1989: 0' $16 \times$ $24 \mathrm{~mm}$, holotype, MNHN-IU-2008-11305 (= MNHNB24021), 1 ㅇ $21 \times 32 \mathrm{~mm}$, allotype, $1 \mathrm{o}^{7} 18.0 \times 27.5 \mathrm{~mm}$, 1 \% $24.0 \times 37.0 \mathrm{~mm}$, paratypes, MNHN-IU-2008-11306 (= MNHN-B24022); dive BL04, 16.V.1989: $30^{\circ 7}, 2$ \% , paratypes, MNHN-IU-2008-11305 (= MNHN-B24056); dive BL06, 18.V.1989: 11 ơ, 19 \%, paratypes, MNHN-IU-2016-10767 (= MNHN-B24057); dive BL10, 22.V.1989: 35 o", 52 ㅇ, paratypes, MNHN-IU-2008-11309 (= MNHN-B24055); dive BL11, 23.V.1989: 2 $17.0 \times 27.0 \mathrm{~mm}, 24.0 \times 38.0 \mathrm{~mm}$, MNHN-IU2016-10768 (= MNHN-B24058).

\section{COMPARATIVE MATERIAL OF AUSTINOGRAEA WILLIAMSI}

Mariana Back-Arc Basin, dive 1845, Alice Springs site, $18^{\circ} 12.805^{\prime} \mathrm{N}, 144^{\circ} 42.425^{\prime} \mathrm{E}, 3640 \mathrm{~m}, 06 . \mathrm{V} .1987: 20^{\prime \prime}$, $2 \%$, all paratypes, MNHN-IU-2008-11121 (= MNHNB20910). 
COMPARATIVE MATERIAL OF GANDALFUS YUNOHANA

Izu-Ogasawara Arc, Shinkai 2000, dive \#1007, Myojin Knoll site, $32^{\circ} 06.19^{\prime} \mathrm{N}, 139^{\circ} 52.04^{\prime} \mathrm{E}, 1263 \mathrm{~m}, 05 . \mathrm{V} .1998$ : ơ $24.9 \times$ $38.0 \mathrm{~mm}$, paratype, MNHN-IU-2008-11865.

\section{SYSTEMATICS}

Family BYTHOGRAEIDAE Williams, 1980

Genus Austinograea Hessler \& Martin, 1989

TYPE SPECIES. — Austinograea williamsi Hessler \& Martin, 1989.

Austinograea hourdezi n. sp.

(Figs 3A; 4A-E; 5A-H; 6A-E; 7A-H)

Austinograea sp. aff. williamsi Guinot, 1990: 898 (Addenda), 900, 901. - Guinot \& Segonzac 2006b: 460, fig. 1. - Mateos et al. 2012: 1, 5, 6, 10, figs 1, 2, table 1 .

TYPE MATERIAL. - Holotype. MNHN-IU-2016-10737, ơ $25.7 \times$ $40.2 \mathrm{~mm}$, southwestern Pacific, Lau Back-Arc Basin, TUIM06MV cruise, dive 142, Tow Cam site, 20 $0^{\circ} 19.07^{\prime} \mathrm{S}, 176^{\circ} 08.24^{\prime} \mathrm{W}, 2719 \mathrm{~m}$, 19.V.2005: right-handed individual, with left cheliped and all P2P5 detached (Figs 4A-C; 6A-E).

Paratypes. MNHN-IU-2016-10738, same data, 1 ơ $29.8 \times 48.1 \mathrm{~mm}$ (left-handed, two spots on both chelae, with weak heterochely and heterodonty) (Fig. 5A-H), 1 o $^{7} 24.7 \times 36.0 \mathrm{~mm}$ (left-handed, with small regenerated right chela, bearing only one spot).

MNHN-IU-2016-10745 (= MNHN-B24060), 3 Ơ $^{7} 21.0 \times 32.8 \mathrm{~mm}$, $18.7 \times 28.0 \mathrm{~mm}, 18.3 \times 29.2 \mathrm{~mm}, 5$ \% $25.0 \times 40.0 \mathrm{~mm}$ (two P1 lacking), $19.1 \times 32.2 \mathrm{~mm}, 18.3 \times 28.2 \mathrm{~mm}, 18.3 \times 28.4 \mathrm{~mm}$ (Fig. 7AH), cl $19.1 \mathrm{~mm}$ (bad condition), Lau Back-Arc Basin, BIOLAU cruise, BL 12, Vai Lili site, $23^{\circ} 13^{\prime}$ S, $176^{\circ} 38^{\prime} \mathrm{W}, 1750 \mathrm{~m}$, 24.V.1989. MNHN-IU-2016-10747 (= MNHN-B24059), $20^{\circ} 18.0 \times 31.0 \mathrm{~mm}$, $17.0 \times 28.0 \mathrm{~mm}, 1$ 우 $16.4 \times 26.8 \mathrm{~mm}$, Lau Back-Arc Basin, BIOLAU cruise, dive BL 03, Hine Hina site, $22^{\circ} 32^{\prime} \mathrm{S}, 176^{\circ} 43^{\prime} \mathrm{W}, 1853 \mathrm{~m}$, 15.V.1989.

MNHN-IU-2016-10739, 1 ( (with two cutters) $28.4 \times 46.8 \mathrm{~mm}$, Lau Back-Arc Basin, Lau Basin 2009 cruise, dive 424, Kilo Moana site, $20^{\circ} 03.23^{\prime} \mathrm{S}, 176^{\circ} 08.01^{\prime} \mathrm{W}, 2623 \mathrm{~m}$, 07.IX.2009.

MNHN-IU-2016-10741, 1 \% $25.3 \times 40.0$ mm, Lau Back-Arc Basin, TUIM06MV cruise, dive 140, Kilo Moana site, $20^{\circ} 03.23^{\prime} \mathrm{S}$, $176^{\circ} 08.01^{\prime} \mathrm{W}, 2623 \mathrm{~m}, 17 . \mathrm{V} .2005$.

MNHN-IU-2016-10740, 1 ơ $21.4 \times 34.3$ mm, Lau Back-Arc Basin, MGLN07MV cruise, dive 232, Tu'i Malila site, 21 ${ }^{\circ} 59.34$ 'S, 176 $34.09^{\prime} \mathrm{W}, 1891 \mathrm{~m}, 11 . \mathrm{IX} .2006$ (preserved in ethanol 85\%).

MNHN-IU-2016-10743, 1 big damaged ơ (with detached legs), Lau Back-Arc Basin, MGLN07MV cruise, dive 231, ABE site, $20^{\circ} 45.65^{\prime} \mathrm{S}, 176^{\circ} 11.45^{\prime} \mathrm{W}, 2130 \mathrm{~m}, 09$.IX.2006 (preserved in formalin $10 \%$ then transferred to ethanol $70 \%$ ).

MNHN-IU-2016-10746 (= MNHN-B27831), 1 9 cl 28.2 mm (left part broken), North Fiji Basin, STARMER II cruise, dive PL 16, White Lady site, $16^{\circ} 59.50^{\prime} \mathrm{S}, 173^{\circ} 55.47^{\prime} \mathrm{E}, 2000 \mathrm{~m}$, 11.VII.1989. MNHN-IU-2016-10742, 4 9 $19.4 \times 39.3 \mathrm{~mm}, 20.5 \times 33.2 \mathrm{~mm}$, $19.0 \times 30.0 \mathrm{~mm}, 25.0 \times 40.0 \mathrm{~mm}$, TUIM06MV cruise, dive 151 , box 2, North Fiji Basin, White Lady site, $16^{\circ} 59.50^{\prime} \mathrm{S}, 173^{\circ} 55.47^{\prime} \mathrm{E}$, $2000 \mathrm{~m}, 30 . \mathrm{V} .2005$.

TYPE LOCALITY. — Southwestern Pacific, Lau Back-Arc Basin, Tow Cam site, $20^{\circ} 19.07^{\circ} \mathrm{S}, 176^{\circ} 08.24^{\circ} \mathrm{W}, 2719 \mathrm{~m}$.

OTHER MATERIAL EXAMINED. - MNHN-IU-2016-10748 (= MNHNB27827), 1 ㅇ cl 29.2 (damaged, left P1 lacking), North Fiji Basin, STARMER II cruise, dive PL 20, White Lady site, $16^{\circ} 59.50^{\prime}$ ' $173^{\circ} 55.47^{\prime} \mathrm{E}, 2000 \mathrm{~m}$.
MNHN-IU-2016-10744, 2 $26.0 \times 42.0 \mathrm{~mm}, 26.0 \times 40.0 \mathrm{~mm}$, Lau Back-Arc Basin, Lau Basin 2009 cruise, dive 427, ABE site, $20^{\circ} 45.65^{\prime}$ S, $176^{\circ} 11.45^{\prime} \mathrm{W}, 2130 \mathrm{~m}, 28 . \mathrm{V} .2009$ (preserved in ethanol $85 \%$ ). This sample with two typical females devoid of spots on chelae palm also contains a female $27.1 \times 44.6 \mathrm{~mm}$ with a spot (a unique spot) on each chela (see Individuals with regenerated chelae).

MNHN-IU-2016-10752, 1 9 $30.0 \times 48.5$ mm, Lau Back-Arc Basin, MGLN07MV cruise, dive 230, Kilo Moana site, $20^{\circ} 03.23^{\prime}$ 'S, $176^{\circ} 08.01^{\prime} \mathrm{W}, 2623 \mathrm{~m}, 07 . \mathrm{IV} .2006$ (preserved in formalin $10 \%$ and then transferred into ethanol $70 \%$ ). This large right-handed female, with heterochely and heterodonty (Fig. 4D, E), is atypical due to the presence two spots on the chelae (on the crusher, one marked dark spot plus a faint another one, only discernible as yellow trace; on the cutter, two indistinct spots, only as yellow traces), conversely to typical females that are devoid of any spot.

MNHN-IU-2016-10768 (= MNHN-B27834), 1 o $22.7 \times 36.5 \mathrm{~mm}$, North Fiji Basin, STARMER II cruise, dive PL 18, Mussel Valley, $18^{\circ} 50^{\prime} \mathrm{S}, 173^{\circ} 29^{\prime} \mathrm{E}, 2750 \mathrm{~m}, 13$.VII.1989. This atypical female bears a spot on each chela.

MNHN-IU-2016-10765, only one big crusher chela (with two spots) and several pereopods, Lau Back-Arc Basin, no other data.

Collection C. R. Fisher. 2 \%, southwestern Pacific, Lau Back-Arc Basin, MGLN07MV, dive J2-232, Tu'i Malila site, 21 ${ }^{\circ} 59.34$ 'S, $176^{\circ} 34.09^{\prime} \mathrm{W}, 1891 \mathrm{~m}, 11 . \mathrm{IX} .2006$ (preserved in formalin 10\% and then transferred into ethanol 70\%); 2 \%, Lau Back-Arc Basin, MGLN07MV, dive 231, ABE site, $20^{\circ} 45.65^{\prime} \mathrm{S}, 176^{\circ} 11.45^{\prime} \mathrm{W}$, 09.IX.2006 (preserved in formalin $10 \%$ and then transferred into ethanol 70\%); 2 \%, Lau Back-Arc Basin, Lau Basin 2009 cruise, dive 425, ABE site, 2045.65'S, 176¹1.45’W, 2130 m, 25.V.2009 (preserved in ethanol 85\%).

ETymology. - Dedicated to Stéphane Hourdez (CNRS, Station biologique de Roscoff, France) in recognition of his valuable contribution to the knowledge of hydrothermal fauna sites (taxonomy, ecology, physiology, adaptation, phylogeny). He actively participated in the taxonomic sampling during the C. R. Fisher's cruises in the Lau Basin, suspecting the presence of new Austinograea.

DisTRIBUTION. - Austinograea hourdezi n. sp. is a widespread species encountered in the southwestern Pacific from numerous vent fields of the Lau and North Fiji Back-Arc Basins. It cohabits with $A$. alayseae at a number of sites, and the two species seem to share a similar distribution.

As $A$. alayseae, $A$. hourdezi n. sp. has not been found in the northwestern Pacific, at least after the revision of the MNHN collection and without, however, the examination of an extensive material from the Mariana Trough. For its part, $A$. williamsi seems to be confined to the northwestern Pacific, in the Mariana Back-Arc Basin, and vent sites of the Mariana Trough.

\section{DESCRIPTION (MALE) \\ Carapace}

Carapace transversely elliptical, flat; regions indistinct. Dorsal surface nearly smooth, except for rare small granules on frontal region and small tubercles on orbital region; numerous small pits. Anterolateral margin marked by rounded edge, slightly granulous. Posterolateral margins convergent; posterior margin slightly concave. Subhepatic regions entirely covered by patches of dense setae. Front broad, not protruded, bluntly pointed medially and with two slightly concave lobes. Eyes, antennules and antennae recessed under front. Suborbital plate absent. Orbit not delimited, only an orbital region that extends as groove lateral to region containing vestigial eyestalks and antennae. Outer side of orbital region tuberculated. 

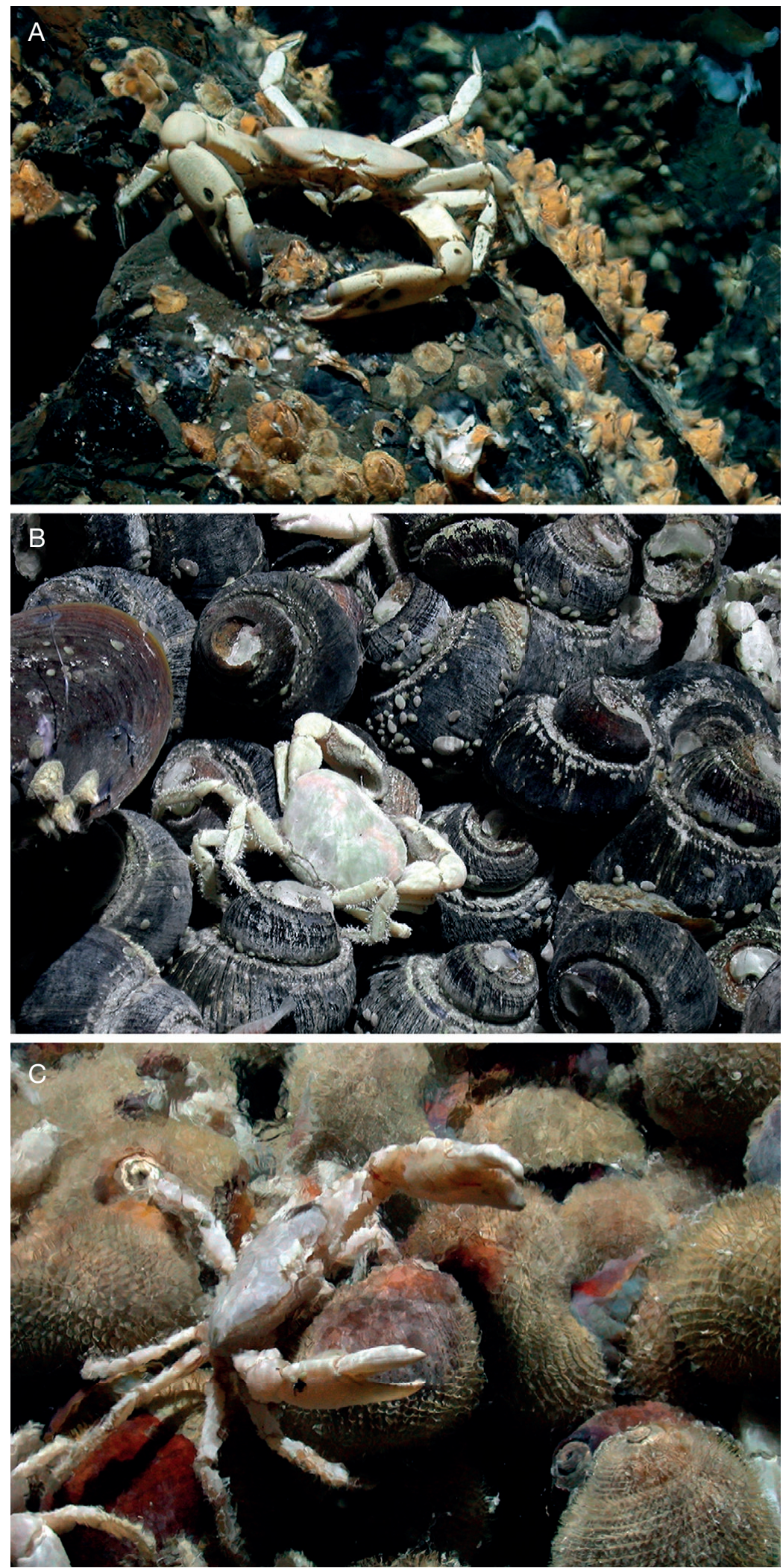

FIG. 3. - Austinograea hourdezi n. sp. photographed in situ: A, Lau Basin, Lau Basin 2009 cruise, dive 432, Tow Cam site, 20¹8.98'S, 17608.19’W, 2723 m, 05.VI.2009 (type locality), among sessiles barnacles Eochionelasmus ohtai ohtai Yamaguchi, 1990. The two dark spots on outer surface of palm of both chelae indicate a male; see patches of dense setae on inner surface of both chelae, and the darkly coloured two-thirds of dactylus of right cheliped; B, C, Austinograea hourdezi n. sp., due to the patch of dense setae on inner surface of both chelae: B, Lau Basin, TUIM07MV cruise, dive 163, ABE site, $20^{\circ} 45.65^{\prime} \mathrm{S}, 176^{\circ} 11.45^{\prime} \mathrm{W}$, 2130 m, 23.VI.2005; on a bed of gastropod Ifremeria nautilei Bouchet \& Warén, 1991; C, Lau Basin, Lau Basin 2009 cruise, dive 431, ABE site, 2045.65'S, $176^{\circ} 11.45^{\prime} \mathrm{W}, 2130 \mathrm{~m}, 03 . \mathrm{Vl} .2009$. The crab and the gastropods Alviniconcha hessleri sensu lato are blurry, the photography in situ having been taken in hydrothermal diffuse area with the emanating fluid visible as shimmering water. Photographies courtesy of C. R. Fisher (Penn State University, USA). 

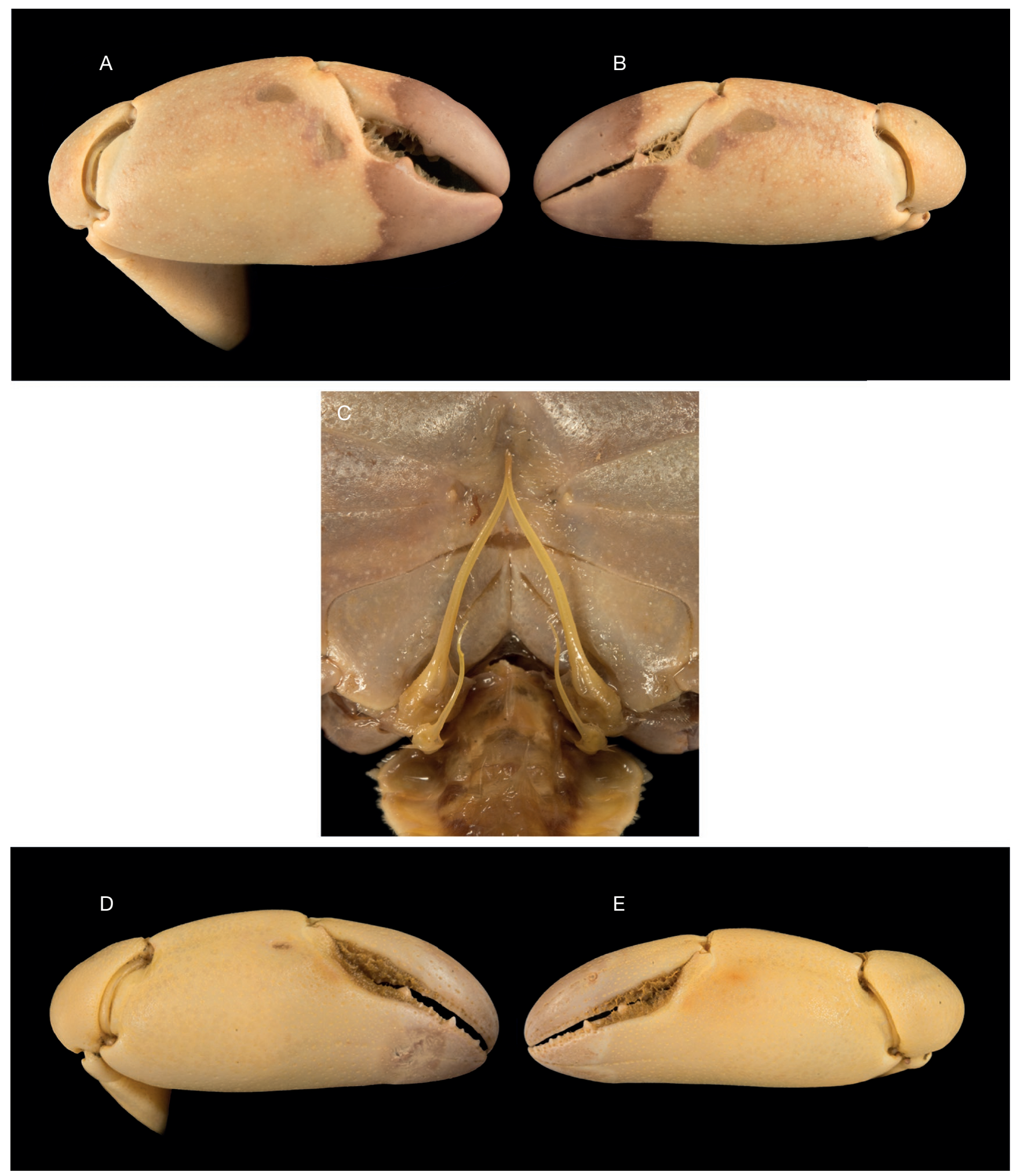

FIG. 4. - A-C, Austinograea hourdezi n. sp., holotype, ơ $25.7 \times 40.2$ mm (right-handed), Lau Back-Arc Basin, TUIM06MV cruise, dive 142, Tow Cam site, $20^{\circ} 19.07$ 'S, $176^{\circ} 08.24^{\prime} \mathrm{W}, 2719 \mathrm{~m}, \mathrm{MNHN}-\mathrm{IU}-2016-10737$ : A, B, chelae with two coloured spots on outer surface of palm of right crusher (A) and left cutter (B); C, G1 and G2 photographed in situ; D, E, Austinograea hourdezi n. sp., atypical o $30.0 \times 48.5$ mm (right-handed), Lau Back-Arc Basin, MGLN07MV cruise, dive 230, Kilo Moana site, $20^{\circ} 03.23$ 'S, $176^{\circ} 08.01^{\prime} \mathrm{W}, 2623 \mathrm{~m}$, MNHN-IU-2016-10752: D, crusher with one marked dark spot and the other one, only discernible by a yellow trace (wound at base of fixed finger is not a spot comparable to that of $A$. jolliveti $\mathrm{n}$. sp.); $\mathbf{E}$, cutter with two indistinct spots, only as yellow traces. 

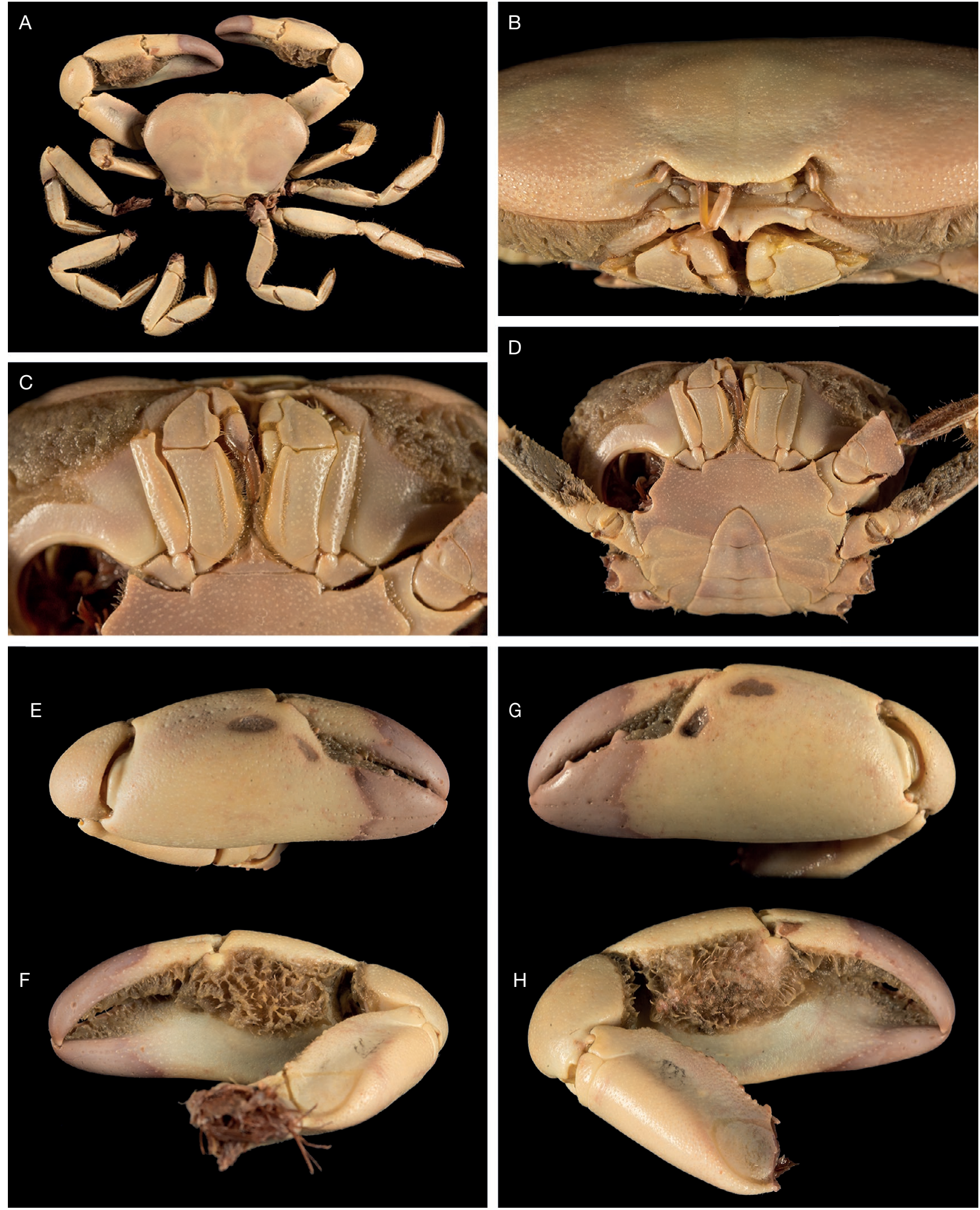

FIG. 5. - Austinograea hourdezi n. sp., paratype, o $29.8 \times 48.1 \mathrm{~mm}$ (left-handed, with weak heterochely and heterodonty), Lau Back-Arc Basin, TUIM06MV cruise, dive 142, Tow Cam site, MNHN-IU-2016-10738: A, dorsal view; B, frontal view; C, mxp3; D, ventral view; E, G, both chelae with two typical spots on outer surface; F, H, both chelae with patches of setae on inner surface: E, F, cutter situated at right; $\mathbf{G}, \mathbf{H}$, crusher situated at left. 
Eyestalk not moveable, showing as fixed piece fused to floor of orbital region; no cornea. Antennules folded horizontally. Antenna inserted in wide supraorbital notch; urinary article fixed, broad, recessed; basal article $(2+3)$ cylindrical, moveable; article 4 slightly elongated, inclined; flagellum of about 10 articles. Proepistome incomplete. Margin of epistome with moderate median projection and formed of two moderately concave lobes, marked by row of low granules. Pterygostomial lobe tuberculous; pterygostomial region smooth, except for small curved ridge.

\section{Thoracopods}

Third maxillipeds completely closing buccal cavity. Ischium long, with marked longitudinal internal groove. Merus: external margin regularly curved, oblique, without marked angle, with distal part markedly narrow and produced; internal margin with prominent lobe in half proximal portion. Carpus inserted in notch of antero-internal margin of merus; propodus thick; dactylus about as long as merus; inner margins of propodus and dactylus with brush-like setae. Exopod longer than endopod ischium. Mxp3 coxa with only proximal portion visible, its lateral projection hidden by junction of thoracic sternum (sternite 4) with pterygostome. Chelipeds heteromorphic, marked heterochely (also in females, see below), with two types of chelae: major cheliped blunt-tip (crusher), stouter and shorter than pointed-tip minor chela (cutter). Carpus with setae on superior margin and inner surface; merus long, triangular in cross section, anterior border straight, with blunt teeth, smaller distally. Propodus of both chelae with two conspicuous, deep depressions at outer surface of palm near base of dactylus (absent in females), both as two dark spots, even well visible in specimens photographed in situ. Inner surface of both chelae dished on half posterior part; thick patches of dense setae largely extending on half anterior part of propodus and partially extending along occluding margins. Dark colour extending on about three-quarters of fixed finger and practically on whole part of dactylus of both crusher and cutter. Crusher: palm convex, inflated, smooth, except for two depressions located near base of dactylus: one horizontally directed and the largest; the other obliquely directed, smaller. Fingers thick, slightly gaping at occluding margins; two weak, blunt teeth, proximal and median, on occluding margin of dactylus; a blunt but marked subproximal tooth and smaller ones on occluding margin of fixed finger. Cutter: palm elongate, with subparallel borders, smooth, except for two depressions near base of dactylus, similar to those of the crusher; both fingers not gaping at the occluding margins; dactylus elongate, hollowed, with occluding margin smooth; fixed finger very thick, dished on inner surface; occluding margin nearly straight, with 2-3 small teeth, size progressively diminishing forwards. P2-P5 shorter than chelipeds; P3 and P4 longest; meri with patch of dense setae on ventral margins, carpi, propodi fringed on dorsal and ventral margins with felt of short, stiff setae, mixed with sparse longer setae, the patch being dense, thicker on inferior margin. Dactyli rather stout, with patches of short setae.

\section{Thoracic sternum}

Thoracic sternum with sutures 4/5-7/8 incomplete but separared by short gap; suture 2/3 complete. Median line only along sternite 8 , hardly continuying along sternite 7 . Junction of sternite 4 with pterygostome represented by only short juxtaposition, without patch of setae. Press-button of locking mechanism acute, very close to suture 5/6.

\section{Pleon}

Pleon of six free segments and telson regularly triangular; pleonal somite 3 widest; pleonal somite 6 longest, anterointernally delineated by raised, thick margin; telson triangular, rounded distally. Both G1 joining at tips. G1: slender, faintly curved, with only short, spiniform setae arranged in two rows along mid-part only. G2: about half the length of G1, with bend about two-thirds length at level of small setiferous area; flagellum rather long, curved, flattened, bladelike.

\section{DESCRIPTION (FEMALE)}

Chelipeds weakly dimorphic (versus dimorphic in males), having almost cutters on both sides. On both chelipeds: inner surface markedly dished on half posterior part of propodus and on fixed finger; thick patches of dense setae extending on half or anterior two-thirds part of propodus and along occluding margins of dactyli. Dark colour extending on about threequarters of fixed finger and on two-thirds of dactylus of both crusher and cutter. Weak heterochely and heterodonty; cutter however smaller than crusher. Crusher: palm hardly inflated, elongated, smooth, without depressions; fingers thick, not or only slightly gaping at the occluding margins; two tiny blunt teeth on occluding margin of dactylus; two tooth and a few smaller ones on occluding margin of fixed finger. Cutter: palm similar to crusher but fingers more elongated, not gaping at occluding margins; palm smooth, without depressions; both fingers; dactylus elongate, hollowed, with occluding margin practically smooth; fixed finger very thick, with occluding margin nearly straight, bearing small teeth, two being more marked. P2-P5 with felt of short, stiff setae, mixed with numerous longer setae. Median line along sternite 8 , hardly continuying along sternite 7 . Dense patches of setae on thoracic sternum near junction of sternite 4 with pterygostome. No pleonal locking mechanism in mature females. Margins of pleon densely fringed with setae. Vulvae large, rounded, with thick membranous area all around median opening.

\section{REMARKS AND COMPARATIVE DIAGNOSIS}

The two characteristic depressions on the propodus of both male chelae, crusher and cutter, of Austinograea hourdezi n. sp. (Figs 3A; 4A, B; 5E, G), typically absent in females (Fig. 7E, $\mathrm{G})$, are similarly located in all the individuals examined, but they are variously delineated by a raised margin and thus may appear quite deep or shallower but practically always coloured as dark or coloured spots, always with a different texture and colour but commonly referred to as "dark spots". The function of the pigmented pits or spots present on the palm of chelipeds (also on the subocular regions in others species) of certain bythograeids is supposed to be sensory. 

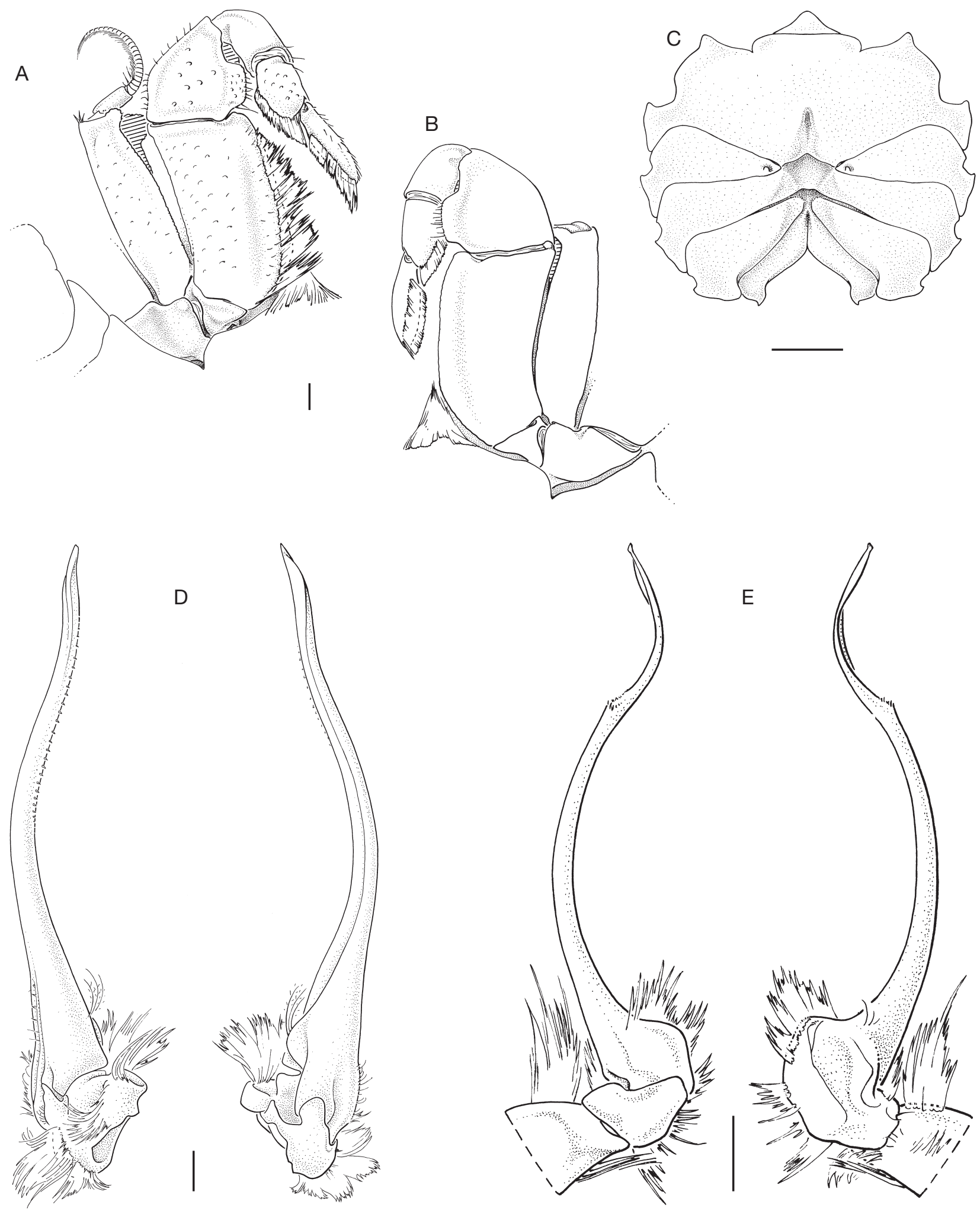

FIG. 6. - Austinograea hourdezi n. sp.: A-C, holotype, ơ $25.7 \times 40.2$ mm (right-handed), Lau Back-Arc Basin, TUIM06MV cruise, dive 142, Tow Cam site, 20¹9.07'S, 176 08.24'W, 2719 m, MNHN-IU-2016-10737: A, B, right and left mxp3, with and without ornamentation; C, thoracic sternum. D, E, paratype, o $29.8 \times 48.1$ mm (left-handed), Lau Back-Arc Basin, TUIM06MV cruise, dive 142, Tow Cam site, MNHN-IU-2016-10738: D, G1, two views; E, G2, two views. Scale bars: A, B, D, E, $1 \mathrm{~mm}$; C, $5 \mathrm{~mm}$. Note the scale bars of the two gonopods, the G2 being about half-length of G1. 
For atypical specimens of $A$. hourdezi n. sp., see below Individuals with regenerated chelae.

Austinograea hourdezi n. sp. may be easily distinguished from $A$. alayseae (Fig. 8A, B), with which it cohabits in several sites, by:

1) subhepatic region covered by patch of dense setae in both sexes (no setae in $A$. alayseae); 2) mxp3: external border oblique, distal end strongly produced (in $A$. alayseae forming a marked angle: proximal portion vertically oriented, with slightly concave border, half distal portion abruptly tilted; distal end weakly produced); inner margin produced in marked lobe (without lobe in $A$. alayseae); 3 ) both male chelae with two deep, dark depressions, marked as spots (without any spot in A. alayseae); 4) in both sexes patches of dense setae on inner surface of palm and along fingers (without setae in $A$. alayseae); 5) marked heterochely: male crusher with short, stout propodus, and short, thick fingers; 6) fixed finger coloured; dactylus coloured on two thirds (in $A$. alayseae pronounced heterochely but propodus of male crusher more elongated; fingers more elongated, narrower); 7) male cutter with occluding margin of dactylus smooth; 8) fixed finger very thick, almost entirely coloured, occluding margin with three small teeth, size progressively diminishing forwards (in $A$. alayseae fingers elongated, armed on both occluding margins with several small teeth interspersed with smaller ones; dactylus coloured at distal end in males and only at tip in females); 9) thoracic sternum with median line at level of sternite 8 and practically not continuying along sternite 7 in both sexes (extending on most part of sternite 7 in both sexes of A. alayseae, see Guinot 1990: fig. 2C); 10) male pleon with triangular telson (rounded in A. alayseae); and 11) G1 rather straigt, with only minute setae along subdistal half (more curved, with several rows of rather long, acute setae along most of length in $A$. alayseae).

The most distinctive character between Austinograea hourdezi n. sp. and $A$. williamsi is in the presence of a two spots in male chelae of $A$. hourdezi n. sp. (Figs 3A; 4A, B; 5E, G) ([versus one spot on the palm of crusher and cutter male chelipeds of A. williamsi, described by Hessler \& Martin (1989: 651, figs 1 b, 9a-c) as "small, often brown-stained, pitted area just proximal to, and in line with, ventral border of dactylus" in "larger males" and absent in females (see also Tsuchida \& Fujikura 2000: fig. 2]). Heterochely and heterodonty are pronounced in males of $A$. hourdezi n. sp. and $A$. williamsi. The male cutter chela of $A$. hourdezi n. sp. has a thick, broad fixed finger, and an occluding margin armed with a few teeth. In A. williamsi the cutter chela is more elongate; the fixed finger is more inflated and broader, with a deeply dished inner surface, and a markedly convex, much toothed occluding margin that fits flush against dactylus. In $A$. hourdezi n. sp. the chelae show a sexual dimorphism that is distinctive from that of A. williamsi (see Hessler \& Martin 1989: figs 9, 10), in which females have cutters for both chelipeds with a markedly concave propodal inner margin and a well dished fixed finger at occluding margin that bears numerous, sharper, delicate teeth. The mxp3 merus of $A$. hourdezi $\mathrm{n}$. sp. is very similar to that of $A$. williamsi, both having an oblique external border, a produced ending and a pronounced inner lobe. Another marked difference is the subhepatic region: covered by dense setae in $A$. hourdezi n. sp., whereas the patch of setae is much more larger in $A$. williamsi, in which it considerably extends below the lateral line.

For the distinction between $A$. alayseae and $A$. williamsi, see the comparative illustrations in Tsuchida \& Hashimoto (2002). The inner surface of palm and most inner surface of the dactylus of the two chelae bear patches of setae in both sexes of $A$. hourdezi n. sp. (Figs 3A-C; 5A, F, H; 7A, B, F, $\mathrm{H})$, as in $A$. williamsi, whereas in both sexes of $A$. alayseae the chelae of both sides are glabrous on palm and dactylus. The $\mathrm{G} 1$ and $\mathrm{G} 2$ of $A$. hourdezi n. sp. and $A$. williamsi (in which the G2 is about less than half the G1's length) are similar, whereas in $A$. alayseae the G1 bears numerous long setae scattered over its entire length.

\section{DisTINCTION OF FEMALES}

As the spots on the cheliped propodus are typically absent in female $A$. hourdezi $\mathrm{n}$. sp. and in both sexes of $A$. alayseae, the more useful significant character to differentiate the females of the two species is the patch of setae at the inner surface of the palm of females of $A$. hourdezi n. sp. (Fig. 7A, B, F, H), as in the males (Figs 3A; 5A, F, H). In contrast, in $A$. alayseae (Fig. 8A, B) the chelae are devoid of setae, in females as in males. The same character allows identification of females of $A$. williamsi, with setose patch at the inner chela surface (Hessler \& Martin 1989: fig. 10), from females of $A$. alayseae, which have glabrous chelae. See the comparative illustration of female Austinograea chelae by Tsuchida \& Hashimoto (2002: fig. 6), which does not show any spot in $A$. williamsi and $A$. alayseae, in contrast with $A$. rodriguezensis, which is shown bearing a spot, as in the males. In $A$. alayseae a thick posterior membrane may cover most of the vulva, leaving a variously developed opening, sometimes only a lateral slit, whereas in $A$. hourdezi n. sp. the medial opening is entirely surrounded by thick membrane (Fig. 7D).

\section{INDIVIDUALS WITH REGENERATED CHELAE}

A few male specimens that display most characters of $A$. hourdezi n. sp. (including mxp3 shape and patches of setae on inner surface of chelae) exhibit a single spot on the outer surface chelae palm, instead of two. The holotype (MNHNIU-2016-10737), from the Lau Basin, Tow Cam site, a large right-handed male $25.7 \times 40.2 \mathrm{~mm}$, typically bears the two characteristic spots on each chela (Fig. 4A, B), such as most of other males that we have examined. Although left-handed and with weak heterochely and heterodonty, a larger male from the same site $29.8 \times 48.1 \mathrm{~mm}$, paratype, MNHNIU-2016-10738, also shows the two typical spots on chelae, even on regenerated cheliped (Fig. 5E, G). But a smaller lefthanded male $24.7 \times 36.0 \mathrm{~mm}$, from the same sample, has an obviously regenerated minor chela that bears only one spot; its left chela, having become the major chela, shows the two typical spots.

Two samples of female $A$. hourdezi n. sp., instead of being devoid of any spot on the chela, bear a spot on both chelae: 

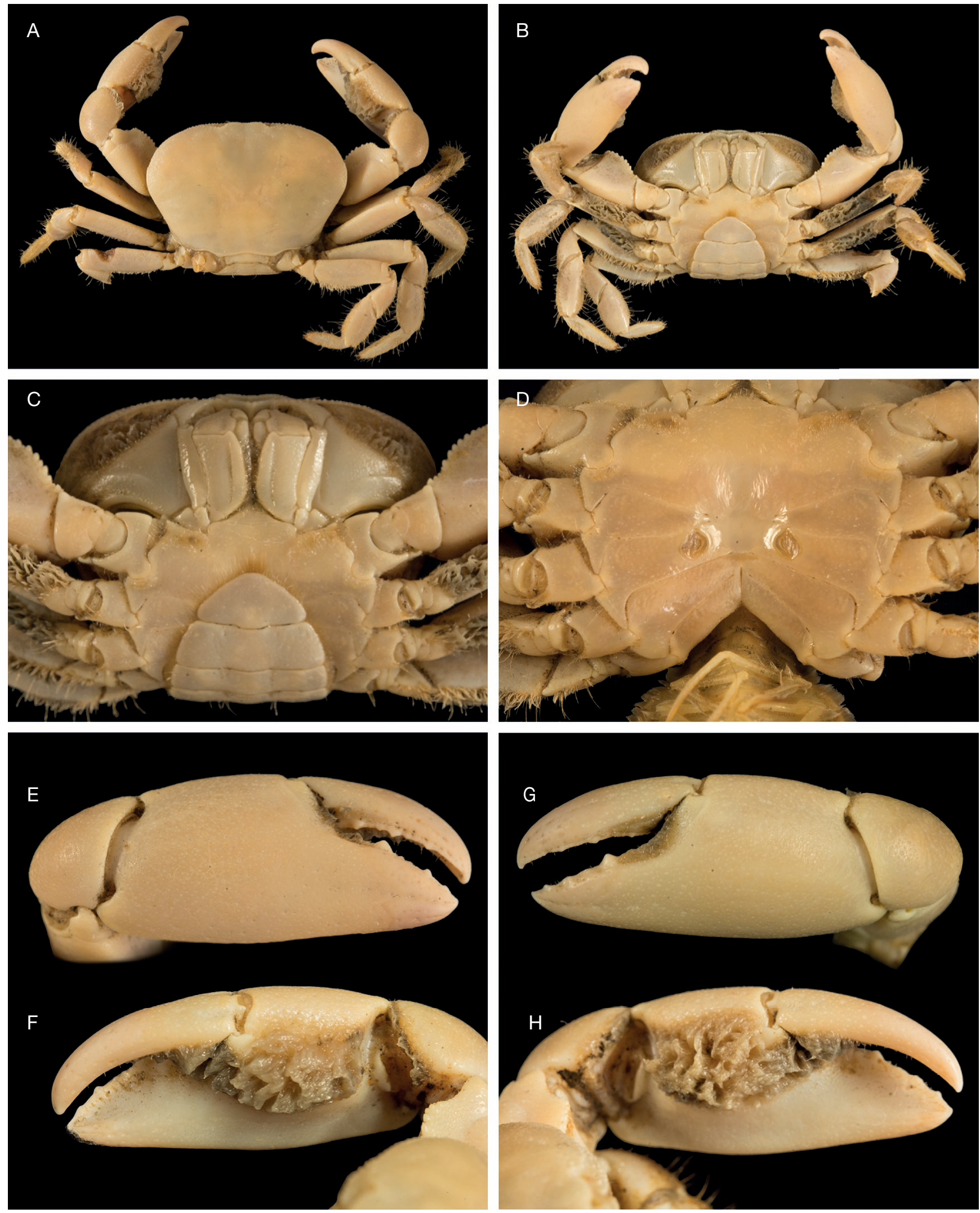

FIG. 7. - Austinograea hourdezi n. sp., paratype, ㅇ $18.3 \times 28.4$ mm (right-handed), Lau Back-Arc Basin, BIOLAU cruise, BL 12, Vai Lili site, 23¹3’S, 176³8’W, 1750 m, MNHN-IU-2016-10745 (= MNHN-B24060): A, dorsal view; B, C, ventral views, with pleon; D, thoracic sternum and vulvae; E, G, both chelae without spots on outer surface; $\mathbf{F}, \mathbf{H}$, both chelae with patches of setae on inner surface; $\mathbf{E}$, F, right crusher; $\mathbf{G}, \mathbf{H}$, left cutter. 

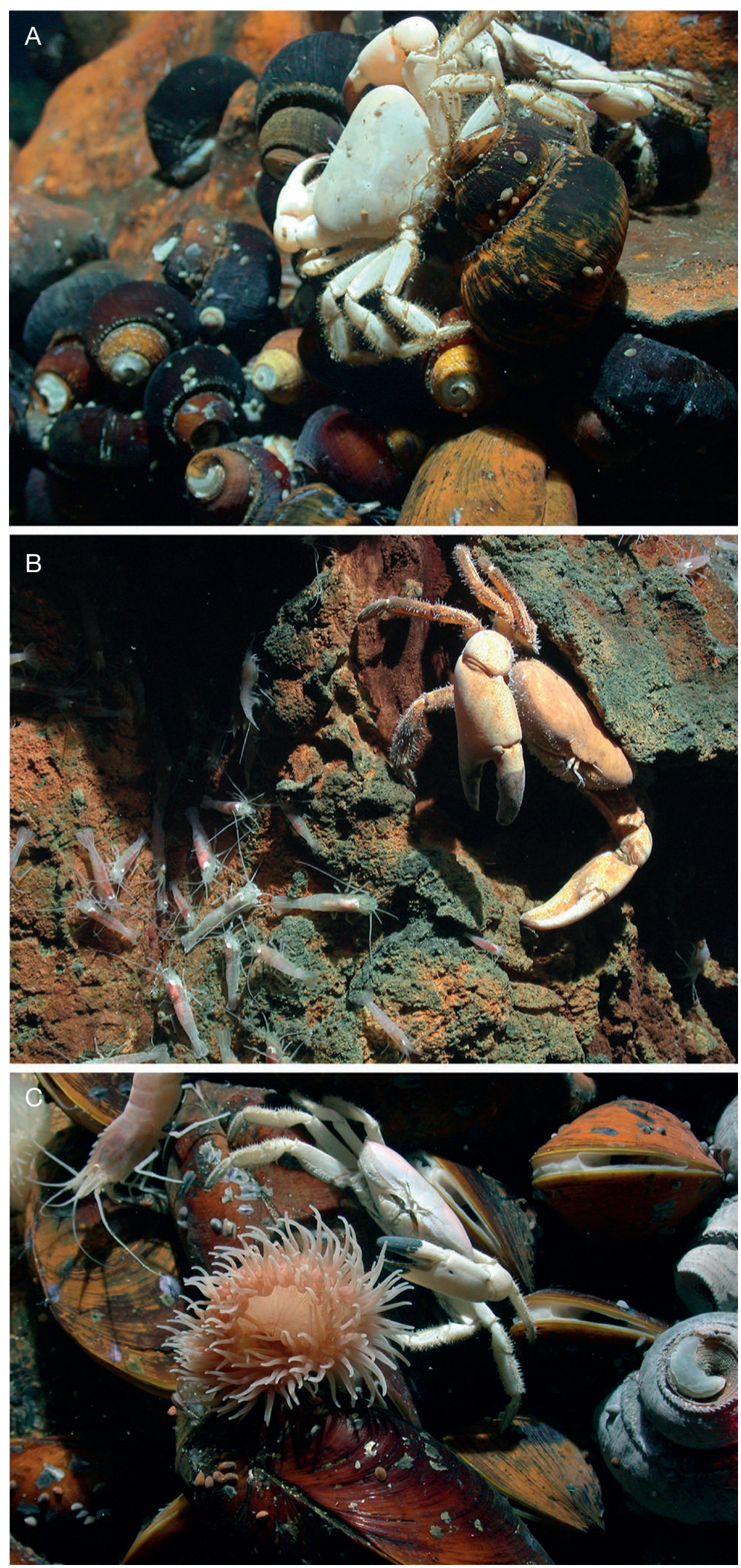

FIG. 8. - A, B, Austinograea alayseae Guinot, 1990, photographed in situ: see absence of patches of setae on inner surface of chelae: A, crab with white carapace, Lau Basin 2009 cruise, Kilo Moana site, 2003.23'S, 17608.01'W, 2621 m, among mussels Bathymodiolus brevior Cosel, Métivier \& Hashimoto, 1994 and snails Ifremeria nautilei Bouchet \& Warén, 1991; B, crab with carapace stained orange due to iron or manganese oxide deposits, and cluster of alvinocaridid shrimps, Lau Basin, TUIM07MV, Kilo Moana site, 2003.23'S, 17608.01'W, 2621 m; C, Austinograea hourdezi n. sp. (presumed identification, see p. 89), Lau Basin, Lau Basin 2009 cruise, Kilo Moana site, among mussels Bathymodiolus brevior, gastropods Ifremeria nautilei, sea anemone probably Cyananthea hourdezi Zelnio, Rodríguez \& Daly, 2009, and alvinocaridid shrimp, Alvinocaris komaii Zelnio \& Hourdez, 2009. This invidual with palm of preserved left cheliped (regenerated?) bearing only a single dark spot is atypical such as many Austinograea species showing regenerated chelipeds; patches of setae discernible just above on inner surface of chela and on right subhepatic region. Photographies courtesy of C. R. Fisher (Penn State University, USA). 
they are left-handed, which means that one chela was regenerated. These females that bear a spot on each cheliped, crusher and cutter, are:

MNHN-IU-2016-10744, 1 9 27.1 × 44.6 mm (left-handed), Lau Back-Arc Basin, Lau Basin 2009 cruise, dive 427, ABE site, $20^{\circ} 45.65^{\prime} \mathrm{S}, 176^{\circ} 11.45^{\prime} \mathrm{W}, 2130 \mathrm{~m}, 28 . \mathrm{V} .2009$ (preserved in ethanol $85 \%$ ). It belongs to the same sample that contains two typical females devoid of spots on chelae palm;

MNHN-IU-2016-10768 (= MNHN-B27834), 1 $22.7 \times$ $36.5 \mathrm{~mm}$, North Fiji Basin, STARMER II cruise, dive PL 18, Mussel Valley, $18^{\circ} 50^{\prime}$ S, $173^{\circ} 29^{\prime} \mathrm{E}, 2750$ m, 13.VII.1989 (was found with a typical male of $A$. alayseae).

A large, right-handed $\$ 30.0 \times 48.5 \mathrm{~mm}(\mathrm{MNHN}$ IU-2016-10752) from the Lau Back-Arc Basin, MGLN07MV cruise, dive 230, Kilo Moana site, $20^{\circ} 03.23^{\prime}$ S, $176^{\circ} 08.01^{\prime} \mathrm{W}$, 2623 m, 07.IX.2006, and identified as $A$. hourdezi n. sp. on the basis of other characters, has the right chela of a crusher type with one marked spot plus a second spot only as a yellow trace, and the cutter with two yellowish spots (Fig. 4D, E), This male chela pattern is unusual for female $A$. hourdezi n. sp., which are generally devoid of any spot (Fig. 7E, G).

A bythograeid that bears only a left cheliped, photographed in situ (Fig. 8C) at the site Kilo Moana during the Lau Basin 2009 cruise and with a single dark spot on the chela could be $A$. hourdezi n. sp., based on the patches of setae discernible just at the suface of the inner chela palm and on setose patches on the right subhepatic region. This could be an atypical specimen of $A$. hourdezi n. sp., with a regenerated cheliped. It was found associated with mussels Bathymodiolus brevior Cosel, Métivier \& Hashimoto, 1994 (see Cosel et al. 1994), gastropods Ifremeria nautilei Bouchet \& Warén, 1991, sea anemone Cyananthea hourdezi Zelnio, Rodríguez \& Daly, 2009 (see Zelnio et al. 2009; E. Rodríguez, pers. comm. 2017). Due to the same features, the seemingly right-handed crab collected at Tow Cam site, dive 240, and photographed in situ (Zelnio et al. 2009: fig. 14B) associated with an unidentifiable actiniarian zoanthidean, could be also identified to $A$. hourdezi n. sp., but it is difficult to discern the presence of spots on the chelae.

All of these specimens with atypical spot(s) on the chelae exhibit all other morphological traits of $A$. hourdezi n. sp., and are not $A$. williamsi nor $A$. rodriguezensis, both of which are characterised by one spot on the outer chela palm, near the dactylus base. We assume that most of these atypical crabs were initially right-handed and that left-handers represent individuals whose asymmetry has been reversed following autotomy and regeneration of the lost cheliped (see Chelae: crusher and cutter. Regenerated chelae). This reversion of chelipeds, which causes a dramatic rearrangement and triggers a new allometric growth, is thought to have induced a novel implantation of the spots on the chelae, mainly when autotomy or loss occurs at a large size of crabs. These atypical individuals, without other equivocal morphological evidence and presumably not genetically cryptic, are here treated as $A$. hourdezi n. sp. subject to their recognition by molecular sequences (in study).
MOLECULAR ANALYSIS

In the early 2000s fragments of Austinograea from the Lau Back-Arc Basin, Valu Fa Ridge, recognised by Guinot (1990) as "Austinograea aff. williamsi" and here described as A. hourdezi n. sp. were sent by D. Guinot to L. A. Hurtado (Texas A\&M University, USA) and V. Leignel (Université du Maine, Le Mans, France) for molecular analyses. Genetic divergence warranted recognition of a new species. The sequences obtained for the $16 \mathrm{~S}$ rDNA, Cytb, and $28 \mathrm{~S}$ rDNA recovered that the uncorrected nucleotide divergence for the mitochondrial 16S rDNA gene was $5.5 \%$ between $A$. hourdezi n. sp. and $A$. williamsi; $7 \%$ between $A$. hourdezi n. sp. and $A$. alayseae; and $5.9 \%$ between $A$. williamsi and $A$. alayseae (Mateos et al. 2012: 1, 3, 5, 6, 10, fig. 2, table 1, as Austinograea aff. williamsi).

\section{Austinograea jolliveti n. sp.}

(Figs 9A-H; 10A-E; 11A-E)

TYPe MATERIAL. - Holotype. $0^{\pi} 12.8 \times 20.0 \mathrm{~mm}$ (right-handed), western Pacific, North Fiji Basin, STARMER II cruise, dive 18 (PL 18), Mussel Valley site, 1850'S, 17329'E, 2750 m, 13.VII.1989 (MNHN-IU-2016-10769) (Figs 9A-H; 11A-E). Paratypes. $10^{7}$ $14.7 \times 25.4 \mathrm{~mm}, 1$ \% $12.4 \times 21.6 \mathrm{~mm}$ (Fig. 10A-E), same data (MNHN-IU-2016-10770).

OTHER MATERIAL EXAMINED. -1 \$ $13.6 \times 22.0 \mathrm{~mm}$ (left-handed), western Pacific, Lau Back-Arc Basin, MGLN07MV cruise, dive 237, ABE site, $20^{\circ} 45.65^{\prime} \mathrm{S}, 176^{\circ} 11.45^{\prime} \mathrm{E}, 2130 \mathrm{~m}$, 25.IX.2006, MNHNIU-2016-10751 (preserved in ethanol 85\%).

Type Locality. - Western Pacific, North Fiji Basin, Mussel Valley site, $2750 \mathrm{~m}$.

ETYMology. - Dedicated to Didier Jollivet (CNRS, Station biologique de Roscoff, France), in recognition of his pioneering work on the ecology of the southwestern Back-Arc Basin hydrothermal communities in 1989 and for his valuable contribution to deciphering the delicate interplay of physical and biological factors in shaping the evolutionary history of hydrothermal vent fauna.

Distribution. - Southwestern Pacific; only collected from one site in the Lau Basin (ABE site) and one site in the North Fiji Basin (Mussel Valley site).

\section{DESCRIPTION (MALE) \\ Carapace}

Carapace transversely elliptical, flat; regions indistinct. Dorsal surface nearly smooth, except for rare small granules on frontal region and tubercles on orbital region; numerous small pits. Anterolateral margin marked by rounded edge, slightly granulous. Posterolateral margins convergent; posterior margin slightly concave. Subhepatic region with dense setae mainly only at lateral edge. Front broad, not protruded, bluntly pointed medially and with two slightly convex lobes. Eyes, antennules and antennae recessed under front. Suborbital plate absent. Outer side of orbital region tuberculated. Proepistome incomplete. Orbital region deeply concave and open laterally, containing antennules, antennae and possible 
eye remnants. Eyestalk absent, podophthalmite fused to floor of orbital region; cornea absent, no visible pigment. Antennules folded horizontally, filling most of orbit. Antenna inserted in wide supraorbital notch; urinary article fixed, broad, recessed, basal article $(2+3)$ cylindrical, moveable; article 4 elongated shorter, inclined. Margin of epistome projecting medially and formed of two markedly concave lobes, marked by row of low granules. Pterygostomial lobe granulous; pterygostomial region mostly smooth.

\section{Thoracopods}

Third maxillipeds completely closing buccal cavity. Ischium long, with marked longitudinal internal groove. Merus about half as long as ischium, narrow; external margin regularly curved, oblique, without marked angle; half distal part markedly narrow and much produced; half proximal internal margin with prominent median lobe. Carpus inserted in notch of anterointernal margin of merus; propodus thick; dactylus about as long as merus; inner margins of propodus and dactylus with brush-like setae. Exopod longer than endopod ischium. Wide mxp3 coxa with only proximal portion visible, its lateral projection hidden by junction of thoracic sternum (sternite 4) with pterygostome. Chelipeds long, heteromorphic. Palm of both chelipeds with inner surface bearing medially thick patches of setae, densely extending along occluding margins of both fingers, thus well dorsally visible along half of fingers. Dark colour extending on about whole fixed finger (the dark coloured of half posterior portion joins the coloured spot), and on two-thirds of dactylus of both crusher and cutter. Major cheliped (crusher) stouter than minor ones (cutter); merus notably elongated, largely extending beyond margin of carapace, narrow, anterior border entirely straight, with regular, small, distally reduced teeth; both fingers thick, blunt-tipped. Crusher: palm rather long, dorsal surface slightly convex, pitted; a conspicuous but hollow depression near base of fixed finger, appearing as pigmented spot, more or less in continuity with black area of fixed finger; dactylus elongate, thick, with only one blunt median tooth; fixed finger thick, with only one blunt proximal tooth on occluding margin; fingers thick, gaping, with blunt tips. Male cutter: palm elongate, nearly flat, smooth, with a conspicuous dark spot near base of fixed finger similar to that of the crusher; both fingers thick, more elongate, occluding, with blunt tips; dactylus with occluding margin smooth; occluding border of fixed finger with one proximal small tooth, and another one small more distally. P2-P5 shorter than chelipeds; P4 longest. Meri of P2, P3 with patch of dense setae on ventral margins, the patch being dense, thicker on inferior margin; meri of P4 and P5 and carpi, propodi of P2-P5 fringed on dorsal and ventral margins with short, stiff setae, mixed with longer setae. Dactyli elongate, with patches of short setae on anterior and posterior margins.

\section{Thoracic sternum}

Thoracic sternum with sutures 4/5-7/8 incomplete. Median line along sternite 8 and hardly continuying along sternite 7 .
Junction of sternite 4 with pterygostome via rather long juxtaposition; no patch of setae. Press-button of locking mechanism acute, close to suture 5/6, lacking on a side in holotype.

\section{Pleon}

Pleon of six free somites and telson, regularly triangular, third somite widest; telson short, bluntly triangular, rounded distally; pleonal somite 6 longest. G1: straight, with sparse, small and short setae, arranged in two rows along mid-part only. G2: about less than half G1's length; flagellum very short, straight, flattened.

\section{DESCRIPTION (FEMALE)}

Subhepatic region without patches of dense setae. Chelipeds slightly dimorphic, both as cutters, major cheliped being hardly longer than minor cheliped; merus not elongated; chelae not markedly dissimilar; as in males, a pigmented spot near base of fixed finger on both propodi; both fingers not gaping, with acute tips. No pleonal locking mechanism. Pleon with margins densely fringed with setae. Vulvae rounded, closed by soft membrane.

\section{COMPARATIVE DIAGNOSIS}

The description of Austinograea jolliveti n. sp. is based on four, rather small specimens, from two vent sites. The species can be, however, distinguished from all other known Austinograea species by: 1) small size (to be checked on additional material); 2) subhepatic region with dense setae only at lateral edge (this feature needs to be checked on additional male material); 3) merus of male cheliped long, markedly extending beyond carapace margin, narrow on its whole length, regularly toothed on dorsal margin; 4) dorsal surface of propodus of both chelae in both sexes (Figs 9E, G; 10A, C) with a differently pigmented spot at the limit of the fixed finger (versus only one spot in male A. williamsi, and two spots in male $A$. hourdezi n. sp., moreover located on the anterior portion of the palm in both species, instead at the basis of fixed finger in $A$. jolliveti n. sp.); and 5) G2 much shorter than G1 and with a very reduced, straight flagellum (Figs 9D; 11E) (compare with fig. 8 of Tsuchida \& Hashimoto 2002, showing the two pairs of gonopods in $A$. alayseae, $A$. williamsi, and A. rodriguezensis).

The unique spot near the base of dactylus on dorsal surface of both chelae in both sexes of $A$. jolliveti n. sp. (Figs 9E, G; 10A, C) is of a different nature from the two depressions of $A$. hourdezi n. sp. It shows as a differently pigmented "pustule" and is similar to the violaceous spot of Bythograea microps Saint Laurent, 1984 (from the East Pacific Rise) in about the same location, i.e., at the base of the palm of the male minor chela and of both female chelae (Guinot \& Segonzac 1997: figs 7C, 9D-F; 2006c: 468, fig. 5; Guinot \& Hurtado 2003). This pigmented spot, supposedly sensory, easily allows distinguishing male and female $A$. jolliveti n. sp. from all other Austinograea species, and also from Gandalfus. 

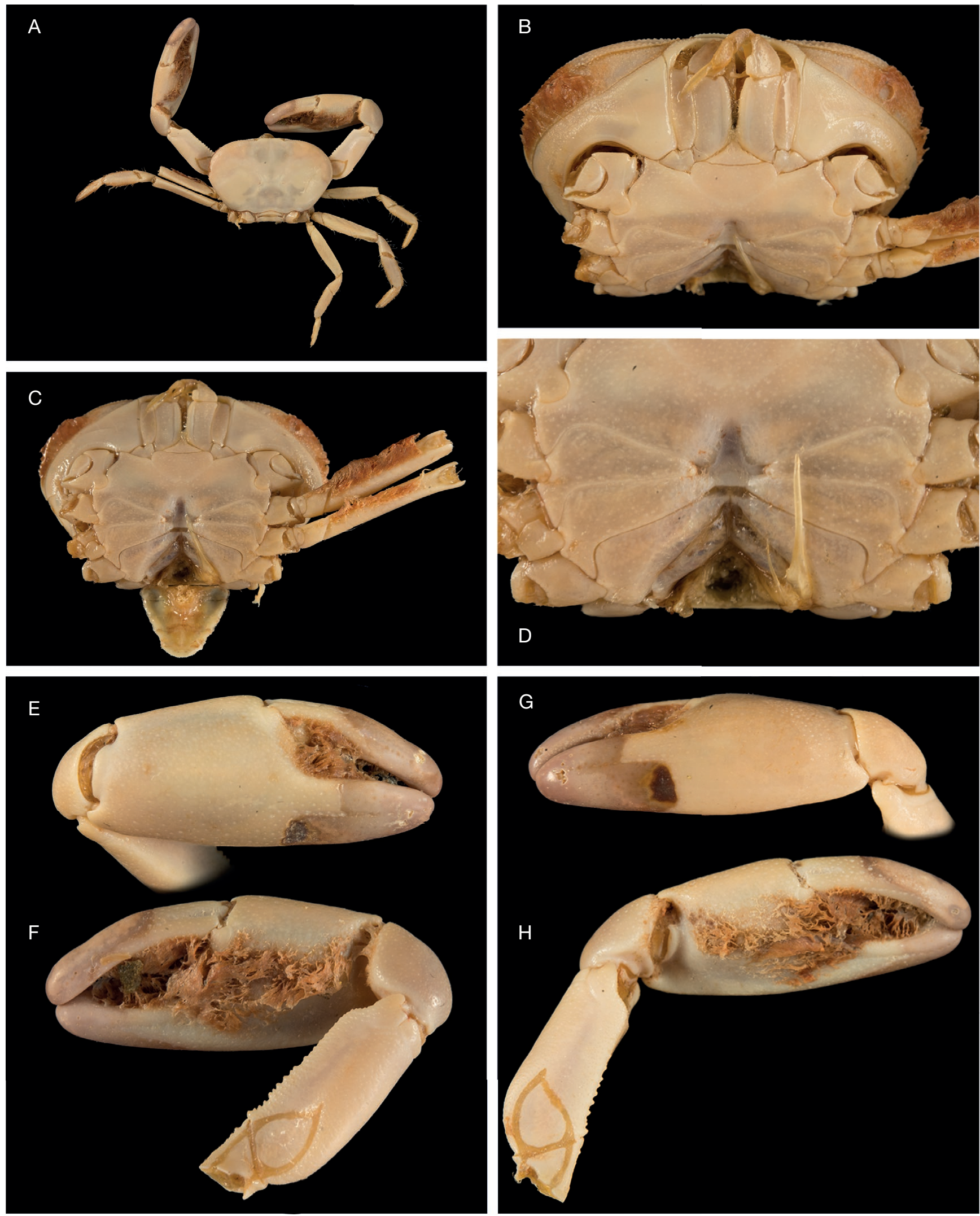

FIG. 9. - Austinograea jolliveti n. sp., holotype, ơ $12.8 \times 20.0 \mathrm{~mm}$ (right-handed), North Fiji Basin, STARMER II cruise, dive 18 (PL 18), Mussel Valley site, 1850'S, $173^{\circ} 29^{\prime} \mathrm{E}, 2750$ m, MNHN-IU-2016-10769: A, dorsal view; B, C, ventral views; D, thoracic sternum with G1 and G2 in situ; E, G, both chelae with one coloured spot at fixed finger base and patch of setae at occluding margins of fingers; $\mathbf{F}, \mathbf{H}$, both chelae with patches of setae on inner surface and extending along occluding margins of fingers; $\mathbf{E}, \mathbf{F}$, right crusher; $\mathbf{G}, \mathbf{H}$, left cutter. Note the long merus. 

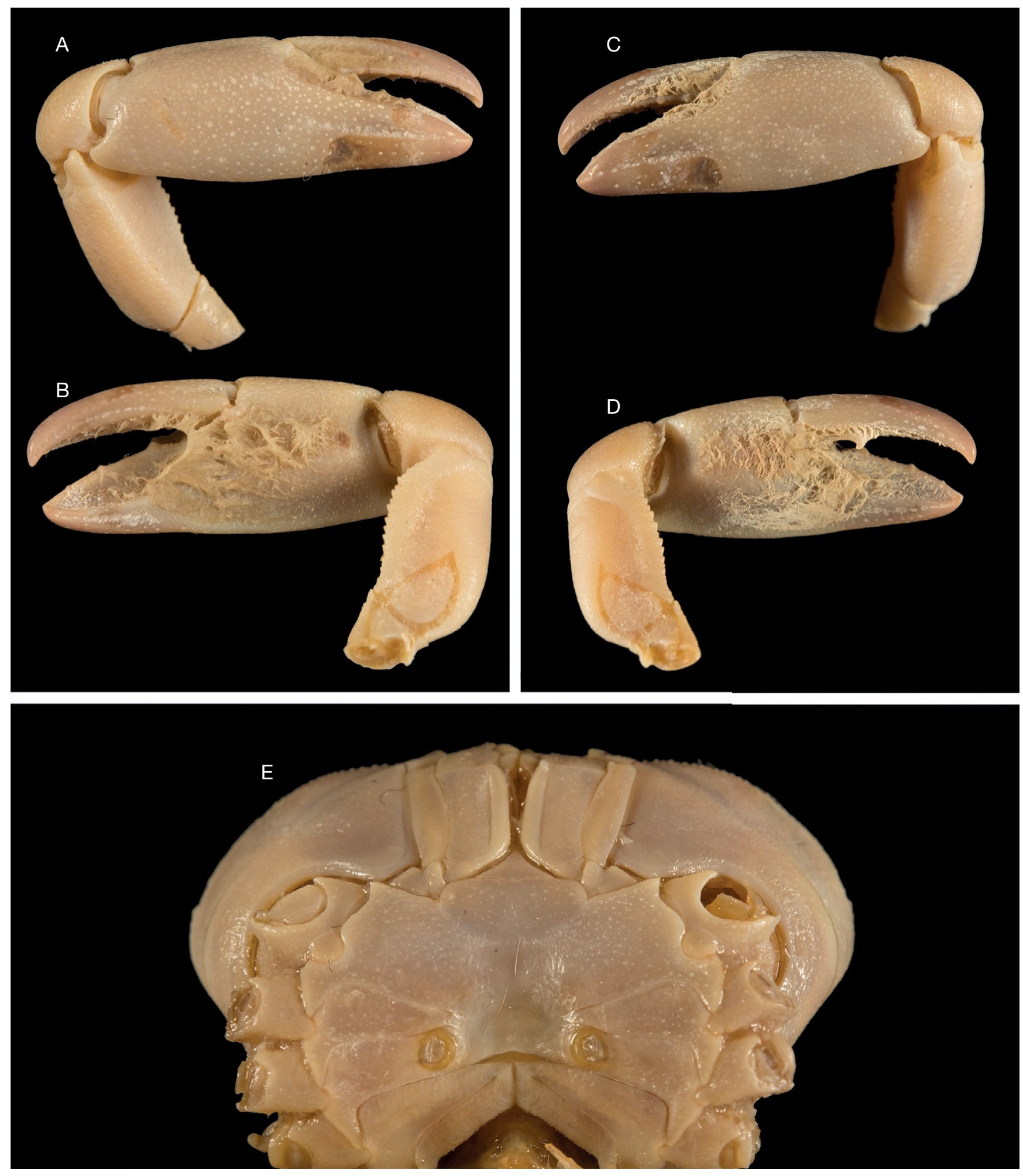

FIG. 10. - Austinograea jolliveti n. sp., paratype, $12.4 \times 21.6 \mathrm{~mm}$ (right-handed), North Fiji Basin, STARMER II cruise, dive 18 (PL 18), Mussel Valley site, 1850’S, $173^{\circ} 29^{\prime} \mathrm{E}, 2750 \mathrm{~m}, \mathrm{MNHN}-\mathrm{IU}-2016-10770$ : A, C, both chelae with one coloured spot at fixed finger base and patches of setae extending proximally between fingers; B, D, both chelae with patches of setae extending between fingers; A, B, right crusher; C, D, left cutter; E, ventral surface with vulvae. 

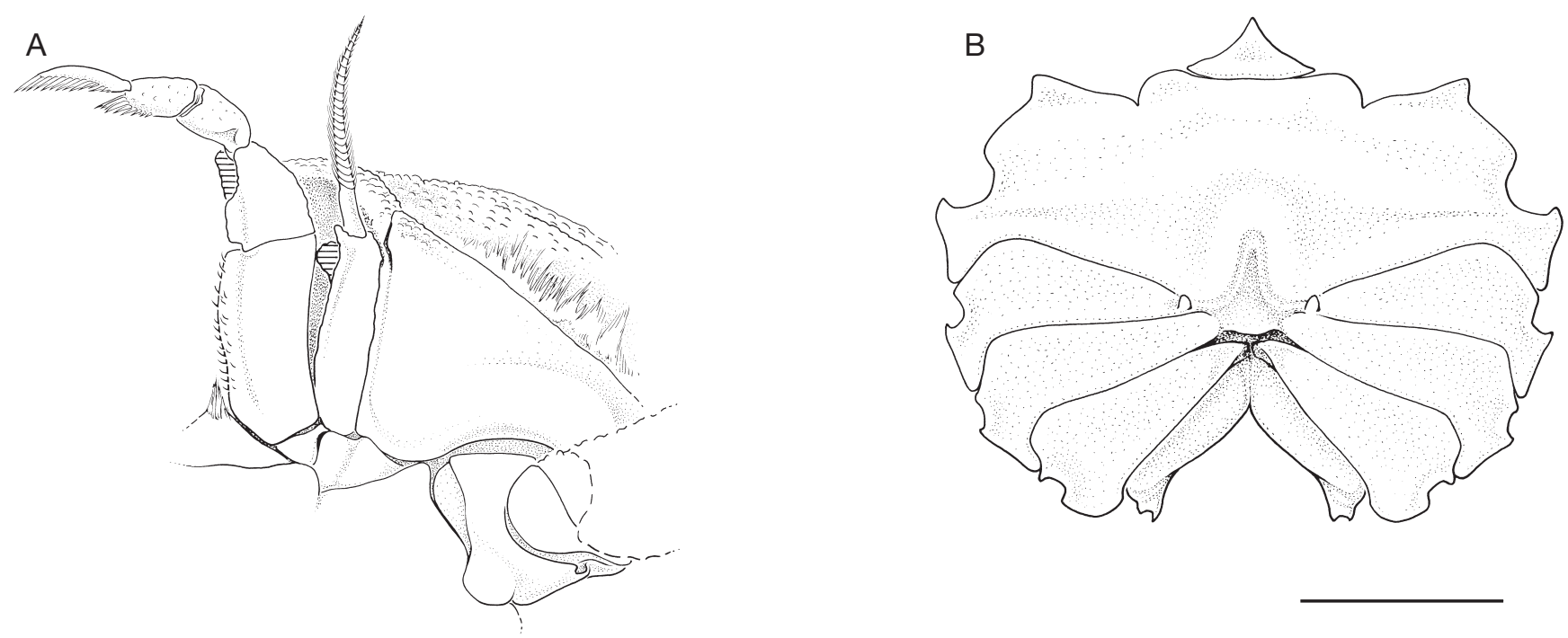

C
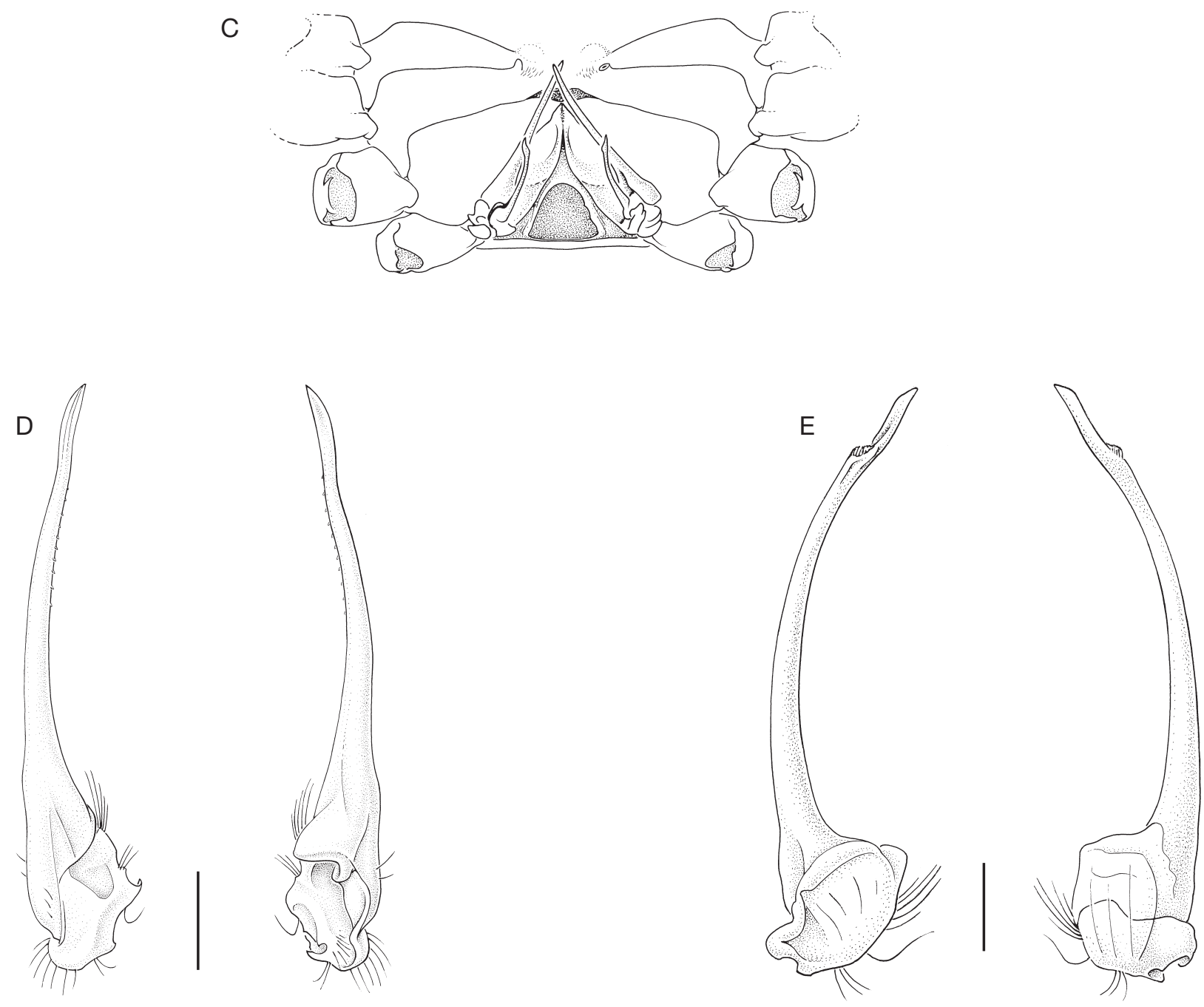

FIG. 11. - Austinograea jolliveti n. sp., holotype, ơ $12.8 \times 20.0$ mm (right-handed), North Fiji Basin, STARMER II cruise, dive 18 (PL 18), Mussel Valley site, $18^{\circ} 50^{\prime}$ S, 1732'ㄹ, 2750 m, MNHN-IU-2016-10769: A, mxp3; B, thoracic sternum; C, G1 and G2 in situ (reconstructed); D, G1, two views; E, G2, two views. Scale bars: $\mathrm{B}, 5 \mathrm{~mm}$; D, $1 \mathrm{~mm}$; E, $0.5 \mathrm{~mm}$ (note the scale bars of the two gonopods, the G2 being about half-length of G1); $A, C$, without scale. 


\section{GENERAL DISCUSSION}

\section{GEOLOGICAL AND BIOGEOGRAPHICAL SETTINGS}

The complex geomorphology of the southwestern Pacific is considered the result of the interaction between the Pacific and Australia plates. Western Pacific Back-Arc Basins constitute a series of biogeographic entities relatively isolated one from each other, which remain hydrothermally active for a few millions years. This complicated system of fragmented ridges originated from the clockwise rotation of the South Carolina and Melanesian Arcs and the collision of the Ontong-Java Plateau about $25 \mathrm{Ma}$ (Hall 2002). The ongoing collision between these two plates occupies a very large area due to the formation of two opposing subduction zones (Vanuatu and Solomon) with active island arcs that contributed to the emergence of back-arc basin spreading centres (Pearce \& Stern 2006) (Figs 1;2). The collision of the Melanesian Arc and the Ontong Java Plateau about $18 \mathrm{Ma}$ resulted in the clockwise rotation of the South Fiji Basin and the emergence of the present-day basins, starting with the westward reorientation of Woodlark Ridge System (presently subducting under the Solomon Islands Arc) and the expansion of the North Fiji Basin about 6-10 Ma and, ultimately, the southern spreading of the Lau Basin about 2 Ma. In the southeastern part, the Pacific plate is subducting westward at the Tonga-Kermadec trench, whereas the Australia plate is subducting eastward and northward in the western area at the Vanuatu, San Cristobal and New Britain trenches (Ruellan \& Lagabrielle 2005).

The tectonic history (and associated hydrographic patterns) of this region likely had a major impact on the vent fauna distribution and may explain some of the patterns of population differentiation and phylogenetic groups admixture presently observed, at least in the Manus and Lau Basins (Thaler et al. 2011, 2014; Plouviez et al. 2013; D. Jollivet, pers. comm. 2017). This system of disconnected ridges that expands over more than $6000 \mathrm{~km}^{2}$ displays quite similar vent communities dominated by deep-sea mussels and symbiotic provannid gastropods that undeniably share a common phylogeographic origin. The separate geologic evolution of the basins since their opening and hydrological barriers can severely impede along-axis dispersal, thus allowing allopatric speciation for species with a short pelagic phase over the bottom (Desbruyères et al. 2006a: fig. 1, table 1) but not necessarily for species with planktotrophic larvae able to feed from the water column and reach the surface waters. Vent-endemic species have an ephemeral lifespan (Van Dover et al. 2002), so they must be able to effectively disperse and colonise new vents after locations become inactive. As bythograeid crabs are benthic, they must disperse through the water column during their larval stages. The strong-swimming larvae of brachyuran crabs may disperse high in the water column (Mitarai et al. 2016), such as larvae of the sea snail or false limpet Shinkailepas Okutani, Saito \& Hashimoto, 1989 that show a vertical migration and long-distance dispersal potential (Yahagi et al. 2017). Thus, although evidence for long-distance dispersal events may occur between basins, taxa of most vent fields are presently evolving separately, with recent speciation events in allopatry possibly linked to the step-by-step colonisation of the ridge system that has been taking place since the opening of the basins about 5-6 Ma (Taylor \& Karner 1983; Auzende et al. 1988, 1997; Taylor 1995; Jollivet 1996; Thaler et al. 2014).

\section{Distribution of BythograEIdAE IN THE BACK-ARC BASINS OF THE WESTERN PACIFIC}

In the western Pacific, instead being linearly distributed along the mid-oceanic ridges, the vent fields occur patchily throughout spreading centers associated with back-arc basins; this non-linear distribution results in complicated connectivity among vent sites and more complex patterns of population differentiation, speciation processes and genetic deviation (Thaler 2012). This non-linear distribution of vent sites can be exploited to test hypotheses on larval and microbial transport, genetic isolation, and speciation.

From south to north, the two opposing subduction zones are associated with a series of small back-arc basins (marginal basins), as follows: Havre Trough behind the Kermadec Arc, Lau Basin behind the Tonga Arc, the North Fiji Basin between the Vanuatu Arc and Fiji Islands, Coriolis, Woodlark Basins, and the Manus Basin behind the New Britain Arc; Mariana Trough; Bonin Arc; and Okinawa Trough (Fig. 1). The junction between the two subduction zones consists of a number of interconnected active spreading centres in the North Fiji and Lau Basins (Desbruyères et al. 1994, 2006a; Taylor 1995; Ruellan \& Lagabrielle 2005). Species of Austinograea are distributed all along these spreading centres, whereas Gandalfus puia McLay, 2007 is only reported further south.

Gandalfus puia, which belongs to the closest genus to Austinograea, occurs only on the Kermadec Arc (26 S-36 $\left.20^{\circ} \mathrm{S}\right)$. It is mainly associated with venting along the Kermadec subduction system, which includes 12 volcanoes (Desbruyères et al. 2006a). The southernmost record for a bythograeid crab is reported near New Zealand with G. puia (McLay 2007). Austinograea hourdezi n. sp. and A. alayseae are found on hydrothermal sites of the Lau and North Fiji Basins, ranging at depths ranging from 1700 to $2700 \mathrm{~m}$ (Fig. 2), located at the boundary between the Pacific and Indo-Australasian plates, and about $1000 \mathrm{~km}$ apart (Auzende et al. 1988; Desbruyères et al. 1994). Austinograea jolliveti n. sp. is also known from the Fiji and Lau Basins, from 2130 to $2750 \mathrm{~m}$.

The Lau Basin, the first back-arc basin to be recognised as a young ocean basin formed by splitting of a volcanic island arc, is an active back-arc basin flanked to the west by the fossil Lau Ridge and to the east by the Tofua Volcanic Arc (Karig 1970; Fouquet et al. 1991). The Valu Fa Ridge, situated at the southern end of the East Lau Spreading Center, is located at the vicinty of the Tofua Volcanic Arc. The vent fields Kilo Moana and Tow Cam are dominated by pillows and lobate basalts with broad, flat domes that are cut by faults and fissures, while the southern vent fields ABE, Tu'i Malila and Vai Lili are characterised by more complex volcanic morphology, with pillows, distinct flow fronts, and larger domes (Ferrini et al. 2008). At the Vai Lili site (Lau Basin), in which many specimens of $A$. hourdezi n. sp. have been 
collected, there are numerous active smokers of two types: black smokers with temperatures ranging from $330^{\circ}$ to $400^{\circ} \mathrm{C}$ and white smokers with temperatures ranging from $250^{\circ}$ to $320^{\circ} \mathrm{C}$. The chemical composition of the fluid is similar to that of other back-arc basin vent systems (Ishibashi et al. 1994; Desbruyères et al. 2006a), with the exception of a very low $\mathrm{pH}$ of 2 and a high content of metallic ions. Animal communities associated with the crabs are generally located around the chimneys, where fluids are percolating at temperatures between $5^{\circ}$ and $33^{\circ} \mathrm{C}$; water temperature remote from the chimneys has been measured at $1.7^{\circ} \mathrm{C}$ (Desbruyères et al. 1994: pl. 1A, B; 2006a). In the Hine Hina site the fluid mixing temperature is generally lesser than $20^{\circ} \mathrm{C}$, and the fluid is released through a dome of highly vesiculated and brecciated andesite; the near-surface rocks are impregnated with sulfides (Chevaldonné et al. 1991: table 2; Desbruyères et al. 1994: pl. 1F; 2006a). The biological community from the Lau Basin figured by Fisher et al. (2007: fig. 1), consisting of light-coloured snails (Alviniconcha hessleri Okutani \& Ohta, 1988 sensu lato (see Denis et al. 1993), black snails (Ifremeria nautilei) and brown mussels (Bathymodiolus brevior see Cosel et al. 1994; Breusing et al. 2015), includes an unnamed white crab without spots on the chelae: it could be $A$. alayseae. Our Figure 8A shows gastropods and mussels at Kilo Moana site photographed in situ associated with an Austinograea that is probably $A$. alayseae due to the chelae devoid of setose patches.

Austinograea hourdezi n. sp. has also been found at the active White Lady vent site of the North Fiji Basin. This site is one of the components of a complex hydrothermal field, which comprises both diffuse fluids $\left(31^{\circ} \mathrm{C}\right)$ and active chimneys with high temperatures $\left(91^{\circ} \mathrm{C}\right.$ and $296^{\circ} \mathrm{C}$ as maximum measured in two different chimneys) (Chevaldonné et al. 1991: table 3; Desbruyères et al. 1994; 2006a). Austinograea jolliveti n. sp. was observed on mussel beds at the Mussel Valley site, located northward on the North Fiji Basin. The diffuse venting site is on a flat volcanic dome framed by a group of collapsed lava lakes with a great number of pillars. Venting shows no oxide or sulfide accumulation, but fresh formations of basaltic glass; the limpid fluid was expelled through a series of low temperature vents (maximum $8.5^{\circ} \mathrm{C}$ ) (Desbruyères et al. 1994; 2006a; Hashimoto et al. 1999).

After the description in 1989 of the first Austinograea, A. williamsi, then of $A$. alayseae in 1990, and today of two new species, $A$. hourdezi n. sp. (as Austinograea sp. aff. williamsi in Guinot 1990) and A. jolliveti n. sp., the study of the rich collection deposited in the MNHN and of a material sent in loan by C. H. Fisher shows that $A$. alayseae, $A$. hourdezi n. sp. and $A$. jolliveti n. sp. are found together in the southwestern Pacific.

Austinograea species are also found in the Manus Basin vent communities. Vents occur at a fast spreading centre on three disjunct and successive ridge segments (Auzende et al. 1996). In the PACMANUS complex (0343.50'S, $151^{\circ} 40.50^{\prime} \mathrm{E}$, $1700 \mathrm{~m}$ ) venting occurs either through fissures zones or diffuse areas with warm fluids $45^{\circ}-63^{\circ} \mathrm{C}$, or through $10-15 \mathrm{~m}$ high smokers expelling acidic fluids with temperatures up to $268^{\circ} \mathrm{C}$, high chlorinity, and high metallic content (Hashimoto et al. 1999; Desbruyères et al. 2006a). There are at least two distinct bythograeid species in the Manus Basin, one with heterochelous, heterodotous and sexually dimorphic chelae (Fig. 12) being apparently different from $A$. alayseae, $A$. hourdezi n. sp. and $A$. jolliveti n. sp, see below "The Austinograea from the Manus Basin".

In the Mariana Trough inhabits another Austinograea that is distinct from the three congeneric species found in the Lau and North Fiji Basins. In fact, A. williamsi appears to be an endemic species to the Mariana Trough, which is a back-arc basin occupying a central position in hydrothermal areas in the northwestern Pacific, being surrounded by the Okinawa Trough, the Izu-Ogasawara Arc, the Mariana Arc, and the Manus Basin. Situated from $19^{\circ} 45^{\prime} \mathrm{N}$ to $14^{\circ} \mathrm{N}$ between the remnant volcanic arc of the West Mariana Ridge and the volcanic front of the Mariana Arc, it corresponds to a wide linear rift valley of an axial volcanic ridge. Maximum measured temperatures of vents was $284^{\circ} \mathrm{C}$ in the Alice Springs field, the first discovered vent, in which 30 species from the chemosynthetic communities were reported, the Alviniconcha snails and the Austinograea crabs being the dominant animals. Austinograea williamsi is found in abundance in snail beds filling the vent openings (Hessler \& Lonsdale 1991; Desbruyères et al. 2006a; Kojima \& Watanabe 2015: figs 25.1, 25.2, table 1).

At the northern end, the Mariana Arc connects with the Izu-Ogasawara arc system that extends south from Tokyo to the Island of Guam, with many submarine volcanoes, and in which rifting plays an important role. Here, Austinograea is replaced by its sister genus Gandalfus, with the species G. yunohana that lives at comparatively shallower depths, 420-1380 m (Takeda et al. 2000: fig. 1, as Austinograea yunohana; McLay 2007; Fujikura et al. 2008; Yang et al. 2010; Kojima \& Watanabe 2015: figs 25.1, 25.2; Yamanaka et al. 2015: fig. 10.1, tables 10.1, 10.2).

The Okinawa Trough is a back-arc basin located between the Eurasian continent and the Ryukyu Island Arc. Among the 109 species reported in the Okinawa Trough hydrothermal vent fields, the bythograeid crab Gandalfus yunohana has been found in a single field, the Minami-Ensei Knoll site, together with a geryonid, Geryon aff. granulatus Sakai, 1978 (Watanabe \& Kojima 2015: fig. 34.1, table 34.1; Yamanaka et al. 2015: figs 10.1, 10.2)

The distribution of bythograeids in the western Pacific supports the analysis by Desbruyères et al. (2006a: figs 2-5, table 1) on global faunal affinities among extant basins and ridges in this vast system. The Lau and North Fiji Basins communities display a strong faunal alliance. Austinograea alayseae and $A$. hourdezi n. sp. co-occur in the Lau Basin, probably at Tow Cam, Hine Hina, Vai Lili, Kilo Moana, Tu'i Malila, ABE sites (see Figs 3; 8), and in the North Fiji Basin; $A$. jolliveti n. sp., apparently more uncommon, cohabits with $A$. hourdezi n. sp. at the ABE site. As $A$. alayseae was likely not always properly identified in classified material and in the unsorted collections, it is likely that it has been confused with the two new species described here. Mariana Basin communities 
display a low similarity with the three southwestern Pacific Basin communities, with endemic $A$. williamsi. The Okinawa Basin and Izu-Ogasawara Arc faunal communities, which are clearly distinct from those of the other back-arc basins, host a distinct genus, Gandalfus that, puzzlingly, is also found on the Kermadec Arc, near New Zealand. It is noteworthy that we have never found $A$. williamsi in the vent fields of the southwestern Pacific.

The bythograeid vent fauna of the southwestern and northwestern Pacific (Fig. 1) proves to be still richer than previously suspected, with presently a total of five species: four Austinograea species, of which two are here described as new, and Gandalfus puia. Another Austinograea species, A. rodriguezensis, inhabits the Central Indian Ridge, and the second species of Gandalfus, G. yunohana, is found off Central Japan (see Yang et al. 2010; 2013: fig. 1 map). The separation between the four Austinograea species needs a careful examination, based on a sufficiently representative material of all taxa, which fortunately is the case for the MNHN collection. There are no apparent differences in the overall size and shape of the carapace in males and females of Austinograea species, thus the chela morphology is the best diagnostic character (see Key to the species).

\section{The AUstinograea From THE MANUS BAsin} Austinograea alayseae has been often reported from the Manus Basin (Galkin 1992, 1997; Hashimoto et al. 1998: fig. 7; 1999; López-González et al. 2005; Guinot \& Segonzac 2006b). According to Galkin (1997: fig. 1), the scavenger and carnivore $A$. alayseae dominates the fauna at the Manus Basin (PACMANUS site), being abundant at vent openings crawling actively on the snail thickets, and also ranges into non-vent terrain. It is reported from active (Kowalczyk) as well as inactive (Binns) (Erickson et al. 2009) sites. Genetic differences between individuals (supposed to be $A$. alayseae) from the Manus Basin and from the Tofua Volcanic Arc at the east of the Lau Basin, located about $3000 \mathrm{~km}$ apart in the southwestern Pacific, have been found (Kim et al. 2014, 2016), suggesting the existence of a separate species, distinct from $A$. alayseae.
Crabs collected in the Manus Basin at the PACMANUS site by the Shinkai 2000 were identified as A. alayseae by Tsuchida \& Hashimoto (2002). We have examined two large specimens from this site (a right-handed $0^{7} 31.3 \times$ $48.8 \mathrm{~mm}$ and a left-handed o $29.6 \times 44.8 \mathrm{~mm}, 3^{\circ} 43.60^{\prime} \mathrm{S}$, $151^{\circ} 40.32^{\prime} \mathrm{E}$, field E, $\left.1676 \mathrm{~m}, 17 . \mathrm{XI} .1998\right)$ deposited in the MNHN (MNHN-IU-2016-10750 [= MNHN-B28761]) (Fig. 12). With the outer surface of chelae devoid of any spot, males correspond neither to $A$. hourdezi n. sp. nor to $A$. jolliveti n. sp.; they are closer to $A$. alayseae due to the shape of mxp3 merus, the setose G1, the glabrous chelae at inner surface, and the glabrous subhepatic regions. Nevertheless, owing to some observed differences (male crusher more elongated, especially the fingers that are markedly gaping; male cutter with the dark colour extending beyond the extreme tip until the two-thirds of the fingers), these two individuals are here separated from $A$. alayseae in waiting more material from the Manus Basin and genetic data (in study). This crab, with the male and female chelae figured Fig. 12A, B, respectively, is preliminarily considered Austinograea sp. aff. A. alayseae.

We discuss below (see Genetic data) the genetic sequences of $A$. alayseae from the Manus Basin provided by Yang et al. (2013) and Kim et al. (2014: table 1): the results show its separation into two branches and suggest some mitogenomic differences, likely supporting the presence of two lineages that could be treated as two species, of which one, hypothetically, could be $A$. alayseae or $A$. hourdezi n. sp., even $A$. jolliveti n. sp., and, in addition, an unnamed species with the chelae as in Fig. 12. Recently, the first transcriptome for a hydrothermal crab was based on two individuals of a vent crab collected from the Manus Basin and identified to A. alayseae (Hui et al. 2017), but, as always, illustration of the sequenced specimens was not provided so that the identity of the sequenced brachyuran remains in doubt. A genetic study using mitochondrial DNA and microsatellite markers revealed that populations of the vent-restricted gastropod Ifremeria nautilei from the Manus Basin did not show genetic subdivisions but were genetically distinct from those of the North Fiji and Lau Basins in which populations were undif-

\section{Key to species of Austinograea Hessler \& Martin, 1989}

A key to the five species of Austinograea is provided, based on chelae, in order to potentially identify the crabs photographed in situ by evaluating the videos of the dives on board or later by examining the photographs.

1. Palm chela with outer surface devoid of coloured spot and inner surface without patches of setae. Subhepatic region of carapace glabrous ................................................................ Austinograea alayseae Guinot, 1990

— Palm chela with outer surface bearing one spot ............................................................................ 2

- Palm chela with outer surface bearing two coloured spots in males, inner surface with patches of setae. Subhepatic region of carapace with patches of setae ................................................. Austinograea hourdezi n. sp.

2. One spot near base of fixed finger .................................................................... Austinograea jolliveti n. sp.

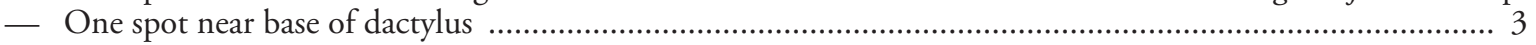

3. Palm chela with inner surface covered by patches of setae; small patch of setae on thoracic sternum at level of P1, especially in females .................................................... Austinograea williamsi Hessler \& Martin, 1989

- Palm chela with inner surface only setose on dactylus near occluding margin and on propodus near base of dactylus; no setae on thoracic sternum at level of P1 in both sexes 

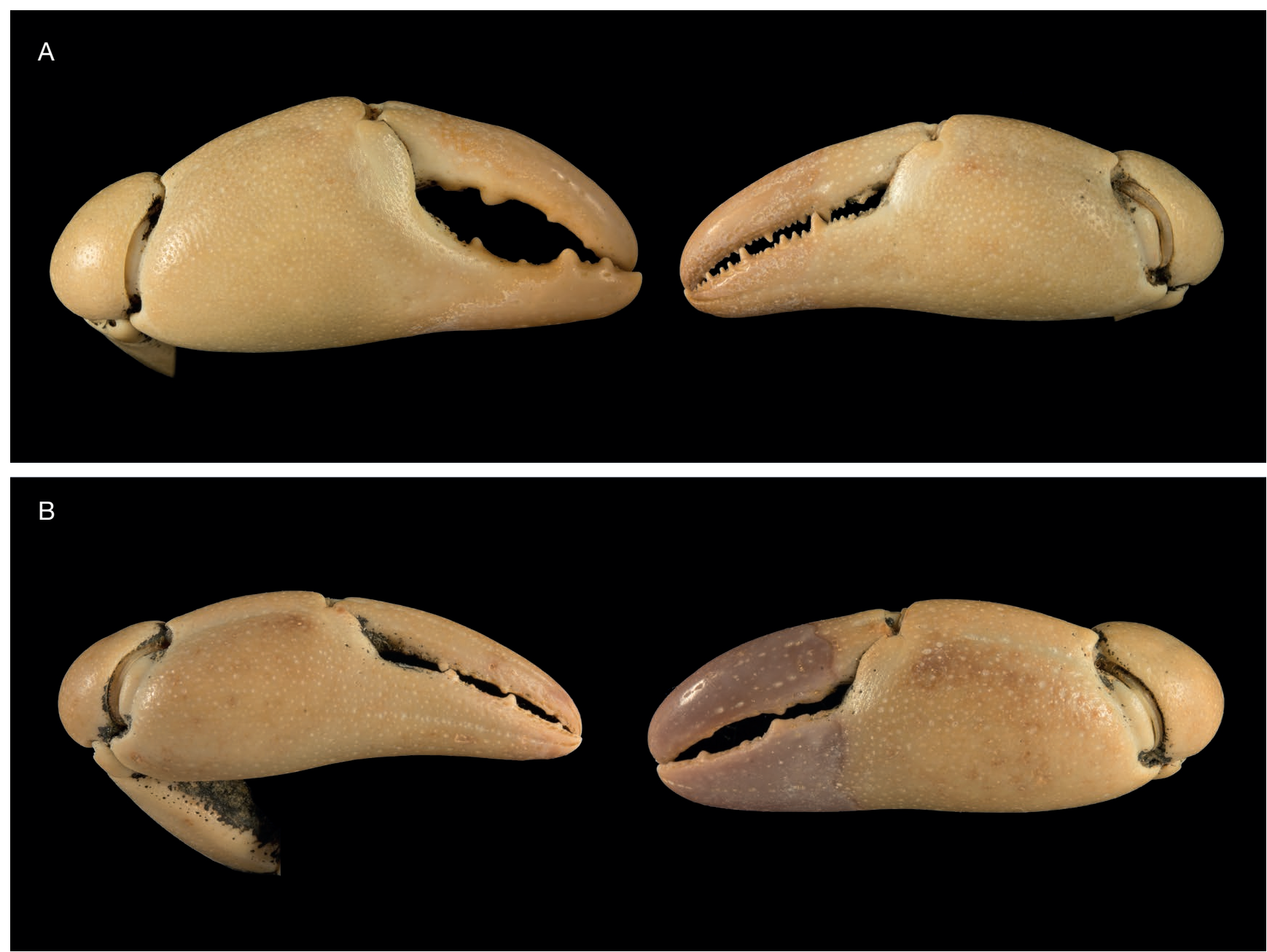

FIG. 12. - Austinograea sp. aff. A. alayseae Guinot, 1990, ơ $31.3 \times 48.8$ mm (right-handed), ㅇ $29.6 \times 44.8$ mm (left-handed), Manus Basin, Shinkai 2000, $3^{\circ} 43.60$ 'S, $151^{\circ} 40.32$ 'E, PACMANUS site, field E, 1676 m (see Tsuchida \& Hashimoto 2002), MNHN-IU-2016-10750 (= MNHN-B28761): A, male chelae, crusher and cutter, outer surfaces of palms; $\mathbf{B}$, female chelae, cutter and crusher, outer surfaces of palms.

ferentiated. The phylogeographic break between the Manus and North Fiji/Lau populations was not interpreted as the result of a colonisation event, but likely due to a vicariant process isolating the existing single population spanning Manus, North Fiji, and Lau Basins into two populations. The process that restricts contemporary gene flow and isolates the Manus Basin population of I. nautilei from widespread populations that occupy the North Fiji and Lau Basins is unknown (Kojima et al. 2000; Thaler et al. 2011). Estimates of gene flow implied migration from the Lau to North Fiji Basin with a splitting time of tens of thousands of generations and genetic isolation between those two basins and the Manus Basin for several hundred thousand generations; for I. nautilei the rather weak gene flow from Lau to North Fiji and the genetic barrier between Manus and North Fiji may be explained by the ocean circulation (Mitarai et al. 2016). Accordingly, the presence of a potential distinct Austinograea in the Manus Basin through similar phylogeographic isolation remains to be detected by morphological examination of specimens from populations sampled in various vent sites and/or by genetic analyses.
It was shown that, in the western Pacific, variable dispersal filters exist, which isolate populations of some, but not all, vent-occurring species from Manus Basin (Thaler 2012), and it would be interesting to determine if Austinograea exhibits strong population isolation between Manus Basin and southern oceanic basins, as exemplified by some other organisms.

CHELAE: CRUSHER AND CUTTER. REGENERATED CHELAE

In many decapod crustaceans growth of chelipeds is isometric until the time of puberty moult, with the same trend continuing in adult females, whereas in males the marked spurt in the level of allometry is accompanied by a sudden increase in the relative size of chelae. Chelipeds differentiate morphologically into major (crusher) and minor (cutter) chelae, based on morphologically and functionally different dentition patterns (handedness) so that they become heterochelous, heterodontous, and sexually dimorphic. This corroborates the constatation that, of the five pairs of pereopods, the decapod chelae are versatile organs of attack and defence that make them the most vulnerable for autotomy (self-amputation) (Mariappan et al. 2000). The 
loss of the right chela is the result of autotomy during inter- and intraspecific competition for limited resources like food, shelter, mate, and as a strategy to avoid predation and wound limitation as well as establishment and maintenance of dominance hierarchies. Thus, the possession of a new major claw is essential for acquisition of limited resources and agonistic and aggressive interactions. With the loss of the right chela, which is a serious problem for many decapods, handedness transitions from the right to left chela, leading to left-handed individuals; after handedness reversal, dentition on the left dactylus of the newly-converted crusher is close to that of the original right crusher without generally attaining the same shape, even after many moults (Masunari et al. 2015). The regenerated major cheliped is more slender than the original, less robust and weaker than previously. Rapid regeneration of the major cheliped over several moults appears to be an appropriate strategy that is beneficial for the injuried crab.

In populations of Austinograea right-handed crabs are predominant, so that the "normal" morphology is observed in males with right crusher and left cutter. Usually, the male crusher is relatively larger and more inflated than the cutter of both sexes, and the male cutter is larger than that of the females. Chela asymmetry is variously developed from species to species. For example, in $A$. williamsi, which live in high densities near active sites of the Mariana Trough, right-handed male individuals were characterised by strong heterochely and heterodonty, and the sexual dimorphism was pronounced; heterochely was observed only in males, with the exception of only one large female (in 36 females) that was reported with heterochely (Tsuchida \& Fujikura 2000: fig. 3). Among the A. williamsi analysed, $60 \%$ of males had a right crusher and a left cutter ("normal" type) and the other $40 \%$ had two cutters; and $5 \%$ of females had a right cutter and a left crusher; the remaining $95 \%$ have two cutters; additionally, numerous males and females had small regenerated chelae or were lacking either left or right chela. Because approximately half of the males of $A$. williamsi did not exhibit heterochely, being also as large as those that did, Tsuchida \& Fujikura (2000: figs 2-4) suggested the crusher may not be related to reproduction. This is not the case of most crabs, in which the major chela of males is used in reproductive behaviour (courtship, copulatory guarding, mating) together for feeding, protection from predators, competing over territory.

The relatively high proportion of left-handed vent crabs with atypical chelae that are found in nature is likely due to the accidental loss of the major cheliped and seems clearly related to the presence of regenerated chelae and handedness reversal: the right crusher being lost, the left cutter is converted to the new crusher. The chelae of these individuals do not share size and morphology of those of their congeners having an original right crusher. Accordingly, there are male specimens that possess two cutter chelae. For investigation of development of chela asymmetry and its use as taxonomical character in vent crabs, this parameter must be taken into account. An additional factor is the presence of numerous individuals lacking the two chelae or only one.
Guinot (1990) reported in $A$. alayseae the presence of male left-handed individuals, with homomorphic chelae close to the cutter type. We have re-examined the sample of paratypes from the Lau basin, Vai Lili site, i.e., $350^{\circ}$ and 52 \%, MNHNIU-2008-11309 (= MNHN-B24055): it contains typical right-handed males and females, with crusher and cutter, but also left-handed males and females with two cutters, which seemingly corresponds to regenerated chelae. Curiously, we have also found large right-handed female $A$. alayseae (the largest $34.3 \times 55.0 \mathrm{~mm} ; 33.4 \times 53.0 \mathrm{~mm}$ ) that have heteromorphic and heterodont chelae, with an heterochely as pronounced as in the males.

Typical males of $A$. hourdezi n. sp. (Figs 4A, B; 5E-H) and, to a less extent, of $A$. jolliveti n. sp. (Fig. 9E-H) show heteromorphic chelipeds, with specific differences and probably also variation in growth pattern. Typically, only large females have a right crusher and a left cutter, and youngest show the cutter type in both chelae. A large number of females of $A$. hourdezi n. sp. with two cutters correspond to individuals bearing regenerated chelae; these individuals, instead of bearing two marked spots on the chelae, exhibit a single marked spot and a second one, faint or indiscernible (Fig. 9E-H). At most, we can understand that males regenerate their chelae with only one spot or not at all spot, but it is puzzling that females, typically devoid of spots on the chelae, regenerate chelae with a spot, as certain males. By contrast, the regeneration of chelae does not affect the presence or absence of setose patches of setae on the inner chela palm, always absent in both sexes of $A$. alayseae and present in both sexes of $A$. hourdezi n. sp. and $A$. williamsi.

Comparative morphometric and statistical analyses of the chelae conducted in populations of all Austinograea species, as Tsuchida \& Fujikura (2000) for A. williamsi, should provide precise information on the percentage of left-handed individuals. The large number of left-handed crabs with regenerated chelae in populations of Austinograea is an issue yet to be resolved. There is very limited knowledge on species' behaviour in vent populations and on hydrothermal communities interactions such as predation or competition that significantly affect community structure. But direct in situ observations with the use of cameras deployed on deep sea observatories have shown that vent species strongly respond to food source, often leading to aggressive behaviour, involving claw attacks (Matabos et al. 2015).

According to environmental data from seven diffuse flow hydrothermal vent sites along the Eastern Lau Spreading Center provided by Podowski et al. (2010: 27, 34, 42, figs 1, 2, 7, 8, tables 3, 5), Austinograea crabs occupied areas with the greatest exposure to vent flow showing a considerable tolerance; they consistently demonstrated a preference for biological substrata in the most hydrothermally active areas, and were likely to be predator-free, without potential predators on adults, since few metazoans are able to tolerate the conditions present in the areas of highest productivity at vents.

Three species of Austinograea were reported as including A. alayseae, $A$. williamsi, and Austinograea spp. when the two species could not be differentiated: only about $15 \%$ of the 
crabs could confidently be identified to the species level, the remaining was separated into these three categories. Presence of sympatric species could explain an aggressive intraspecific behaviour during feeding time in absence of food supply, development of territoriality, and sexual competition.

It has been shown that in stone crabs Menippe spp. declawed crabs were less mobile or less motivated to feed (Duermit et al. 2017), but comparisons with vent crabs are risky.

\section{IDENTIFICATION OF AUSTINOGRAEA SPECIES IN FAUNAL ASSEMBLAGES}

Identification of faunal assemblages that have colonised the extreme hydrothermal environments is a difficult task. In publishing reports of the cruises, a challenge is to give a name to the collected organisms, generally very poorly known and often new to science.

In a series of papers on animal communities of the Eastern Lau Spreading Center and Valu Fa Ridge, a difficulty was encountered in identifying the crabs. Sen et al. (2013: fig. 3A, tables 2-4) reported that the bythograeid crabs could be identified as Austinograea williamsi or A. alayseae only if the inside of the cheliped was visible. Although the species were identified when possible, they were grouped as Austinograea spp. for the purpose of statistical analyses. It is clear that these authors were dealing either with the true $A$. alayseae, which has glabrous chelae, or with the species here described as new, $A$. hourdezi n. sp., with patches of dense setae on the inner surface of chelae in both sexes (Figs 5A, F, H; 7A, B, F, H), or A. jolliveti n. sp. (Figs 9A-H; 10A-E; 11A-E), but without the probability of $A$. williamsi (also with patches of setae on chelae) that is apparently confined to the nortwestern Pacific. According to Sen et al. (2014), in a paper analysing the progression of Lau Basin hydrothermal sites over time and characterising the different stages of succession of the vent communities, as Austinograea williamsi and A. alayseae could not be reliably distinguished, they were again regarded as Austinograea spp. Lau vent crabs were referred to as solitary fauna (non-aggregated) that were found only in early and mid-successional stages of vent, and seemed well-adapted to take advantage of the high levels of primary production associated with venting, but largely disappeared when active venting decreased below a certain level. Similarly, Sen et al. (2016: 602, 610, tables 2, 5) stated that from dorsal images the Austinograea species inhabiting the Lau vents could not be reliably distinguished as $A$. alayseae or $A$. williamsi. Thus, they were grouped together as Austinograea spp. in the comparison between peripheral and near-vent communities: crabs, along with shrimps, were present in higher abundances in the active sites than the peripheral sites. The genetic divergence for the mitochondrial 16S rDNA gene reported between the three species $A$. williamsi, A. alayseae and $A$. hourdezi n. sp. (Mateos et al. 2012: 10, fig. 2, as Austinograea aff. williamsi) were not considered.

Zelnio \& Hourdez (2009), by studying the alvinocaridid shrimps from hydrothermal vents (sites Kilo Moana, Tow Cam, ABE) collected by the TUIM07MV cruise at the Lau Basin, mentioned the presence of crabs living in association with shrimps, mussels and snails (see Fig. 3A). They have recognised two bythograeid species, Austinograea alayseae and A. williamsi. As these explored sites are the same where $A$. hourdezi n. sp. occurs in abundance and from where A. williamsi seems lacking, it is likely that these authors were dealing with A. alayseae and $A$. hourdezi n. sp., or perhaps $A$. jolliveti n. sp.

\section{GENETIC DATA}

According to Kim et al. (2013: 1, 6) identification of bythograeids based on morphological characteristics "often leads to incorrect species recognition due to a lack of taxonomic factors and the existence of sibling (or cryptic) species" (but these authors do not give any specific example), and "systematics based on morphological identification is not only timeconsuming, but it is also difficult due to a lack of taxonomists for vent organisms". Kim et al. (2013) considered inevitable the use of DNA barcoding for vent organisms using mitochondrial cytochrome c oxidase subunit 1 (CO1). As existence of pseudogenes has been recorded in Austinograea alayseae, Kim et al. (2013) performed long PCR for the amplification of $\mathrm{CO} 1$ in this species. Based on a phylogeny with other COI sequences from other vent crabs, they concluded about the presence of Numts in A. alayseae, but all the reported substitutions were synonymous and sequences were devoid of stop codons or indels (see Chu et al. 2015).

To establish the mitochondrial genome of $A$. alayseae, Kim et al. (2014: 251, table 1) used specimens collected from two geographically distinct hydrothermal vents, the Tofua Arc Basin (accession no. KC851803) and the Manus Basin (accession no. JQ035660) respectively, located about $3000 \mathrm{~km}$ apart in the southwestern Pacific. Their genomes were found identical except for the mitochondrial control region (a marker whose resolution is higher than that of COI and useful for comparisons at the population level), which showed about $17.5 \%$ of nucleotide divergence. Moreover, Kim et al. (2013) previously found several highly divergent COI in a series of $A$. alayseae specimens from the Tonga Arc. The observed genetic differences in the mitochondrial control region, which cannot be attributed to gene polymorphism, indicated a clear separation of $A$. alayseae into two distinct OTUs, suggesting a "putative sub-species level". They likely correspond to the presence of two closely-related but different geographic taxa, perhaps the true $A$. alayseae and the species here described as new, $A$. hourdezi n. sp., which co-occur in several sites, perhaps also $A$. jolliveti $\mathrm{n}$. sp. that seems to be uncommon. It is not unlikely that such various results could be based on misidentified specimens. Analyses of the genome are fully required to compare the populations of Austinograea species from different vents, contributing significantly to our knowledge on the diversity and improving taxonomic research base on morphology. But fully exploiting reciprocal benefits requires that the recovered genetic data are based on a correct identification of the species, with, at the very least, a traceable origin of the sequenced individuals useable by non-specialists.

The complete mitogenome of Gandalfus yunohana has been obtained from one crab collected at the Nikko Seamount, $472 \mathrm{~m}$, on the Izu-Ogasawara Ridge (Yang et al. 2010), 
in order to esteem its phylogenetic relationships with the closest relative brachyurans. For the phylogenetic study of complete mitochondrial genome of another deep-sea vent crab $G$. puia from the Tonga Arc vent field and for comparison with the genome of $A$. alayseae, Kim et al. (2016) used the same material than previously in 2014 (Kim et al. 2014: table 1), i.e., specimens (JQ035660 and KC851803) from two remote regions, the Tofua Arc and the Manus Basins. In the resulting phylogenetic tree, mitogenomic differences were expressed as a bifurcation in two distinct branches for $A$. alayseae, as precedingly. As a consequence, without a clear morphological diagnosis of analysed individuals, there is a possibility that such a sequence diversity reflects a species admixture as it is the case in the Lau and North Fiji Basins with the possible sympatric co-occurrence of $A$. alayseae, $A$. hourdezi n. sp. and $A$. jolliveti n. sp. Possibility of a separate species in the Manus Basin should not be rejected, see Fig. 12A, B.

Austinograea alayseae was similarly separated into two branches in the tree of brachyuran phylogenetic relationships based on the alignment of concatenated 13 mitochondrial coding genes by Mandon et al. (2017: fig. 1) in a study of the mitogenome of Segonzacia mesatlantica Williams, 1988. The GenBank number KC851803 corresponds, as precedingly, to Austinograea from the Manus Basin (Kim et al. 2014: table 1), and NC_020314 is a reference sequence identical to KC851803 (P. Mandon, pers. comm. June 2017) and thus corresponds to the same sequence of the same crab that was collected in the Manus Basin from the Vienna Woods site, $2484 \mathrm{~m}$ (Yang et al. 2013: supplementary material). The Vienna Woods site is an important field of active and fossil chimneys about $300 \mathrm{~m}$ in diameter, with the associated fauna essentially constituted by gastropods Alviniconcha hessleri sensu lato, Ifremeria nautilei, galatheids, shrimps, cirripeds, and bythograeids (Auzende et al. 1996: fig. 7).

In a series of papers on the complete mitogenome of brachyuran species, the genomes of $A$. alayseae, $A$. rodriguezensis, Gandalfus yunohana and $G$. puia were downloaded from GenBank and included in reconstructed phylogenetic trees, all showing occurrence of $\mathrm{T}$ and $\mathrm{A}$ nucleotides that differed from that all of other studied Brachyura (Xin et al. 2017a: 309; 2017b; Tang et al. 2017).

Molecular basis of adaptive evolution by a transcriptome analysis performed in $A$. alayseae collected from the Manus Basin revealed that candidate genes related to harsh condition adaptation and in order to facilitate inhabiting the extreme environment were identified, namely genes related to sensory, circadian rhythm, hormone, hypoxia stress, metal detoxification, high osmotic pressure and pathogens; in the degenerated eyestalk, transcription of phototransduction related genes, important for retinal function, was greatly reduced (Hui et al. 2017).

\section{MAIN CHARACTERS OF AUSTINOGRAEA}

The family Bythograeidae (ranked to superfamily level, Bythograeoidea Williams, 1980, see diagnosis in Davie et al. 2015c) is endemic to deep-sea hydrothermal vents, with a combination of characters that is not known in other brachyuran families.

The thoracic sternum is rather wide, all sutures are widely interrupted, and the median line extends along sternite 8 and practically not or variously along sternite 7 (Figs 4C; 6C; 7C, D; 9B-D; 10E; 11B; Guinot 1990: fig. 2C).

As stated by Hessler \& Martin (1989), a junction sternum/ pterygostome characterises the genus Austinograea, without modifying the location of the branchial afferent openings (Milne Edwards openings) but with, however, an implication on the shape and embayment of the mxp3 coxa. Junction is well visible in $A$. williamsi (Hessler \& Martin 1989: 645, 657, figs 6a, 7a, 8b), in $A$. alayseae (Guinot 1990: 882, fig. 2A, pl. 1, fig. B), in A. rodriguezensis (see Tsuchida \& Hashimoto 2002: figs 4,7$)$. The same pattern occurs in Gandalfus yunohana (Takeda et al. 2000: fig. 2B), and probably also in G. puia, although not mentioned or figured by McLay (2007). Such a junction is absent in the other bythograeids (Hessler \& Martin 1989: figs 1b, 6b, c, 8a, c, 15b), where there are only various stages of extension of sternite 4 towards the pterygostome, resulting in different shapes of the mxp3 coxa and branchial afferent openings: Cyanagraea Saint Laurent, 1984 and Allograea Guinot, Hurtado \& Vrijenhoek, 2002 with a wide gap between the sternite 4 and the pterygostome, thus mxp3 coxa largely exposed; Bythograea Williams, 1980 with a narrower gap between the sternite 4 and the pterygostome, a larger portion of the elongated mxp3 coxa being intercalated; Segonzacia Guinot, 1989 with the sternite 4 rather close to the pterygostome but not completely separating the mxp3 coxa from the cheliped. The Austinograea/Gandalfus group is thus distinguished by a complete junction, so that the mxp3 coxa is completely separated from the cheliped, and its distal portion deeply recessed. The junction thoracic sternum/ pterygostome does not significantly vary along Austinograea species: $A$. hourdezi n. sp. (Figs 5C, D; 7C, D); A. jolliveti n. sp. (Figs 9B, C; 10E); A. alayseae (Guinot 1990: fig. 2A).

The modality of protection of the penis, i.e., the external, muscular projection of the ejaculatory duct that is inserted into the G1 during mating, shows in Brachyura a regular pattern that is practically constant at familial and even suprafamilial levels. Bythograeidae shows a condylar protection, i.e., the penis is enclosed inside the condyle of the P5 coxa, but in exhibiting two distinct patterns. The male gonopore opening, from which emerges the penis, is either located on the anterior margin of the coxo-sternal condyle (most bythograeids: Bythograea, Cyanagraea, Segonzacia, see Guinot et al. 2013: 84 , fig. $8 \mathrm{H}$, table 4 ), or it is partially located on the coxa itself (Austinograea and Gandalfus).

In Brachyura the two pairs of gonopods are conservative features, and the G2 morphology has a phylogenetic significance, its reduction implying a functional change of the female copulatory system. Guinot (1979) hypothetised that a long G2 could be regarded as plesiomorphic, the shortness of the complete G2 (with reduction of the flagellum) apomorphic, and medium length G2 represented an intermediate state (see also Guinot \& Hurtado 2003; Guinot et al. 2013). In some rare heterotremes the G2 shape shows several character 
states within a family, e.g. in Calappidae De Haan, 1833, even within a genus, e.g. Calappa Weber, 1795, and a molecular multi-locus phylogeny of this family supported the long G2 as the ancestral state (Ewers-Saucedo et al. 2015, 2017). The Bythograeidae displays this gonopodal diversity (Guinot et al. 2013): in most bythograeids, Bythograea, Cyanagraea and Segonzacia, the G2 is longer than G1 or equal to the G1 length (Hessler \& Martin 1989: fig. 14; McLay 2007: table 2). McLay (2007: table 2) distinguished Gandalfus from Austinograea notably on the basis of a long G2 (equal to or greater than G1), with the flagellum much longer that the peduncle (G2 peduncle about one third of overall length in G. yunohana; about one half of overall length in $G$. puia). In Austinograea the G2 is distinctly shorter than the G1, with remarkable variation along species (especially in the flagellum size), but, however, remains rather short (see comparative figures in Tsuchida \& Hashimoto 2002: fig. 8). The G2 is about half the length of G1 in A. alayseae (Guinot 1990: fig. 3) and $A$. rodriguezensis (see Tsuchida \& Hashimoto 2002 : fig. 8), about less than half the $\mathrm{G} 1$ length in $A$. williamsi (Hessler \& Martin 1989: fig. 14a-e; Tsuchida \& Fujikura 2000: figs 6-8), A. hourdezi n. sp. (Figs 4C; 6D, E) and $A$. jolliveti n. sp. that, moreover, has a very reduced flagellum (Figs 9C, D; 11D, E). McLay (2007) considered the long bythograeid G2 was the ancestral condition and, compared to the long G2 of other bythograeids, the short G2 of the Austinograeal Gandalfus group was interpreted as the derived condition in the family, also supported by the eye regression pattern (see Davie et al. 2015a).

The rows of spines on the G1 dorsal surface of Austinograea williamsi were postulated to be used to keep the position of the G1 "by hooking the female gonopore", and the short setae on the G1 ventral surface "to sense" the female seminal receptacle (Tsuchida \& Fujikura 2000: 413, fig. 7). Micromorphological studies seem to show that in A. williamsi the G1 proximal foramen is too small for the G2 insertion, suggesting that the G2 acts "as a sensor" guiding the G1, i.e., the typical intromittent, inseminating structure, into the female seminal receptacle (Tsuchida \& Fujikura 2000: 413, fig. 8). According to McLay (2007), however, it is likely that the bythograeid G2 has a role in sperm transfer and, when it is long, may have a role in disrupting sperm from previous matings.

The ocular regression, to variable degrees, is a main characteristic of the family Bythograeidae (Williams 1980), the Austinograea/Gandalfus group having the most drastic reduction of eyes. In Austinograea the eyestalks are reduced, the eyes are fixed, and the cornea is vestigial or absent, unpigmented, without facets (Hessler \& Martin 1989: figs 4, 5a; Guinot 1990: figs 1, 4; Tsuchida \& Hashimoto 2002: fig. 3). Similarly, in Gandalfus eyes are fixed, with the stalks embedded in the orbital wall, and a vestigial cornea (Takeda et al. 2000: fig. 4A-C; McLay 2007: figs 2A, 3, 4, table 3). As Austinograea and Gandalfus are not the deepest living of bythograeids and Gandalfus is even the shallowest occurring bythograeid genus (from 270-239 to 1647 m), McLay (2007) noted that the pattern of eye development was not strictly correlated with depth.
A study of the locomotor activity in 'eyeless crabs' under different lighting conditions by Kabasawa (1992: 21) presumably used $G$. yunohana, as the specimens were collected from the Kaikata Seamount by the Shinkai 2000 at 470 m. Experimental observations have shown that crabs had photo-sensivity, became active in the dark and the circadian rhythmicity did not occur under continuous darkness.

As the vent crabs have reduced eyestalks and vestigial cornea, they evolve alternatives in adapting to constant darkness, thus chemical communication should be the predominant mode of their behaviour, such as predation and mating. Hui et al. (2017) discovered that, in the eyestalk of the practically blind A. alayseae, immune related genes were highly expressed, indicating the eyestalks might be involved in the crab immune responses, thus their important roles in the environment adaptation; in the degraded eyestalk, 10 olfactory receptor and three gustatory receptor genes were identified; and, although eyestalks of $A$. alayseae are degraded, three transcripts encoding important eyestalk prohormone and hormone were characterised.

Many questions remain to understand the evolutionary mechanisms underlying adaptation to life in the dark of bythograeids. The colourless body (except for the pigmented areas on carapace or spots on chelae, with different texture, in some species) and the ocular regression of vent crabs, to a greater extent in the Austinograea/Gandalfus group, allowed a comparison with cavernicolous/troglobitic brachyurans (Guinot 1990: fig. 6). In contrast to adults, larval stages of bythograeids are bright red and have pigmented compound eyes. As megalopae and postlarvae of brachyuran crabs are benthic and with a limited dispersal ability, the dispersion is only possible via planktonic larval stages. And, in fact, zoeae of Bythograea thermydron Williams, 1980 were reported as possessing image-forming compound eyes, with a visual pigment sensitive to the blue light of mesopelagic waters; when larvae begin to descend to vents and settle at the vents, they lose their image-forming optics, resulting in benthic megalopae that possess high-sensitivity naked-retina (Jinks et al. 2002). The newly hatched larvae of Gandalfus yunohana have pigmented compound eyes and are phototactic (Miyake et al. 2007; Hamasaki et al. 2010: fig. 2)

The female reproductive system described in Austinograea williamsi by Köhnk et al. (2017: fig. 7) is characterised by the remarkable size of the ovary, the shape and orientation of the seminal receptacle that consists of a single chamber, the lack of a cuticular chamber, the vagina of concave type connected to the rotated seminal receptacle by the most dorsal part, all features interpreted as distinctive from other brachyurans. This configuration could not be checked in other Austinograea species, but we presume it is uniform in the whole genus.

In Austinograea williamsi setal patches are found on the inner surface of the chelae (in both sexes), on subhepatic regions (in both sexes), and on the thoracic sternum close to the chelipeds (generally more in females than in males) (Hessler $\&$ Martin 1989: figs 1, 2, 4A, 6a, 10c). These setose areas harbor large numbers of bacteria, which are well known to be the main primary producers in hydrothermal vent communities 
(Van Dover 2000). It should be noted, however, that patches of setae on chelae, subhepatic and thoracic regions are not evenly distributed in all species of Austinograea, A. alayseae being the most glabrous (no setae on chelae and carapace), in contrast to $A$. hourdezi n. sp. and $A$. jolliveti n. sp.

The gastric mill of bythograeids, extensively studied in A. williamsi, known to be an opportunistic scavenger and with gut contents including portion of small bivalve shells, shows characteristic features; but nothing about the non-specialised nature of the foregut of the vent crabs was considered indicative of their unique habitat (Martin et al. 1998).

According to Tudge et al. (1998), who examined the spermatozoal ultrastructure in three species of bythograeids, Bythograea thermydron, Segonsacia mesatlantica (Williams, 1988), and Austinograea alayseae, spermatozoal evidence suggested a relationship between the bythograeids and the deep-water but not hydrothermal crab Calocarcinus africanus Calman, 1909 and wider relationships with the Xanthoidea MacLeay, 1838. They concluded that either $C$. africanus could be assigned to the Bythograeidae or that a separate own group could be erected for Calocarcinus Calman, 1909, which resulted in the establishment of Calocarcininae Števčić, 2005 within the Trapezoidea Miers, 1886. Mateos et al. (2012) did not found any indication of $C$. africanus being the closest relative to Bythograeidae. The relationships of Bythograeidae with other Brachyura is still debated (Davie et al. 2015b; Leignel et al. 2017).

Studies on the early life history of bythograeids are crucial to elucidate the mechanism of population maintenance at the hydrothermal vents, which are generally active for no more than a decade (Van Dover et al. 2002). The larval development of Gandalfus yunohana consists of fifth or sixth zoeal stages and a megalopa (Hamasaki et al. 2010; Nakajima et al. 2010); Tsuchida et al. (1998) reported moulting and growth of adults reared in tanks for more than six years. Thirty-three larval morphological characters of the first stage zoea were compared by Nakajima et al. (2010) to those of various brachyuran families. Gandalfus yunohana shared 22 characters with the first zoeal stage of Calocarcinus, which may support affinities of Bythograeidae with $C$. africanus, as proposed by Tudge et al. (1998). It is likely that the larval development of Austinograea species is roughly similar to that of Gandalfus. More work on larval descriptions and molecular phylogenetics are required to resolve the relationships between these crabs.

\section{CONCLUSION}

In conclusion, in the western Pacific six evolutionary brachyuran lineages can be distinguished based on external morphology for the two genera Austinograea and Gandalfus in view of their sister group relationship. Single distinct species inhabit vent fields along the Central Indian Ridge $(A$. rodriguezensis), the Mariana Back-Arc Basin (A. williamsi), the Tonga-Kermadec Arc (G. puia), and along the Izu-Ogasawara Arc (G. yunohana). In contrast, vents in North Fiji and Lau
Back-Arc Basins may host at least three Austinograea species; if an additional Austinograea species is later recognised in the Manus Basin (in study), four bythograeid species would inhabit the southwestern Pacific. Within the snail complex Alviniconcha Okutani \& Ohta, 1988, the dominant inhabitant of hydrothermal vents throughout southwestern Pacific and Indian oceans, DNA sequences for mitochondrial genes have revealed six distinct evolutionary lineages, five cryptic species having been previously confused under the previously monotypic genus Alviniconcha hessleri; the oldest dates of speciation events in the Alviniconcha complex of species is presumed to have been initiated about $60 \mathrm{Ma}$ before the emergence of the western Pacific Ridge (Kojima et al. 2001; Hidaka et al. 2015; Johnson et al. 2015; D. Jollivet, pers. comm. 2017). We can draw a parallel between the western Pacific brachyuran lineages (morphologically recognisable) and the allopatric/sympatric gastropod lineages, which, however, could not be distinguished by their external morphology.

Our findings of these two new bythograeid species belonging to a genus until now known only by two species in the hydrothermal fields of the western Pacific provide important insights into the biodiversity and biogeography of vent endemic ecosystems. There is no convincing evidence of what is responsible for much of this brachyuran diversity in the western Pacific: speciation without geographic isolation, i.e., sympatric speciation, or allopatric speciation due to secondary contact zones between species with entirely separate geographical ranges but subjected to population dispersal and to subsequent recolonisation of habitats. Is this success related to the non-linear distribution of vents in this vast area and oceanic circulation patterns? Detection of cryptic species in hydrothermal systems is a phenomenon that is rapidly increasing mainly through genetic approaches in various groups, including annelids, sea anemones, mussels, gastropods, and crustaceans. Genetic analyses of the westernPacific bythograeids, which have not yet resulted in the identification of extensive cryptic diversity, will perhaps recover a more complex biodiversity pattern of brachyuran crabs than previously recognised in this vast area. The ChuBacArc campaign scheduled in 2019 by Didier Jollivet and Stéphane Hourdez (Roscoff) in several back-arc basins of the western Pacific will undoubtedly provide a better understanding of the evolutionary biology of hydrothermal species, including Austinograea crabs.

Increasing attention needs to be paid to detrimental impacts of commercial activities, especially mineral extraction, and to a lesser extent the disruptive removal of specimens from their natural environments and scientific over-sampling as well as unintentional and intentional damage sampling on vent ecosystems (Vrijenhoek 2010; Van Dover 2011, 2014; Keaveney et al. 2016; Van Dover et al. 2016). Protection and future preservation of biological communities of the unique hydrothermal environments require knowledge of the biodiversity and connectivity of associated species, together with cooperation, effective deep-sea resource management and policy at national and international levels. 


\section{Acknowledgements}

The authors wish to thank the Chief Scientists D. Desbruyères (Ifremer, France), J. Hashimoto (JAMSTEC, Japan), R. C. Vrijenhoek (MBARI, USA), C. R. Fisher (Penn State University, USA), the captains and crews of the RV Nadir, Atalante, Natsuchima, Melville, Thomas Thompson, and crews of the D/S Nautile, Shinkai 2000, ROV Jason II of the STARMER II and BIOLAU cruises (Ifremer, France), BIOACCESS 98 (JAMSTEC, Japan), TUIM06MV (MBARI, USA), TUIM07MV, MGLN07MV, and Lau Basin 2009 (Penn State University, USA) for the collection of the samples. We also thank S. Hourdez (CNRS, Station biologique de Roscoff, France) who provided the specimens studied here and the video tapes of the dives where they have been sampled. We are very grateful to S. Hourdez and D. Jollivet (CNRS, Station biologique de Roscoff, France) for their valuable comments on the ecological data and evolutionary history of hydrothermal vent fauna, and Y. Lagabrielle (CNRS, Université de Rennes 1) for checking the geological settings. We are indebted to E. Rodríguez (Ohio State University, USA) for the identification of the sea anemone photographed in situ Fig. 8C. The TUIM06MV cruise was funded by grant from the US National Science Foundation to R. C. Vrijenhoek (OCE-0241613) and C. L. Van Dover (OCE-0350554). The TUIM07MV, MGLN07MV and Lau Basin 2009 cruises were funded by NSF Grant OCE 003403953.

We are much indebted to C. L. Van Dover for patiently and carefully reading the entire manuscript and providing her expert comments and suggestions, and L. A. Hurtado for his helpful remarks. M. Takeda is thanked for his encouragement.

We gratefully acknowledge the valuable assistance of J.-F. Dejouannet (IRD at MNHN, Paris, DGD REVE, UMS2700/ Plateau d'Iconographie scientifique) for the line-drawings, the photographs and the preparation of the illustration.

\section{REFERENCES}

AuZENDE J.-M., LAFOY Y. \& MARSET B. 1988. — Recent geodynamic evolution of the North Fiji Basin (SW Pacific). Geology 16: 925929. https://doi.org/10.1130/0091-7613(1988)016<0925:RGE OTN $>2.3 . \mathrm{CO} ; 2$

Auzende J.-M., Urabe T., Ruellan E., Chabroux D., Charlou J.-L., Gena K., Gamo T., Henry K., Matsubayashi O., MatsuMOTO T., AKa J., NAGAYA Y. \& OKAMURA K. 1996. — "Shinkai 6500" dives in the Manus Basin: New STARMER Japanese-French Program. JAMSTEC Deep-Sea Research 12: 323-334.

Auzende J.-M., Hashimoto J., Fiala-Médioni A., Ohta S. \& THE TEAM BIOACCESS 1997. —Étude géologique et biologique in situ de deux zones hydrothermales du bassin de Manus (Papouasie Nouvelle-Guinée). Comptes rendus de l'Académie des Sciences sér. III Sciences de la Vie A 325: 585-591.

Beedessee G., Watanabe H., Ogura T., Nemoto S., Yahagi T., NaKagaWa S., NaKamura K., TAKaI K., KoONJUl M. \& Marie D. E. P. 2013. - High connectivity of animal populations in deep-sea hydrothermal vent fields in the Central Indian Ridge relevant to its geological setting. PloS ONE 8: e81570. https:// doi.org/10.1371/journal.pone.0081570

Breusing C., Johnson S. B., Tunnicliffe V. \& Vrijenhoek R. C. 2015. - Population structure and connectivity in Indo-Pacific deep-sea mussels of the Bathymodiolus septemdierum complex.
Conservation Genetics 16: 1415-1430. https://doi.org/10.1007/ s10592-015-0750-0

Chevaldonné P., Desbruyères D. \& Le Haître M. 1991. Time-series of temperature from three deep-sea hydrothermal vent sites. Deep-Sea Research II 38: 1417-1430. https://doi. org/10.1016/0198-0149(91)90014-7

Chu K. H. C., Schubart C. D., Shih H.-T. \& Tsang L. M. 2015. - Genetic diversity and evolution of Brachyura (Chapter 71-13), in Castro P., Davie P. J. F., Guinot D., Schram F. R. \& VON VAupel Klein J. C. (eds), Decapoda: Brachyura, Treatise on Zoology - Anatomy, Taxonomy, Biology. Vol. 9C-2, Crustacea. Brill, Leiden and Boston: 775-820.

Corbera J. \& SEgONZAC M. 2010. - A new Styloptocuma species (Crustacea, Cumacea) from hydrothermal vent fields of the Lau and North Fiji Basins (West Pacific). Zoosystema 32 (3): 439-447. https://doi.org/10.5252/z2010n3a5

Cosel R. von, Métivier B. \& Hashimoto J. 1994. — Three new species of Bathymodiolus (Bivalvia: Mytilidae) from hydrothermal vents in the Lau basin and the North Fiji Basin, Western Pacific, and the Snake Pit Area, Mid-Atlantic Ridge. Veliger 37: 374-392.

Davie P. J. F., Guinot D. \& NG P. K. L. 2015a. — Anatomy and functional morphology of Brachyura (Chapter 71-2), in CASTRO P., Davie P. J. F., Guinot D., Schram F. R. \& Von Vaupel KLEIN J. C. (eds), Decapoda: Brachyura, Treatise on Zoology Anatomy, Taxonomy, Biology. Vol. 9C-1, Crustacea. Brill, Leiden and Boston: 11-163.

Davie P. J. F., Guinot D. \& NG P. K. L. 2015b. — Phylogeny of Brachyura (Chapter 71-16), in CASTRO P., DAVIE P. J. F., GUINOT D., Schram F. R. \& von Vaupel Klein J. C. (eds), Decapoda: Brachyura, Treatise on Zoology - Anatomy, Taxonomy, Biology. Vol. 9C-2, Crustacea. Brill, Leiden and Boston: 921-979 p.

Davie P. J. F., Guinot D. \& NG P. K. L. 2015c. - Systematics and classification of Brachyura (Chapter 71-18), in CASTRO P., Davie P. J. F., Guinot D., Schram F. R. \& von Vaupel Klein J. C. (eds), Decapoda: Brachyura, Treatise on Zoology - Anatomy, Taxonomy, Biology. Vol. 9C-2, Crustacea. Brill, Leiden and Boston: $1049-1130$.

Denis F., Jollivet D. \& Moraga D. 1993. - Genetic separation of two allopatric populations of hydrothermal snails Alviniconcha spp. (Gastropoda) from two south western Pacific back-arc basins. Biochemical Systematics and Ecology 21: 431-440. https:// doi.org/10.1016/0305-1978(93)90101-V

De Ronde C. E. J. \& STUCKer V. K. 2015. - Seafloor hydrothermal venting at volcanic arcs and backarcs, in SigURDSSON H., Houghton B., McNutT S., RYMER H. \& STIX J. (eds), Encyclopedia of Volcanoes. 2nd ed. Academic Press, Amsterdam: 823849. https://doi.org/10.1016/B978-0-12-385938-9.00047-X

Desbruyères D., Alayse-Danet A.-M., Ohta S. \& the ScienTIFIC Parties OF BIOLAU AND STARMER CRUISES 1994. Deep-sea hydrothermal communities in Southwestern Pacific back-arc basins (the North Fiji and Lau Basins): composition, microdistribution and food web. Marine Geology 116: 227-242. https://doi.org/10.1016/0025-3227(94)90178-3

Desbruyères D., Hashimoto J. \& Fabri M. 2006a. - Composition and biogeography of hydrothermal vent communities in Western Pacific Back-Arc Basins, in CHRIsTIE D. M., Fisher C. R., LeE S.-M. \& Givens S. (eds), Back-Arc Spreading Systems: Geological, Biological, Chemical, and Physical Interactions. Geophysical Monographs 166: 215-234.

Desbruyères D., Segonzac M. \& Bright M. (eds) 2006b. Handbook of Deep-Sea Hydrothermal Vent Fauna. Second completely revised edition. Denisia 18: 1-544.

Duermit E., Shervette V., Whitaker J. D., Kingsley-Smith P. R. \& WiLbE D. 2017. - A field assessment of claw removal impacts on the movement and survival of stone crabs Menippe spp. Fisheries Research 193: 43-50. https://doi.org/10.1016/j. fishres.2017.03.019 
Erickson K. L., Macko S. A. \& Van Dover C. L. 2009. - Evidence for a chemoautotrophically based food web at inactive hydrothermal vents (Manus Basin). Deep-Sea Research II 56: 1577-1585. https://doi.org/10.1016/j.dsr2.2009.05.002

Ewers-Saucedo C., Hayer S. \& Brandis D. 2015. - Functional morphology of the copulatory system of box crabs with long second gonopods (Calappidae, Eubrachyura, Decapoda, Crustacea). Journal of Morphology 276 (5): 517-525. https://doi. org/10.1002/jmor.20322

Ewers-Saucedo C., Wares J. P., Hanel R. \& Brandis D. 2017. Evolution of male copulatory organs in box crabs (Crustacea, Brachyura, Calappidae). Journal of Crustacean Biology 36 (6): 804814. https://doi.org/10.1163/1937240X-00002479

Ferrini V. L., Tivey M. K., Carbotte S. M., Martinez F. \& ROMAN C. 2008. - Variable morphologic expression of volcanic, tectonic, and hydrothermal processes at six hydrothermal vent fields in the Lau back-arc basin. Geochemistry Geophysics Geosystems 9 (7): 1-33. Q07022. https://doi.org/10.1029/2008GC002047

FisHer C. R, TAKAI K. \& LE BRIS N. 2007. — Hydrothermal vent ecosystems. Oceanography 20 (1): 14-23. https://doi.org/10.5670/ oceanog.2007.75

Fouguet Y., von Stackelberg U., Charlou J. L., Donval J. P., Foucher J. P., Erzinger J., Herzig P., MüHe R., Wiedicke M., SoAKAi S. \& Whitechurch H. 1991. - Hydrothermal activity in the Lau back-arc basin: sulfides and water chemistry. Geology 19 (4): 303-306. https://doi.org/10.1130/00917613(1991)019<0303:HAITLB>2.3.CO;2

Fujikura K., OKuTANi T. \& Maruyama T. 2008. - Deep-sea life: biological observations using research submersibles. Tokai University Press, Hadano (Japan).

GALKIN S. V. 1992. - Bottom fauna of the hydrothermal vents in the Manus Basin. Okeanologiya 32 (6): 1102-1110. [in Russian; English translation in Oceanology 32 (6): 768-774]

GALKIN S. V. 1997. - Megafauna associated with hydrothermal vents in the Manus Back-Arc Basin (Bismarck Sea). Marine Geology 142 (1): 197-206. https://doi.org/10.1016/S0025-3227(97)00051-0

Guinot D. 1979. - Morphologie et phylogenèse des Brachyoures. Muséum national d'Histoire naturelle, Paris (Mémoires du Muséum national d'Histoire naturelle, Sér. A - Zoologie; 112): $1-354$, pls $1-25$.

Guinot D. 1990. - Austinograea alayseae sp. nov., crabe hydrothermal découvert dans le bassin de Lau, Pacifique sud-occidental (Crustacea Decapoda Brachyura). Bulletin du Muséum national d'Histoire naturelle 4e sér., 11, section A (4): 879-903.

Guinot D. 1997. - Brachyuran crabs, in DesbruYÈres D. \& SeGONZAC M. (eds), Handbook of Deep-Sea Hydrothermal Vent Fauna. Editions Ifremer, Brest: 208-214.

GUINOT D. \& HuRTADO L. A. 2003. - Two new species of hydrothermal vent crabs of the genus Bythograea from the southern East Pacific Rise and from the Galapagos Rift (Crustacea Decapoda Brachyura Bythograeidae). Compte Rendus Biologies 326: 423-439. https://doi.org/10.1016/S1631-0691(03)00126-4

Guinot D. \& Segonzac M. 1997. - Description d'un crabe hydrothermal nouveau du genre Bythograea (Crustacea Decapoda Brachyura) et remarques sur les Bythograeidae de la dorsale du Pacifique oriental. Zoosystema 19 (1): 121-149.

Guinot D. \& SegonZac M. 2006a. - Crustacea, Brachyura, in Desbruyères D., Segonzac M. \& Bright M. (eds), Handbook of Deep-Sea Hydrothermal Vent Fauna. Second completely revised edition. Denisia 18: 455, 460, 461, 466-472.

Guinot D. \& SegOnZaC M. 2006b. - Austinograea alayseae Guinot, 1990, in Desbruyères D., SegOnZaC M. \& Bright M. (eds), Handbook of Deep-Sea Hydrothermal Vent Fauna. Second completely revised edition. Denisia 18: 460-461.

Guinot D. \& SEGONZAC M. 2006c. - Bythograea microps de Saint Laurent, 1984, in DesbruYères D., SEGONZAC M. \& BRight M. (eds), Handbook of Deep-Sea Hydrothermal Vent Fauna. Second completely revised edition. Denisia 18: 468.
Guinot D., TAVAres M. \& CASTro P. 2013. - Significance of sexual openings and supplementary structures on the phylogeny of brachyuran crabs (Crustacea, Decapoda, Brachyura). Zootaxa 3665 (1): 1-414. https://doi.org/10.11646/zootaxa.3665.1.1

Haimin Y., DaO M., ImHOlT T., HuAng J., WheEler K., Bonilla A., SurEsh S. \& OrTIZ C. 2010. - Protection mechanisms of the iron-plated armor of a deep-sea hydrothermal vent gastropod. Proceedings of the National Academy of Sciences 107 (3): 987-992. https://doi.org/10.1073/pnas.0912988107

HALL R. 2002. - SE Asia and the SW Pacifc: computer-based reconstructions, model and animations. Journal of Asian Earth Sciences 20: 353-431. https://doi.org/10.1016/S1367-9120(01)00069-4

Hamasaki K., NaKajima K., Tsuchida S., Kado R \& Kitada S. 2010. - Number and duration of zoeal stages of the hydrothermal vent crab Gandalfus yunohana from laboratory reared specimens. Journal of Crustacean Biology 30 (2): 236-240. https:// doi.org/10.1651/09-3199.1

HASHIMOTO J. 2006. — Austinograea yunohana Takeda, Hashimoto \& Ohta, 2000, in DesbruyÈrEs D., SEgOnZAC M. \& Bright M. (eds), Handbook of Deep-Sea Hydrothermal Vent Fauna. Second completely revised edition. Denisia 18: 464.

HASHIMOTO J., JOLLIVET D. \& KAIYO 88 SHIPBOARD PARTY 1989. - The hydrothermal vent communities in the North Fiji Basin: Results of Japan-France Cooperative Research on board KAIYO 88. UMI/La mer Tokyo 27 (2): 62-71 (in Japanese with English abstract and legends).

Hashimoto J., OHTA S., FujiKura K. \& MiURa T. 1995. — Microdistribution pattern and biogeography of the hydrothermal vent communities of the Minami-Ensei Knoll in the Mid-Okinawa Trough, Western Pacific. Deep-Sea Research I 42 (4): 577-598. https://doi.org/10.1016/0967-0637(94)00037-S

Hashimoto J., Ohta S., Fiala-Médioni A. \& Participants of THE BIOACCESS CRUISE ' 96 IN THE MANUS Basin 1998. Hydrothermal vent communities in the PACMANUS site, Manus Basin. Results of the BIOACCESS Cruise '96 in the Manus Basin. JAMSTEC Deep-Sea Research 14: 91-102 (in Japanese, with abstract and captions in English).

Hashimoto J., Ohta S., Fiala-MÉdioni A., Auzende J.-M., Kojima S., Segonzac M., Fujiwara Y., Hunt J. C., Gena K., Miura T., Kikuchi T., Yamaguchi T., Toda T., Chiba H., Tsuchida S., Ishibashi J., Henry K., Zbinden M., Pruski A., InOUE A., KOBAYASHI H., BiRRIEN J.-L., NAKA J., YAMANAKA T., C. Laporte C., Nishimura K., Yeats C., Malagun S., Kia P., Oyaizu M. \& KaTAYAMA T. 1999. - Hydrothermal vent communities in the Manus Basin, Papua New Guinea: Results of the BIOACCESS cruises'96 and '98. InterRidge News 8: 12-18.

Hessler R. R. \& LONSDALE P. 1991. — Biogeography of Mariana Trough hydrothermal vent communities. Deep-Sea Research Part a-Oceanographic Research Papers 38: 185-199. https://doi. org/10.1016/0198-0149(91)90079-U

HessLer R. R. \& MARTIN J. W. 1989. - Austinograea williamsi, new genus, new species, a hydrothermal vent crab (Decapoda: Bythograeidea) from the Mariana Back-Arc Basin, western Pacific. Journal of Crustacean Biology 9 (4): 645-661. https:// doi.org/10.2307/1548594

Hessler R. R., Lonsdale P. \& Hawkins. J. 1988. — Patterns on the ocean floor. New Scientist 24: 47-51.

Hidaka H., Ogura T., Watanabe H., Kano Y. \& Kojima S. 2015. Population History of a Hydrothermal Vent-Endemic Gastropod Alviniconcha hessleri in the Mariana Trough, in ISHIBASHI J.-I., KYOKO O. \& MichinaRI S. (eds), Subseafloor Biosphere Linked to Hydrothermal Systems. TAIGA Concept. Chapter 26. Springer, Tokyo Heidelberg New York Dordrecht London: 325-333. https://doi.org/10.1007/978-4-431-54865-2_26

Hui M., Song C., LiU Y., Li C. \& CUI Z. 2017. — Exploring the molecular basis of adaptive evolution in hydrothermal vent crab Austinograea alayseae by transcriptome analysis. Plos One 12 (5): e0178417. https://doi.org/10.1371/journal.pone.0178417 
Ishibashi J., Grimaud D., Nojiri Y., AuZEnde J.-M. \& Urabe T. 1994. - Fluctuation of chemical compositions of the phaseseparated hydrothermal fluid from the North Fiji Basin Ridge. Marine Geology 116: 215-226. https://doi.org/10.1016/00253227(94)90177-5

Jinks R. N., Markley T. L., Taylor E. E., Perovich G., Dittel A. I., EPIFAnio C. E. \& Cronin T. W. 2002. — Adaptive visual metamorphosis in a deep-sea hydrothermal vent crab. Nature 420 (6911): 68-70. https://doi.org/10.1038/nature01144

Johnson S. B., Warén A., Tunnicliffe V., VAN Dover C., Wheat C. G., Schultz T. F. \& VRijenhoek R. C. 2015. - Molecular taxonomy and naming of five cryptic species of Alviniconcha snails (Gastropoda: Abyssochrysoidea) from hydrothermal vents. Systematics and Biodiversity 13 (3): 278-295. https://doi.org/10. 1080/14772000.2014.970673

Jollivet D. 1996. — Specific and genetic diversity at deep-sea hydrothermal vents: an overview. Biodiversity and Conservation 5 : 1619-1653. https://doi.org/10.1007/BF00052119

Jollivet D., Hashimoto J., Auzende J. M., Honza E., Ruellan E., DutT S., Iwabuchi Y., JarVis P., Joshima M., KaWai T., KaWAMOTO T., Kisimoto K., LAFOY Y., MatSUMOTO T., MitsuZaWA K., Naganuma T., NaKa J., OtsuKa K., Otsuki A., Bhaskar Rao Y. J., Tanahashi M., Tanaka T., Temakon J. S., Urabe T., VeIVAU T. \& YOKOKURA T. 1989. - First observations of faunal assemblages associated with hydrothermalism in the North-Fiji back-arc basin. Comptes rendus de l'Académie des Sciences sér. III Sciences de la Vie A 309 (8): 301-308.

KABASAWA H. 1992. - Locomotor activity in eyeless crab from hydrothermal vents. Biennial Report of the Keikyu Aburatsubo Marine Park Aquarium 16: 21-23.

KaRIG D. E. 1970. — Ridges and basins of the Tonga-Kermadec Island Arc System. Journal of Geophysical Research 75 (2): 239254. https://doi.org/10.1029/JB075i002p00239

Keaveney S., Gutierrez-Heredia L., Keogh C. \& Reynaud E. G. 2016. - Applications for advanced 3D imaging, modelling, and printing techniques for the biological sciences. Conference paper. https://doi.org/10.1109/VSMM.2016.7863157

Kim S. J., LeE K. Y. \& JU S.-J. 2013. — Nuclear mitochondrial pseudogenes in Austinograea alayseae hydrothermal vent crabs (Crustacea: Bythograeidae): effects on DNA barcoding. Molecular Ecology Resources 13 (5): 781-787. https://doi.org/10.1111/1755-0998.12119

KIM S. J., KIM H. S. \& JU S.-J. 2014. - Mitochondrial genome of the hydrothermal vent crab Austinograea alayseae (Crustacea: Bythograeidae): genetic differences between individuals from Tofua Arc and Manus Basin. Mitochondrial DNA 25 (4): 251252. https://doi.org/10.3109/19401736.2013.800489

Kim S. J., Moon J. W. \& Ju S.-J. 2016. — Complete mitochondrial genome of the blind vent crab Gandalfus puia (Crustacea: Bythograeidae) from the Tonga Arc. Mitochondrial DNA Part A, 27 (4): 2719-2720.

KÖHNK S., BAUdEWIG J., BRANDIS D. \& Boretius S. 2017. — What's in this crab? MRI providing high-resolution three-dimensional insights into recent finds and historical collections of Brachyura. Zoology 121: 1-9. https://doi.org/10.1016/j.zool.2016.11.004

Kojıмa S. 2002. — Deep-sea chemoautosynthesis-based communities in the Northwestern Pacific. Journal of Oceanography 58: 343-363. https://doi.org/10.1023/A:1015869927288

Kojima S. \& Watanabe H. 2015. - Vent Fauna in the Mariana Trough, in Ishibashi J.-I., KYOKO O. \& Michinari S. (eds), Subseafloor Biosphere Linked to Hydrothermal Systems. TAIGA Concept. Chapter 25. Springer, Tokyo Heidelberg New York Dordrecht London: 313-324.

Kojima S., Segawa R., Fujiwara Y., Hashimoto J. \& Ohta S. 2000. - Genetic differentiation of populations of a hydrothermal vent-endemic gastropod, Ifremeria nautilei, between the North Fiji Basin and the Manus Basin revealed by nucleotide sequences of mitochondrial DNA. Zoological Science 17: 11671174. https://doi.org/10.2108/zsj.17.1167
Kojima S., Segawa R., Fujiwara Y., Fujikura K., Ohta S. \& Hashimoto J. 2001. - Phylogeny of hydrothermal-ventendemic gastropods Alviniconcha spp. from the Western Pacific revealed by mitochondrial DNA sequences. Biological Bulletin 200: 298-304. https://doi.org/10.2307/1543511

Komai T. \& SegonZaC M. 2004. - A new genus and species of alvinocaridid shrimp (Crustacea: Decapoda: Caridea) from hydrothermal vents on the North Fiji and Lau Basins, southwestern Pacific. Journal of the Marine Biological Association of the UK 84: 1179-1188. https://doi.org/10.1017/S0025315404010628h

Komai T. \& Tsuchida S. 2014. - Deep-sea decapod crustaceans (Caridea, Polychelida, Anomura and Brachyura) collected from the Nikko Seamounts, Mariana Arc, using a remotely operated vehicle "Hyper-Dolphin". Zootaxa 3764: 279-316. https://doi. org/10.11646/zootaxa.3764.3.3

Leignel V., Hurtado L. A. \& Segonzac M. 2017. - Ecology, adaptation and acclimatisation mechanisms of Bythograeidae Williams, 1980, a unique endemic hydrothermal vent crabs family: current state of knowledge. Marine and Freshwater Research 68: 1-15. https://doi.org/10.1071/MF17007

López-GonzÁlez P. J., RodrígueZ E. \& SEgOnZaC M. 2005. A new species of sea anemone (Cnidaria: Anthozoa: Actinaria) from Manus Basin hydrothermal vents, South-Western Pacific. Marine Biology Research 1: 326-337. https://doi. org/10.1080/17451000500380306

MA Y. 2011. - Specific genes screening and gene function analysis in the hydrothermal crab, Gandalfus yunohana. Master thesis, Zhejiang University. [in Chinese]

Mandon P., AZnar-Cormano L., Hourdez S. \& SAmadi S. 2017. - Assembly of the mitochondrial genome of the hydrothermal vent crab Segonzacia mesatlantica and detection of potential nuclear pseudogenes. Mitochondrial DNA Part B, 2: 1: 291-293. https://doi.org/10.1080/23802359.2 017.1318674

Mariappan P., Balasundaram C. \& Schmitz B. 2000. — Decapod crustacean chelipeds: an overview. Journal of Biosciences 25 (3): 301-313. https://doi.org/10.1007/BF02703939

Martin J. W. \& HANEY T. A. 2005. - Decapod crustaceans from hydrothermal vents and cold seeps: a review through 2005. Zoological Journal of the Linnean Society 145: 445-522. https:// doi.org/10.1111/j.1096-3642.2005.00178.x

Martin J. W., JourharZadeh P. \& FitTERER P. 1998. — Description and comparison of major foregut ossicles in hydrothermal vent crabs. Marine Biology 131 (2): 259-267. https://doi.org/10.1007/ s002270050318

Masunari N., Hiro-oku M., Dan S., Nanri T., Kondo M., Goto M., TAKada Y. \& SAigusa M. 2015. - Chela asymmetry in a durophagous crab: predominance of right-handedness and handedness reversal is linked to chela size and closing force. Journal of Experimental Biology 218: 3658-3670. https://doi. org/10.1242/jeb.120196

Matabos M., Cuvelier D., Brouard J., Shillito B., Ravaux J., Zbinden M., Barthelemy D., Sarradin P.-M. \& SARRazin J. 2015. - Behavioural study of two hydrothermal crustacean decapods: Mirocaris fortunata and Segonzacia mesatlantica, from the lucky strike vent field (mid-Atlantic ridge). Deep Sea Research Part II Tropical Studies in Oceanography 121: 146-158. https:// doi.org/10.1016/j.dsr2.2015.04.008

Mateos M., Hurtado L. A., Santamaria C. A., Leignel V. \& Guinot D. 2012. - Molecular systematics of the deep-sea hydrothermal vent endemic brachyuran family Bythograeidae Williams, 1980: a comparison of three Bayesian species-tree methods. PloS ONE7 (3): e32066, 14 p. https://doi.org/10.1371/ journal.pone.0032066

MCLAY C. L. 2007. - New crabs from hydrothermal vents of the Kermadec Ridge submarine volcanoes, New Zealand: Gandalfus gen. nov. (Bythograeidae) and Xenograpsus (Varunidae) (Decapoda: Brachyura). Zootaxa 1524: 1-22. 
Mitarai S., Watanabe H., Nakajima Y., Shchepetkin A. F. \& MCWILliams J. C. 2016. — Quantifying dispersal from hydrothermal vent fields in the western Pacific Ocean. Proceedings of the National Academy of Sciences 113 (11): 2976-2981. https:// doi.org/10.1073/pnas.1518395113

Miyake H., Kitada M., Tsuchida S., OKuyama Y. \& NaKamura K. 2007. - Ecological aspects of hydrothermal vent animals in captivity at atmospheric pressure. Marine Ecology 28: 86-92. https://doi.org/10.1111/j.1439-0485.2006.00115.x

NaKajima K., Hamasaki K., Tsuchida S., Kado R. \& Kitada S. 2010. - First zoeal stage of the hydrothermal vent crab, Gandalfus yunohana (Decapoda, Brachyura, Bythograeidae). Crustaceana 83 (5): 525-537. https://doi.org/10.1163/001121610X491022

Nakamura K., Watanabe H., Miyazaki J., Takai K., KaWagucci S. Noguchi T., Nemoto S., Watsuji T-o, Matsuzaki T., Shibuya T., OKamura K., MochizUKi M., Orihashi Y., Ura T., Asada A., Marie D., Koonjul M., Singh M., BeedesSEe G., Bhikajee M. \& TAmaKi K. 2012. — Discovery of new hydrothermal activity and chemosynthetic fauna on the Central Indian Ridge at $18^{\circ}-20^{\circ}$ S. PLoS ONE 7 (3): e32965. https://doi. org/10.1371/journal.pone.0032965

NG P. K. L., Guinot D. \& Davie P. J. F. 2008. - Systema Brachyurorum: Part 1. An annotated checklist of extant brachyuran crabs of the world. Raffles Bulletin of Zoology Supplement 17: 1-286.

Pearce J. A. \& Stern R. J. 2006. - Origin of Back-Arc Basin Magmas: Trace Element and Isotope Perspectives. Back-Arc Spreading Systems: Geological, Biological, Chemical, and Physical Interactions. Geophysical Monograph Series 166: 63-86.

Plouviez S., Faure B., Le Guen D., Lallier F. H., Bierne N. \& JOLLIVET D. 2013. - A new barrier to dispersal trapped old genetic clines that escaped the Easter Microplate tension zone of the Pacific vent mussels. PLoS ONE 8: e81555. https://doi. org/10.1371/journal.pone.0081555

Podowski E. L., Ma S., Luther III G. W, WARdrop D. \& Fisher C. R. 2010. - Biotic and abiotic factors affecting distributions of megafauna in diffuse flow on andesite and basalt along the Eastern Lau Spreading Center, Tonga. Marine Ecology Progress Series 418: 25-45. https://doi.org/10.3354/meps08797

RuELLAN E. \& LAGABRIELLE Y. 2005. - Subductions et ouvertures océaniques dans le Sud-Ouest Pacifique. Oceanic subductions and active spreading in the Southwest Pacific. Géomorphologie : relief, processus, environnement 11 (2): 121-142. https://doi. org/10.4000/geomorphologie.307

SEgONZAC M. 2006. - Austinograea williamsi Hessler \& Martin 1989, in Desbruyères D., Segonzac M. \& Bright M. (eds), Handbook of Deep-Sea Hydrothermal Vent Fauna. Second completely revised edition. Denisia 18: 463.

Sen A., Becker E. L., Podowski E. L., Wickes L. N., Ma S., Mullaugh K. M., Hourdez S., Luther III G. W. \& Fisher C. R. 2013. - Distribution of mega fauna on sulfide edifices on the Eastern Lau Spreading Center and Valu Fa Ridge. Deep Sea Research Part I: Oceanographic Research Papers 72: 48-60. https://doi.org/10.1016/j.dsr.2012.11.003

Sen A., Podowski E. L., Becker E. L., Shearer E. A., Gartman A., YÜCel M., Hourdez S., Luther G. W. III \& Fisher C. R. 2014. - Community succession in hydrothermal vent habitats of the Eastern Lau Spreading Center and Valu Fa Ridge, Tonga. Limnology and Oceanography 59 (5): 1510-1528. https://doi. org/10.4319/lo.2014.59.5.1510

Sen A., Kim S., Miller A. J., Hovey K. J., Hourdez S., Luther III G. W. \& Fisher C. R. 2016. - Peripheral communities of the Eastern Lau Spreading Center and Valu Fa Ridge: community composition, temporal change and comparison to near-vent communities. Marine Ecology 37 (3): 599-617. https://doi. org $/ 10.1111 /$ maec. 12313

ShielDS J. D. \& SEGONZAC M. 2007. — New nemertean worms (Carcinonemertidae) on bythograeid crabs (Decapoda: Brachyura) from Pacific hydrothermal vent sites. Journal of Crustacean Biology 27 (4): 681-692. https://doi.org/10.1651/S-2794.1

Takeda M., Hashimoto J. \& OHTA S. 2000. — A new species of the family Bythograeidae (Crustacea, Decapoda, Brachyura) from the hydrothermal vents along volcanic front of the Philippine Sea Plate. Bulletin of the National Science Museum Tokyo, ser. A (Zool.) 26 (4): 159-172.

TANG B.-P., XIN Z.-Z., LiU Y., Zhang D.-Z., WANG Z.-F., ZHANG H.-B., Chai X.-Y, Zhou C.-L. \& LiU Q.-N. 2017. — The complete mitochondrial genome of Sesarmops sinensis reveals gene rearrangements and phylogenetic relationships in Brachyura. PLoS ONE 12 (6): e0179800. https://doi.org/10.1371/journal. pone. 0179800

Tarasov V. G., Gebruk A. V., Mironov A. N. \& Moskalev L. I. 2005. - Deep-sea and shallow-water hydrothermal vent communities: Two different phenomena? Chemical Geology 224: 5-39. https://doi.org/10.1016/j.chemgeo.2005.07.021

TAYLOR B. (ED.) 1995. - Backarc Basins; tectonics and magmatism. Springer Science + Business Media, LLC, New York, xxv + 524 p. https://doi.org/10.1007/978-1-4615-1843-3

TaYlor B. \& Karner G. D. 1983. - On the evolution of marginal basins. Reviews of Geophysics 21 (8): 1727-1741. https:// doi.org/10.1029/RG021i008p01727

Thaler A. D. B. 2012. — Population Genetics of Species associated with Deep-sea Hydrothermal Vents in the Western Pacific. Thesis, Marine Science and Conservation, Duke University, 114 p.

Thaler A. D., Zelnio K., Saleu W., Schultz T. F., Carlsson J., Cunningham C., Vrijenhoek R. C. \& Van Dover C. L. 2011. - The spatial scale of genetic subdivision in populations of Ifremeria nautilei, a hydrothermal-vent gastropod from the southwest Pacific. BMC Evolutionary Biology 11 (1):372. https:// doi.org/10.1186/1471-2148-11-372

Thaler A. D., Plouviez S., Saleu W., Alei F., Jacobson A., Boyle E. A., Schultz T. F., Carlsson J. \& Van Dover C. L. 2014. - Comparative population structure of two deep-sea hydrothermal-vent-associated decapods (Chorocaris sp. 2 and Munidopsis lauensis) from Southwestern Pacific Back-Arc Basins. PLoS ONE 9 (7): e101345. https://doi.org/10.1371/journal. pone.0101345

TSUCHIDA S. 2006. - Austinograea rodriguezensis, in DESBRUYÈres D., Segonzac M. \& Bright M. (eds), Handbook of Deep-Sea Hydrothermal Vent Fauna. Second completely revised edition. Denisia 18: 462.

TSUCHIDA S. \& FUJIKURA K. 2000. - Heterochely, relative growth, and gonopod morphology in the bythograeid crab, Austinograea williamsi (Decapoda, Brachyura). Journal of Crustacean Biology 20 (2): 407-414. https://doi.org/10.1163/20021975-99990052

TsuCHIDA S. \& HASHIMOTO J. 2002. — A new species of bythograeid crab, Austinograea rodriguezensis (Decapoda, Brachyura), associated with active hydrothermal vents from the Indian Ocean. Journal of Crustacean Biology 22 (3): 642-650. https://doi. org/10.1163/20021975-99990276

Tsuchida S., Fujikura K., Hashimoto J., Fujiwara Y., Hunt J. C. \& LINDSAY D. J. 1998. - Molting of bythograeid crabs under laboratory conditions. JAMSTEC Journal of Deep Sea Research 14: 515-520. [In Japanese with English abstract, tables and figures]

Tudge C. C., Jamieson B. G. M., Segonzac M. \& Guinot D. 1998. - Spermatozoal ultrastructure in three species of hydrothermal vent crab, in the genera Bythograea, Austinograea and Segonzacia (Decapoda, Brachyura, Bythograeidae). Invertebrate Reproduction and Development 34: 13-23. https://doi.org/10.1 080/07924259.1998.9652349

VAN Dover C. L. 2000. - The Ecology of Deep-sea Hydrothermal Vents. Princeton University Press, New Jersey, $424 \mathrm{p}$.

VAN Dover C. L. 2002. - Trophic relationships among invertebrates at the Kairei hydrothermal vent field (Central Indian Ridge). Marine Biology 141: 761-772. https://doi.org/10.1007/ s00227-002-0865-y 
VAN Dover C. L. 2011. — Tighten regulations on deep-sea mining. Nature 470: 31-33. https://doi.org/10.1038/470031a

VAN DOVER C. L. 2014. - Impacts of anthropogenic disturbances at deep-sea hydrothermal vent ecosystems: A review, in KENNedy R., Allcock L., FirTh L. \& Power A. M. (eds), Managing Biodiversity in a Changing Ocean. Marine Environmental Research Special Issue 102: 59-72. https://doi.org/10.1016/j. marenvres.2014.03.008

Van Dover C. L., Humphris S. E., Fornari D., Cavanaugh C. M., Collier R., Goffredi S. K., Hashimoto J., Lilley M. D., Reysenbach A. L., Shank T. M., Von Damm K. L., Banta A., Gallant R. M., Gotz D., Green D., Hall J., Harmer T. L., Hurtado L. A., Johnson P., McKiness Z. P., Meredith C., Olsen E., Pan I. L., Turnipseed M., Won Y., Young C. R. III \& VRIJENHOEK R. C. 2001. - Biogeography and ecological setting of Indian Ocean hydrothermal vents. Science New Series 294 (5543): 818-823.

Van Dover C. L., German C. R., Speer K. G., Parson L. M. \& VRIJENHOEK R. C. 2002. - Evolution and biogeography of deep-sea vent and seep invertebrates. Science 295 (5558): 12531257. https://doi.org/10.1126/science.1067361

Van Dover C. L., Arnaud-Haond S., Clark M. R., Smith S., Thaler A. D. \& VAN DeN Hove S. 2016. - Application of Biological Studies to Governance and Management of the Deep Sea, in Clark M. R., Consalvey A. \& Rowden A. A. (eds), Biological Sampling in the Deep Sea. John Wiley \& Sons, Ltd, Chichester, UK. https://doi.org/10.1002/9781118332535.ch18

VRIJENHOEK R. C. 2010. - Genetic diversity and connectivity of deep-sea hydrothermal vent metapopulations. Molecular Ecology 19 (20): 4391-4411. https://doi.org/10.1111/j.1365294X.2010.04789.x

Watanabe W. \& Beedessee G. 2015. - Vent Fauna on the Central Indian Ridge, in IsHIBASHI J.-I., KYOKO O. \& MiCHINARI S. (eds), Subseafloor Biosphere Linked to Hydrothermal Systems. TAIGA Concept. Chapter 16. Springer, Tokyo Heidelberg New York Dordrecht London: 205-214.

Watanabe W. \& KojIma S. 2015. - Vent Fauna in the Okinawa Trough, in Ishibashi J.-I., KYOKO O. \& Michinari S. (eds), Subseafloor Biosphere Linked to Hydrothermal Systems. TAIGA Concept. Chapter 34. Springer, Tokyo Heidelberg New York Dordrecht London: 449-459. https://doi.org/10.1007/978-4431-54865-2_34

Williams A. B. 1980. - A new crab family from the vicinity of submarine thermal vents on the Galapagos Rift (Crustacea: Decapoda: Brachyura). Proceedings of the Biological Society of Washington 93: 443-472.

Xin Z.-Z., LiU Y., Zhang D.-Z., Wang Z.-F., Zhang H.-B., TANG B.-P., Zhou C.-L., Chai X.-Y. \& LiU Q.-N. 2017a. - Mitochondrial genome of Helice tientsinensis (Brachyura: Grapsoidea:
Varunidae): Gene rearrangements and higher-level phylogeny of the Brachyura. Gene 627: 307-314. https://doi.org/10.1016/j. gene.2017.06.036

XIN Z.-Z., LiU Y., Zhang D.-Z., Chai X.-Y., Wang Z.-F., ZHANG H.-B., Zhou C.-L., TANG B.-P. \& LiU Q.-N. 2017b. — Complete mitochondrial genome of Clistocoeloma sinensis (Brachyura: Grapsoidea): Gene rearrangements and higher-level phylogeny of the Brachyura. Science Reports 7 (1): 4128. https://doi.org/10.1038/ s41598-017-04489-9

Yahagi T., Watanabe H. K., Kojima S. \& Kano Y. 2017. — Do Larvae from deep-sea hydrothermal vents disperse in surface waters? Ecology 98 (6): 1524-1534. https://doi.org/10.1002/ecy.1800

YamanaKa T., Shimamura S., Nagashio H., Yamagami S., ONIShi Y., Hyodo A., Mampuku M. \& Mizota C. 2015. - A Compilation of the Stable Isotopic Compositions of Carbon, Nitrogen, and Sulfurin Soft Body Parts of Animals Collected from Deep-Sea Hydrothermal Vent and Methane Seep Fields: Variations in Energy Source and Importance of Subsurface Microbial Processes in the Sediment-Hosted Systems, in ISHIBASHI J.-I., KYOKO O. \& MiCHINARI S. (eds), Subseafloor Biosphere Linked to Hydrothermal Systems. TAIGA Concept. Chapter 10. Springer, Tokyo Heidelberg New York Dordrecht London: 105-129.

Yang J.-S., Nagasawa H., Fujiwara Y., Tsuchida S. \& Yang W.-J. 2010. - The complete mitogenome of the hydrothermal vent crab Gandalfus yunohana (Crustacea: Decapoda: Brachyura): a link between the Bythograeoidea and Xanthoidea. Zoologica Scripta 39 (6): 621-630. https://doi.org/10.1111/j.14636409.2010.00442.x

YANG J.-S., Lu B., Chen D.-F., YU Y.-Q., YANG F., NAGASAWA H., TSUCHIDA S., FuJIWARA Y. \& YANG W.-J. 2013. - When did decapods invade hydrothermal vents? Clues from the Western Pacific and Indian Oceans. Molecular Biology and Evolution 30 (2): 305-309. https://doi.org/10.1093/molbev/mss224

Yorisue T., InOUe K., MiYaKe H. \& KojIma S. 2012. — Trophic structure of hydrothermal vent communities at Myojin Knoll and Nikko Seamount in the northwestern Pacific: Implications for photosynthesis-derived food supply. Plankton Benthos Research 7 (2): 35-40. https://doi.org/10.3800/pbr.7.35

Zelnio K. A. \& Hourdez S. 2009. - A new species of Alvinocaris (Crustacea: Decapoda: Caridea: Alvinocarididae) from hydrothermal vents at the Lau Basin, southwest Pacific, and a key to the species of Alvinocarididae. Proceedings of the Biological Society of Washington 122 (1): 52-71. https://doi. org/10.2988/07-28.1

Zelnio K. A., Rodríguez R. \& Daly M. 2009. - Hexacorals (Anthozoa: Actiniaria, Zoanthidea) from hydrothermal vents in the south-western Pacific. Marine Biology Research 5: 547-571. https://doi.org/10.1080/17451000902729662 
